\title{
Different aspects regarding the surveillance of surgical site infections
}

Citation for published version (APA):

Ramcharan, A. A. (2014). Different aspects regarding the surveillance of surgical site infections. [Doctoral Thesis, Maastricht University]. Maastricht University. https://doi.org/10.26481/dis.20141114ar

Document status and date:

Published: 01/01/2014

DOI:

10.26481/dis.20141114ar

Document Version:

Publisher's PDF, also known as Version of record

\section{Please check the document version of this publication:}

- A submitted manuscript is the version of the article upon submission and before peer-review. There can be important differences between the submitted version and the official published version of record.

People interested in the research are advised to contact the author for the final version of the publication, or visit the DOI to the publisher's website.

- The final author version and the galley proof are versions of the publication after peer review.

- The final published version features the final layout of the paper including the volume, issue and page numbers.

Link to publication

\footnotetext{
General rights rights.

- You may freely distribute the URL identifying the publication in the public portal. please follow below link for the End User Agreement:

www.umlib.nl/taverne-license

Take down policy

If you believe that this document breaches copyright please contact us at:

repository@maastrichtuniversity.nl

providing details and we will investigate your claim.
}

Copyright and moral rights for the publications made accessible in the public portal are retained by the authors and/or other copyright owners and it is a condition of accessing publications that users recognise and abide by the legal requirements associated with these

- Users may download and print one copy of any publication from the public portal for the purpose of private study or research.

- You may not further distribute the material or use it for any profit-making activity or commercial gain

If the publication is distributed under the terms of Article $25 \mathrm{fa}$ of the Dutch Copyright Act, indicated by the "Taverne" license above, 


\section{DIFFERENT \\ ASPECTS \\ REGARDING THE \\ SURVELLANCE \\ OF \\ SURGICAL \\ SITEINFECTIONS}

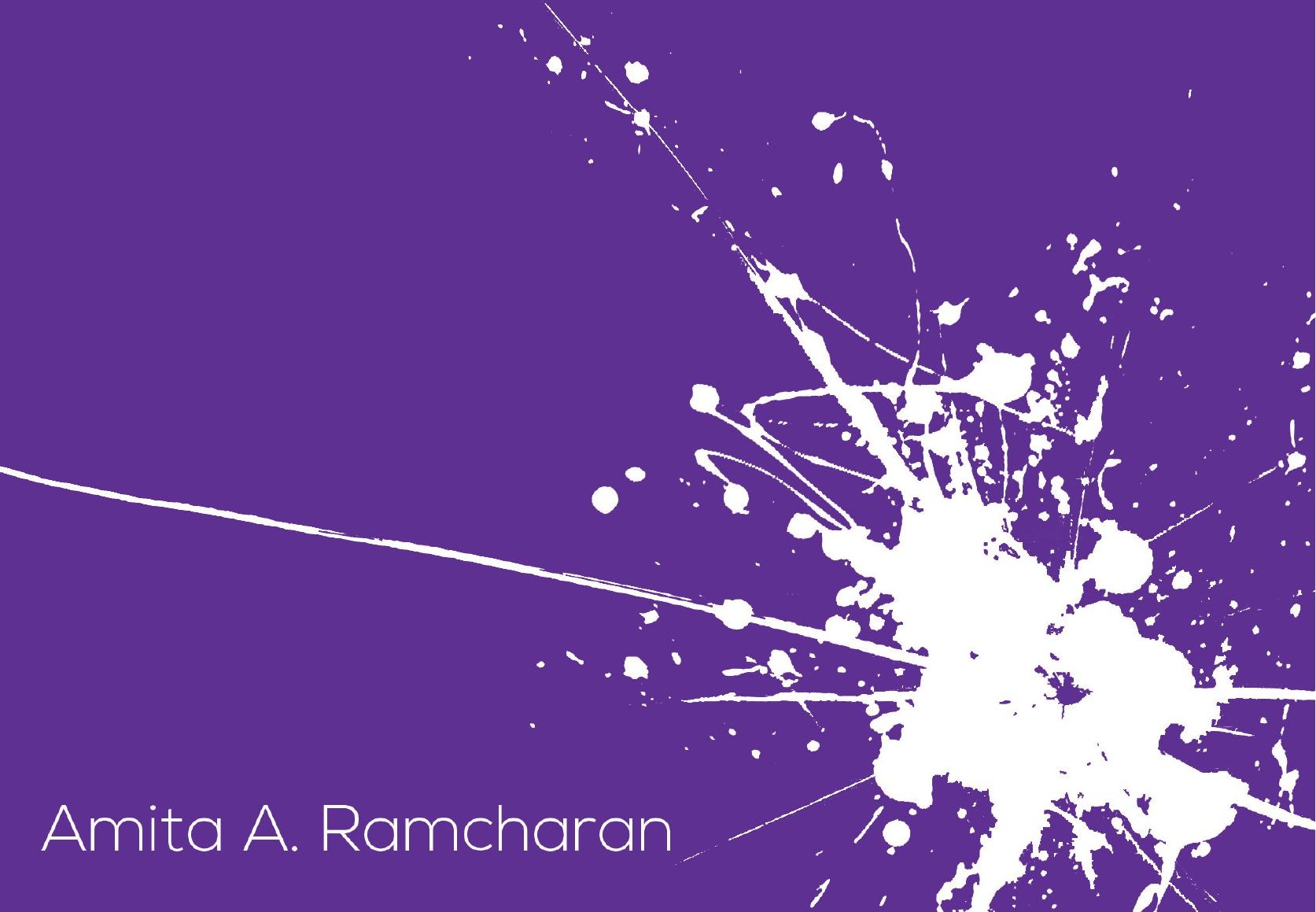





\section{Different aspects regarding the surveillance of surgical site infections}

Amita Ashnadevi Ramcharan 


\section{Colofon}

ISBN: 978-90-822614-1-7

The research presented in this thesis was conducted at the School for Public Health and Primary Care (CAPHRI), Department of Medical Microbiology, of Maastricht University Medical Centre. CAPHRI participates in the Netherlands School of Primary Care Research (CaRe). CAPHRI was classified as 'excellent' by the external evaluation committee of leading international experts that reviewed CAPHRI in December 2010.

Printing of this thesis was financially supported by: Astellas Pharma B.V. \& Pfizer Nederland.

Cover design: Mayk Lucchesi \& Ivo Smits

Printed by: Drukkerij MUMC+

C)Amita Ramcharan, Maastricht 2014

All rights reserved. No part of this thesis may be reproduced, stored in a retrieval system of transmitted in any form or by any means, electronic or mechanical, including photocopy, without prior written permission of the publisher and copyright owner, or where appropriate, the publisher of the articles. 


\title{
Different aspects regarding the surveillance of surgical site infections
}

\author{
PROEFSCHRIFT \\ ter verkrijging van de graad van doctor \\ aan de Universiteit Maastricht \\ op gezag van de Rector Magnificus, \\ Prof. Dr. L.L.G. Stoete \\ volgens het besluit van het College van Decanen, \\ in het openbaar te verdedigen \\ op vrijdag 14 november 2014 om 10.00 uur \\ door \\ Amita Ashnadevi Ramcharan
}

Geboren op 11 juni 1986 te Eindhoven 


\section{Promotores}

Em. Prof. Dr. C.A. Bruggeman

\section{Co-promotores}

Dr. E.E. Stobberingh

Dr. F.H. van Tiel

Beoordelingscommissie

Em. Prof. Dr. P.J.E.H.M. Kitslaar (voorzitter)

Prof. Dr. C.H.C. de Jong

Prof. Dr. J.F.B.M.H. Fiolet

Prof. Dr. P.H.M. Savelkoul

Prof. Dr. J.E. Degener 
"Do what you can, with what you have, where you are"

Theodore Roosevelt 



\section{Contents}

Chapter 1 General introduction \& outline of the thesis

Chapter 2 What determines the (in-) efficacy of a surveillance system to reduce surgical site infections after gastrointestinal surgery?

Chapter 3 Microbiology of surgical site infections after gastrointestinal surgery in the south region of the Netherlands

Chapter 4 A cross-sectional study on surveillance of surgical site infections after vascular surgery

Chapter 5 Does sarcopenia result in a higher risk for developing surgical site infections after colorectal surgery?

Chapter 6 General discussion \& summary

Samenvatting

List of abbreviations

Dankwoord

Curriculum vitae

List of publications

Valorisation of the manuscript 



$$
=\mathcal{I}
$$




\section{Surgical site infections - general}

Health care-associated infections (HAIs), also referred to as nosocomial infections, are "infections that patients acquire during the course of receiving health care treatment for other conditions" [1]. The infectious signs and symptoms are neither present nor incubating upon the patient's admission to the hospital, but become manifest after forty-eight hours (after admission), or after the third calendar day of admission to the health care facility $[2,3]$. HAls received lots of public attention during the last decade, as the consequences of these infections have a significant impact on health-related quality of life. HAls result in delayed wound healing and increased use of antibiotics, hospitalisation days, and health care costs. Furthermore, HAls are a significant burden in terms of patient morbidity and even mortality [2, 4-10].

Surgical site infections (SSIs) are the most common hospital-acquired infections in surgical patients and account for approximately $17 \%$ of all HAls. Other common nosocomial infections are urinary tract infection, infections of the bloodstream, pneumonia, skin, gastrointestinal tract, and central nervous system $[3,11-13]$ (Figure 1).

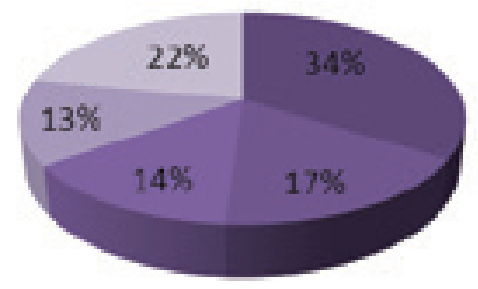

- Urinary tract infections

- Surgical site infections

Bloodstream infections

Pneumonia

Other

Figure 1: Types of health care-associated infections in hospitals Source: Center for Disease Control and prevention [14]

Surgical site infections, also called surgical wound infections, are defined by the Centers for Disease Control and prevention (CDC) [8] as "infections occurring within thirty days after a surgical operation (or within one year if an implant is left in place after the procedure)" [1].

As the infection of the surgical site may occur at any depth, the CDC classified the infections into superficial, deep and organ/space infections. A superficial SSI 
involves only the skin or subcutaneous tissue of the incision. If the deep soft tissues of the incision are involved, then the infection is considered a deep SSI. An organ/space SSI involves any part of the body, other than the incision, opened or manipulated during the operative procedure [1] (Figure 2).

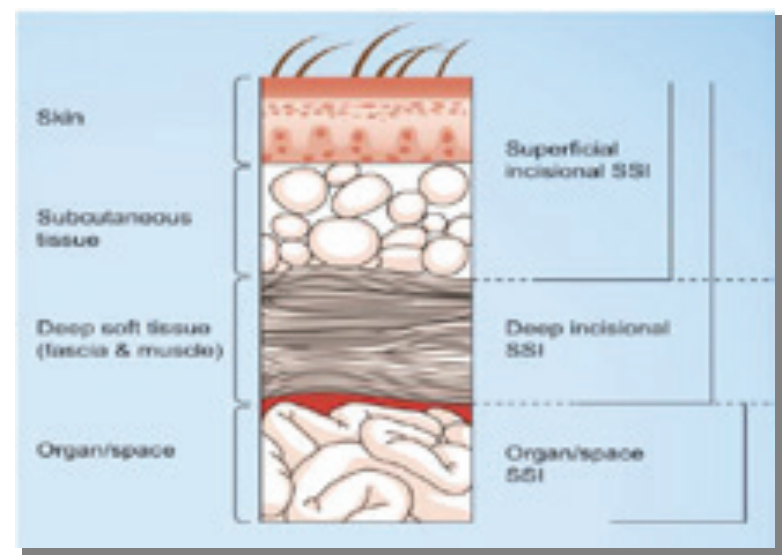

Figure 2: Types of surgical site infections

Source: Center for Disease Control and prevention [14]

Superficial SSIs are the most common SSIs and are generally treated locally. Treatment of deep or organ/space infections often requires more invasive treatment, such as intravenous antibiotics, drainage procedures or re-operations [9].

According to a national study with currently over 90 participating hospital in the Netherlands, the prevalence of SSI was 5.5\% among all hospitalised surgical patients [15]. This percentage is comparable to studies in other European countries with SSI rates ranging from 3.5 to $11.6 \%[5,16-21]$.

\section{Risk factors surgical site infections}

Despite many efforts to prevent the risk of HAls, SSIs remain a serious problem in health care settings. Over the past decades, many studies have been performed worldwide to identify the multifactorial risk factors of SSIs [22, 23]. Some factors are non-modifiable, others are modifiable, and some are patient-related, while others are surgery- or environment-related [24, 25]. Knowledge of the individual risks of SSIs is important for two reasons: 1) to decide which targeted prevention 
and surveillance methods should be implemented, and 2) it contributes to better interpret the comparisons of SSI outcomes between different health care facilities, surgical disciplines or patient populations.

\section{Patient- and surgery- or environment-related non-modifiable risk factors of SSIs}

Examples of non-modifiable patient-related risk factors are obesity, comorbidities (e.g., diabetes mellitus and inflammatory bowel disease), smoking behaviour, existing infections at surgical site, the patient's immune response, the ASA-score (American Society of Anaesthesiologists), age and gender of the patient [24-26].

Obesity, defined by the World Health Organization (WHO) as having a body mass index of more than $30 \mathrm{~kg} / \mathrm{m}^{2}$, has been identified as a major risk factor of SSIs, with the highest rates in morbid obese patients [27-29]. The higher the Body Mass Index (BMI), the higher the chance on an SSI, as obese patients are inefficient in energy expenditure, have an impaired immune response, and a decreased circulation into fat tissue [30, 31].

With regard to age, the outcome of an SSI among elderly patients is worse than in younger patients, due to the diminished host response and the increasing risk for post-operative morbidity and mortality [32]. Additionally, ageing comes along with a decline in muscle mass, muscle strength, and muscle quality, a condition termed by Rosenberg in 1989 as sarcopenia [33]. Involuntary weight loss is common in the elderly and results in poor outcome, revision surgery, use of non-steroidal antiinflammatory drugs, and may extend the duration of surgery [8, 34]. As to gender, several studies described a higher risk of SSI in male patients compared to women. An explanation could be the biological differences between men and women regarding skin and/or other anatomy $[43,44]$. Co-morbidities are found to be associated with SSIs, with diabetes mellitus as the most frequently considered one [35]. Another population at risk are patients undergoing surgery for inflammatory bowel disease (IBD), i.e., Crohn's disease or ulcerative colitis, due to immunosuppressive therapy [36-38].

Smoking has been associated with delayed wound healing and weight loss, compromised immune and respiratory system, and an increased risk of mortality [39-41].

Finally, the ASA-score is a classification system to evaluate the patient's medical status prior to a surgical procedure, based on class 1 to 6 : class 1 ) a healthy patient, class 2) a patient with a mild systemic disease, class 3) a patient with a severe systemic disease, class 4 ) a patient with a life-threatening disease, class 5) a patient 
with a life expectation less than twenty-four hours with or without surgery, and finally class 6) a patient who is brain-dead [42]. An ASA-score of 3 or higher is associated with a high risk of developing SSIs [37, 43].

Surgery-related factors that are not modifiable include the complexity of the surgical procedure, previous surgery, size and type of the health care facility, type of surgery (e.g., elective or acute) and surgical wound class (clean, cleancontaminated contaminated or dirty) $[44,45]$.

The complexity of the surgical procedure determines the position and size of the surgical site. Laparoscopic surgery is an example of surgery using very small incisions, whereas more complex surgery, such as colorectal surgery, may require a larger incision. It has been shown that colorectal surgery is associated with a high risk of SSI due to the probability of bacterial contamination from the colon, with rates of SSI as high as $26 \%$ [46-50]. After vascular surgery SSI rates vary between $4 \%$ and $25 \%[51,52]$. This variation may be explained by factors, such as their underlying vascular disease and multiple co-morbidities. Also peri-operative events contribute to the increased risk after vascular surgery, such as the implantation of a vascular graft or other foreign material. This foreign material creates a microenvironment that is convenient for bacterial attachment and colonization and thereby protects causative potential pathogens from the host defence and from antimicrobial therapy (Figure 3).

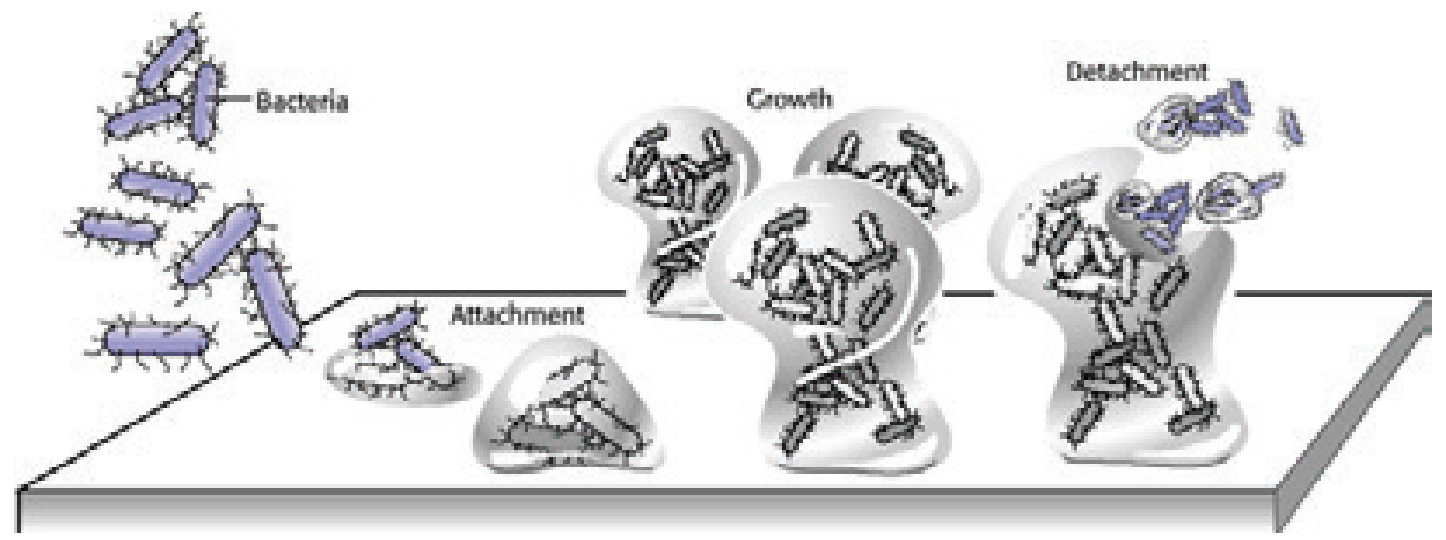

Figure 3: Illustration of the biofilm bacterial colonization process.

1) The bacteria need to find an inert surface (e.g., implant). Implants or dead tissue that have been integrated by the host with some type of surface are not inert and will resist colonization. 2) The colonization process will continue until mature colonies are formed. 3) Once mature, the colonies can change based on environmental signals or signals between colonies.

Source: Rockwood \& Green's Fractures in Adults, 6th Edition. Chapter 18: Local Complications, Kirti D. Moholkar \& Bruce H. Ziran. @ 2006 Lippincott Williams \& Wilkins. 
Other surgery-related risk factors are failed arterial reconstruction and presence of a groin incision [51, 53-55].

With regard to the size and type of the hospital, higher infection rates are described in large and university hospitals, very likely due to an unfavourable casemix of patients and the limited experience of the surgeons in training [56]. The CDC classified type of wound into four wound classes, i.e., clean, clean-contaminated, contaminated and dirty, according to the likelihood and degree of bacterial contamination of the wound at the time of the surgical procedure, and other wound characteristics, such as size, depth, and location [1, 57] (Table I). Emergency surgery and dirty/contaminated surgical wounds yield higher SSI rates than elective surgery or clean surgical wounds $[45,58,59]$.

\section{Table I: Definitions wound classifications by the Centers for Disease Control and prevention}

\section{Wound class}

1. Clean:

2. Clean-Contaminated

3. Contaminated:

4. Dirty
Contamination of the surgical wound

An uninfected operative wound in which no inflammation is encountered and the respiratory, alimentary, genital, or uninfected urinary tract is not entered. In addition, clean wounds are primarily closed and, if necessary, drained with closed drainage. Operative incisional wounds that follow nonpenetrating (blunt) trauma should be included in this category if they meet the criteria.

An operative wound in which the respiratory, alimentary, genital, or urinary tracts are entered under controlled conditions and without unusual contamination. Specifically, operations involving the biliary tract, appendix, vagina, and oropharynx are included in this category, provided no evidence of infection or major break in technique is encountered.

Open, fresh, accidental wounds. In addition, operations with major breaks in sterile technique (e.g., open cardiac massage) or gross spillage from the gastrointestinal tract, and incisions in which acute, non-purulent inflammation is encountered are included in this category.

Old traumatic wounds with retained devitalized tissue and those that involve existing clinical infection or perforated viscera. This definition suggests that the organisms causing post-operative infection were present in the operative field before the operation.

\section{Source: Centers for Disease Control and prevention [14]}

There is a clear relationship between infection rates and wound class from clean to dirty. Clean wounds, e.g., after vascular surgery, have a 1-6\% rate of SSI. Clean- 
contaminated wounds, e.g., after a gynaecologic procedure, have a 3-11\% rate. For, contaminated wounds, such as wounds after laparotomy with intestinal spillage, $10-17 \%$ rates of SSI have been determined. And finally dirty wounds, after abdominal exploration for intra-abdominal abscesses, show infection rates of more than $27 \%$ [60-62].

Culver et al. [52] created a risk classification system, known as the NNIS (National Nosocomial Infections Surveillance) risk index. The system combines the CDC's wound classification, of either contaminated or dirty, with procedure-specific excessive operative time and an ASA-score of 3 or higher. Additionally, the system is widely used, operation-specific and a good method to correct for differences in patient case-mix $[52,63]$. After introduction of antibiotics prophylaxis in the $1950 \mathrm{~s}$ [64], the SSI rates decreased to $2.1 \%$ in clean wounds, $3.3 \%$ in clean-contaminated, $6.4 \%$ in contaminated, and $7.1 \%$ in dirty wounds [52]. There is, however, considerable variation in SSI within each class according to the type of surgery being performed [59] and some authors acknowledge deficiencies of the NNIS index with regard to the lack of other important risk factors of specific procedures that primarily need to be identified and incorporated [65].

\section{Patient- and surgery- or environment-related modifiable risk factors of SSI}

Most healthy people, approximately 30\%, are carriers of the bacterium Staphylococcus aureus in the nose. Nasal carriage of S. aureus is a major risk of SSIs, especially for those patients who received an implantation following vascular of orthopaedic surgery [66-68].

Patients can be treated pre-operatively to diminish the chance for developing an SSI caused by S. aureus. Eradication of S. aureus prior to surgery can be achieved with nasal mupirocin ointment and chlorhexidine showers and has shown to decrease the occurrence of SSIs, significantly for cardiothoracic patients [68-73].

Other modifiable patient-related risk factors that are commonly present among older patients include nutritional status [24, 74, 75]. Patients who are malnourished are at a high risk of surgical complications. Malnutrition is associated with causes of SSI, such as, impaired host immune response and low serum albumin level, and result in higher morbidity, delayed recovery and longer hospitalisation, mortality, and higher health care costs [76, 77]. Peri-operative nutritional supplements, such as provision of calories, proteins, electrolytes, vitamins and minerals, have been described to adjust the immune and inflammatory response of the malnourished patient $[78,79]$. 
Other pre- and peri-operative measures include antimicrobial prophylaxis, disinfection of the patient's skin, not shaving of the surgical site and normothermia during surgery. Surgical antimicrobial prophylaxis refers to the small administration of an antimicrobial agent, given 15-60 minutes before the surgical incision. Timing, choice and duration of prophylaxis should be based on guidelines [80]. With regard to the skin preparation, duration of the surgical scrub and the type of skin disinfectant influence the development on SSIs. Several antiseptic agents are used for pre-operative skin preparation at the incision site and include products containing iodine, alcohol or chlorhexidine gluconate, all with broad-spectrum antimicrobial activity $[81,82]$. Pre-operative hair shaving of the surgical site has also been associated with a significantly higher SSI risk of SSI than either the use of depilatory cream or no hair removal at all [14, 82]. Hypothermia is a fall in body temperature below 36 degrees and is one of the most common risk factors of SSIs. The best way to avoid hypothermia is to achieve normothermia during surgery by active warming, in order to maintain the core temperature of the patient and to prevent vasoconstriction and decreased blood flow to surgical sites [83].

Thus, by far the most important surgery- or environment-related modifiable risk factor of SSI is the (lack of) adherence to the above and other measures. Due to the difficulty to change behaviour of the health care staff, adherence to guidelines and protocols is frequently suboptimal [84, 85], for example, incorrect use of nose- and mouth masks, the incorrect use of surgical clothing and drapes, and wearing jewellery $[9,86,87]$. Moreover, hand hygiene by health care staff, one of the most effective means to prevent SSIs, has a poor compliance $[88,89]$. Reasons not to adhere to infection preventive guidelines include insufficient time, inaccessibility to hand hygiene supplies, irritating agents, lack of knowledge of guidelines, negligence, and understaffing $[90,91]$. Continuous instructions and training on the guidelines and feedback on the results of the measurements are needed to improve compliance [92].

Other surgery- or environment-related modifiable risk factors are a prolonged preand post-operative stay. Patients who are less physically capable and have a greater in-hospital exposure time are at an increased risk for developing SSIs. An explanation is the widespread use of antibiotics that can lead to antibiotic-resistant microorganisms being present. Also, many patients are treated in the same hospital area that might provide an opportunity for microorganisms to spread between them and cause infections $[25,93]$. 
Duration of the surgical procedure can be influenced by factors, such as the experience or skills of the surgeon in charge and the complexity of the procedure [94]. The length of the operation has also been identified as a risk factor of SSIs. Procedures longer than 3-4 hours showed to increase the risk of SSIs substantially, as longer operation duration allow for more personnel traffic and thereby negatively affecting the air flow in the operating theatre $[25,95]$.

\section{Microbial spectrum of surgical site infections}

During a surgical procedure the patient's skin barrier is breached and bacteria from the skin and the direct environment are able to enter the wound, colonize the wound, and eventually cause an infection [51]. Besides the positive association between antibiotics, the patient's immune system and causative pathogens, antibiotics can also directly negatively interact with the immune system and increase the risk for an infection [96, 97].

Which microorganisms are involved in SSIs depend amongst others on factors, such as the wound type, the depth and location, the degree of tissue perfusion, the host immune response, but also the adherence to guidelines with regard to the choice of antibiotic prophylaxis and hygiene measures $[98,99]$. The hands of health care staff may become constantly colonized with pathogenic flora, e.g., S. aureus and gram-negative bacilli [100].

As previously mentioned, S. aureus from the patient's skin flora is the most frequent cause of infections associated with clean surgical procedures, e.g., vascular procedures $[51,101]$. Other common bacteria in clean surgeries are coagulase-negative staphylococci, Escherichia coli, Pseudomonas aeruginosa, enterococci, Proteus species, Klebsiella pneumonia and streptococci [53]. In contaminated and dirty procedures, e.g., colorectal procedures, the microorganisms are even more diverse and the predominant organisms include gram-negative rods and enterococci besides skin flora [80, 102].

Surgical antimicrobial prophylaxis is recommended prior to the incision in many cases. The higher diversity of potential pathogens in contaminated wounds compared to clean wounds is an argument for broad-spectrum of antibiotic coverage [14]. The choice of antibiotics depends on the antimicrobial agent's pharmacokinetics and pharmacodynamics, the patient's medication allergies, and the required spectrum of antimicrobial activity [103].

According to evidence-based guidelines antimicrobial prophylaxis must meet the following requirements: 1) an appropriate choice, that is be based on the 
susceptibility of the expected microorganisms, 2) a correct dosage, 3) administration at the right time (15-60 minutes prior to incision), and 4) no antibiotic administration after 24 hours post-operatively to diminish adverse effects and antibiotic resistance as much as possible $[14,103]$. In the Netherlands, the Dutch Working Party on Antibiotic Policy SWAB (Dutch acronym: Stichting Werkgroep AntibioticaBeleid) has developed guidelines for the therapeutic and prophylactic use of antibiotics for hospitalised patients, aiming at the optimal use of antibiotics and the control of antibiotic resistance.

The increase of resistant microorganisms is a global concern. Factors that contribute to this phenomenon are the unrestricted availability of antibiotics in many countries, inadequate stewardship of antibiotic prescription [104]. As a result of resistance, antimicrobial treatment and hospital stay are prolonged, and therapy costs are increased $[9,102]$. In the Netherlands, where the rate of antibiotic consumption in humans is low, resistance due to Extended-Spectrum BetaLactamases (ESBL's) in enterobacteriaceae, is emerging [105]. Thus, surveillance data on the causative microorganisms of an SSI and the antimicrobial susceptibility patterns are important to understand the scope and magnitude of the emerging antimicrobial resistance and to make an optimal choice.

\section{Prevention of surgical site infections}

Strategies for the prevention of SSIs are based on reducing the risk of bacterial contamination and consequently the development of SSI [9]. Many of the patientand surgery-related risk factors are mentioned above, but only some factors are modifiable [87].

In the past 10 years, several organizations have developed programs with the aim to decrease rates of post-operative complications, including SSIs. Special attention has been paid to a so-called bundle approach, an approach combining several patient- and procedure-related risk factors, to reduce the chance on an SSI after the surgical procedure $[9,89,106]$. Pre-operative strategies are intended to optimally prepare the patient before incision, such as the use of appropriate antisepsis and hand hygiene before incision for all surgical team members. Other preventive strategies are focussed on environmental and factors, such as ventilation of the operating theatre, and cleaning and disinfection of environmental surfaces. Examples of post-operative care are protection of an incision site with 
sterile dressing and washing hands before and after any contact with the surgical site $[9,101]$.

In the Netherlands, hospitals currently participate in a national programme intended to improve patient safety, i.e., the patient safety programme VMS (Dutch acronym: VeiligheidsManagementSysteem). The programme consists of eleven targets, one of which is the prevention of SSIs. To achieve this, a bundle of four evidence-based interventions is to be implemented, assuring compliance by means of repeated measurements of the behaviour of the health care staff. The goal is to achieve a compliance of at least $90 \%[85,107,108]$. The elements of the bundle are (1) no pre-operative hair removal of the patient, (2) correct timing of pre-operative administration of prophylactic antibiotics, (3) peri-operative normothermia, and (4) restricted entry and door movements during the surgical procedure. The choice for these elements was based on guidelines issued by the Dutch Working Party on Infection Prevention WIP (Dutch acronym: Werkgroep InfectiePreventie) and were systematically reviewed in the literature regarding the evidence for their efficacy $[109,110]$. First, pre-operative hair removal includes shaving, clipping or creams. As shaving before incision is associated with a higher prevalence of SSI compared to clipping [111], CDC and WIP recommend removing body hair only in case of surgical technical reasons. In case hair has to be removed, CDC and WIP recommend the use of a clipper [14, 110,112]. Antibiotic prophylactic antibiotics have been shown to prevent the development of SSI, although several factors (as the appropriateness, timing, dosage, duration and route of prophylaxis administration) can hamper its effect [113]. As mentioned before, the optimal time for administration preoperatively is between sixty and fifteen minutes before surgical incision. The choice of the antibiotic dosage and duration depend on the type of surgical procedure and the expected microorganisms [80, 103]. Third, achieving normothermia by active warming has been shown to decrease surgical site infections after surgery $[114,115]$. Finally, the WIP advises to limit the number of personnel present in the operating theatre and to limit the traffic in and out the operating theatre during the surgical procedure [110]. It has been shown that compliance with a bundle of infection preventive measures significantly decreases the SSI rate [85] (Figure 4). 


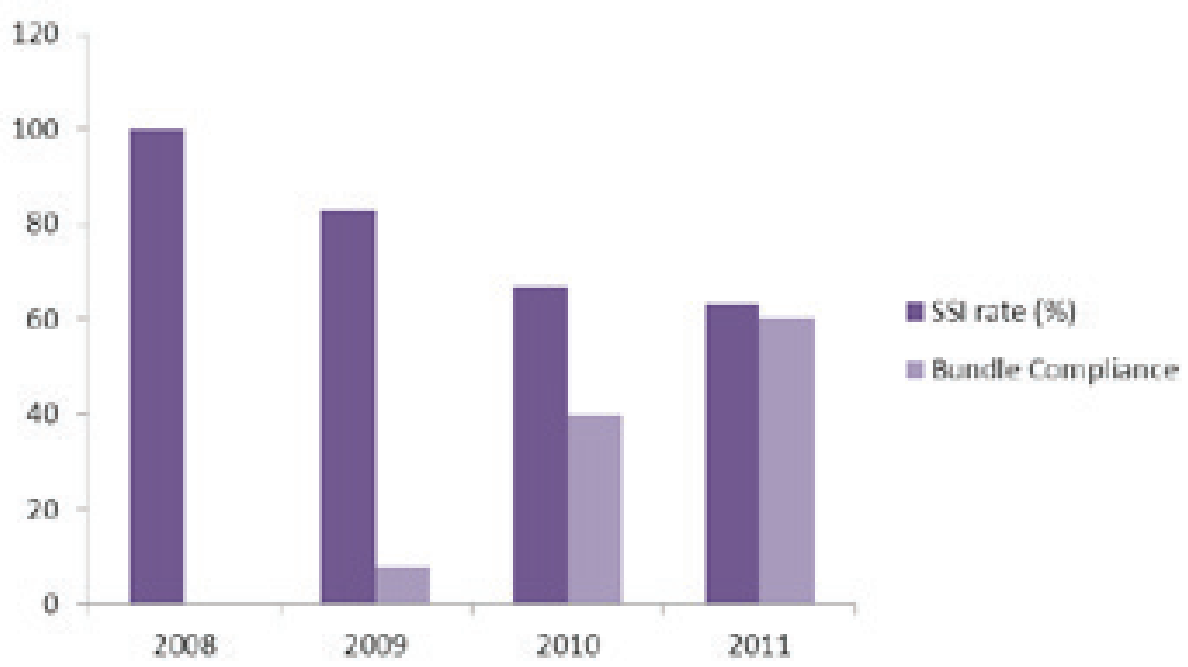

Figure 4: Annual changes in the surgical site infection (SSI) rate and bundle compliance and the $95 \%$ confidence interval.

Footnote: 2008 was taken as the reference year of SSI and the relative changes after adjustment for confounding variables are provided [85]

\section{Infection Surveillance and Control}

A surveillance program is essential for the detection of SSIs and determination of the SSI rates in health care institutions. Surveillance of SSI and giving feedback of relevant data to surgeons has been shown to reduce SSIs [14, 116, 117]. As it is expected that variation in SSI rates depends on the type of hospital and patient case-mix, it is important that infection criteria are clearly defined and that methods for data collection are standardised [118-121].

In 1974 the CDC initiated a nationwide study to infection control procedures, known as the SENIC (Study on the efficacy of nosocomial infection control) Project. The primary objectives were (1) to determine whether the implementation of infection surveillance and control programmes decreased the number of nosocomial infections, $(2)$ to describe the present status of those programmes and the infection rates, and (3) to determine the relation between characteristics of hospitals and patients, elements of the infection control programmes, and variations in the infection rate. The project showed that with accurate infection control activities and routine feedback to the medical staff, infection rates significantly decreased by $30 \%$ [122]. 
In general, surveillance during hospitalisation, also called in-hospital surveillance, is performed for each patient who undergoes surgery. Infection control personnel routinely collects data from the patient's medical records and consultations with the surgeon in charge, i.e., demographic patient characteristics, data on the surgical procedure, risk factors of SSI, bacteriological data by cultural assessment, and any signs for an SSI based on national and international criteria regarding the assessment of SSIs [1, 123]. However, as the trend towards shorter length of stay is increasing, a higher proportion of SSIs manifests after discharge [124]. As a result, postdischarge surveillance (PDS) has become increasingly important. The performance of in-hospital surveillance alone will result in an underestimation of the actual one [119, 125-127].

For each individual patient, a surveillance period of thirty days after surgery is recommended to ensure accurate information concerning the development of SSI, in patients without an implant. The choice of thirty days was based on prevalence studies showing that between $12 \%$ and $84 \%$ of all SSIs are detected after discharge of the patient from the hospital $[12,121,125,128]$. In case an implant is in place the follow-up period is extended to one year, because implant-associated infection can manifest much later [14, 25, 129].

In the Netherlands, a national nosocomial surveillance programme was developed in 1996, known as PREZIES (Dutch acronym: Preventie van Ziekenhuisinfecties door Surveillance). The PREZIES programme consists of a standardized surveillance system in participating hospitals, during and after hospitalisation, collects reference data for national policy-making, and creates a base to stimulate further intervention research $[15,130]$. As a result, benchmarking data is offered to the participating hospitals.

Postdischarge surveillance can be performed actively or passively. The active method includes direct observation of the surgical site by health care staff, e.g., an independent infection control nurse who is familiar with the definition of an SSI, to discuss wound signs and symptoms. This is carried out during morning shifts and in different sections of the medical and surgical wards. Direct observation has seemed to be a reliable surveillance method, but can be time-consuming and is often only feasible if the follow-up after surgery occurs at the health care facility where the procedure was performed [131]. Other examples of active surveillance are telephone interviews with patients and questionnaires about the patient's surgical wound by infection control nurses. Disadvantages of questionnaires is that not all are returned, and that surgeons and infection control nurses are not always in 
agreement regarding the diagnosis of SSI [132]. Additionally, self-assessment of the surgical wounds, either by a telephone interview or questionnaire, may not always be reliable due to information bias $[127,131,133,134]$. Although patients are able to report signs and symptoms of the wound, the assessment does not always reflect the clinical interpretation of the infection control nurse [134].

The passive surveillance method is used when the health care worker checks the patient's readmissions of SSI or contacts medical staff for medical or nursing reports of infection, e.g., detection of an SSI when patients are (re-) hospitalised or examination of the outpatient medical record $[125,126]$. This method is often used in hospitals, as it is achievable and reliable. Although this passive method requires different physical and human resources, the return rate of the data seems to be acceptable, because almost every patient is seen by their surgeon during hospitalisation and after discharge [127].

Depending on the surveillance method used and the type of surgery, different rates of SSI are found after discharge ranging from 12 to $84 \%$ [127]. A study to SSIs after vascular surgery with a passive surveillance method showed that almost $50 \%$ of all SSIs was found after discharge within thirty days [135], up to more than $50 \%$ within ninety days [136], while others found lower amounts of $25 \%$ or less. With active surveillance up to $43 \%$ of all SSIs can be found within thirty days after discharge $[125,137]$. The figure below shows a peak incidence of SSI during the first (mainly during hospitalisation) and second (mainly postdischarge) postoperative week. The study found that $90 \%$ of the superficial SSIs was detected at day 25 , and $90 \%$ of the deep SSIs was detected at day 122 (Figure 5). 


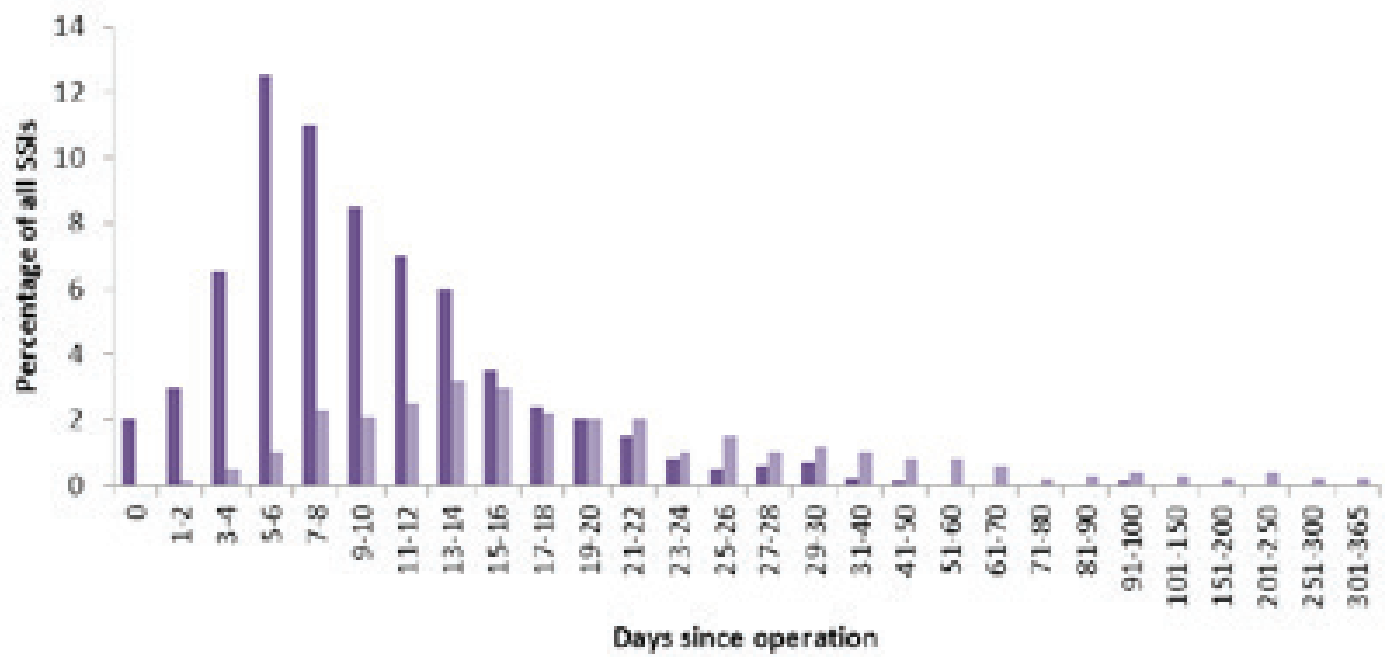

ESSls during stay = S5ls after discharge

Figure 5: Time curve showing the percentage of all SSIs (both superficial and deep, with data from all procedures and all Postdischarge Surveillance methods together) that developed during hospitalisation and after discharge, by post-operative day.

Source: Manniën et al. (2006) [125] 


\section{Aims and outlines of this thesis}

This thesis was written with the aim to diminish the risk of patients within a health care facility for developing surgical site infections. Throughout the thesis, data to assist health care personnel in reducing infections associated with health care is provided, by describing the assessment, planning, implementation and evaluation of a Dutch safety management system, the VMS safety bundle. Surveillance methods for SSI and the assessment of compliance with infection control measures are crucial, including standardised definitions of SSI, consistent classification criteria, the ability to detect SSIs after discharge, the ability to adjust for differences in the severity of illness between patient populations, and the assessment of microbiological laboratory data to identify bacteria and patterns of susceptibility to antibiotics.

In chapter 2, we retrospectively assessed the incidence of SSI after gastrointestinal surgery during and after hospitalisation, and evaluated the (in-) efficacy of the VMS safety programme, designed at an academic medical centre, on the incidence of SSI. To achieve this, an analysis based on a logistic regression model to determine risk factors for SSIs after gastrointestinal surgery was performed. In chapter $\mathbf{3}$, we retrospectively analysed the microbiological results of the wounds after gastrointestinal surgery, i.e., the microorganisms isolated from wound swabs and blood samples, as well as the antimicrobial susceptibility, and discussed the appropriateness of the prophylactic antibiotic choice. In chapter 4, a cohort study was conducted to determine the incidence and risk factors for SSIs after vascular surgery and the effect of the Dutch VMS safety bundle on the incidence of SSI was evaluated. In addition, the most frequently isolated microorganisms involved were determined, as well as the antimicrobial susceptibility patterns of the bacteria associated with SSIs. Finally, in chapter 5, we retrospectively investigated the prevalence of sarcopenia and sarcopenic obesity in patients after a colorectal surgical procedure and the relationship of sarcopenia with gender-specific body composition and surgical site infections. Thereby, the microbial spectrum of SSIs of sarcopenic patients to that of SSIs of patients without sarcopenia was compared. 


\section{References}

1. Horan TC, Gaynes RP, Martone WJ, Jarvis WR, Emori TG. CDC definitions of nosocomial surgical site infections, 1992: a modification of CDC definitions of surgical wound infections. Infect Control Hosp Epidemiol, 13(10), 606608 (1992).

2. Collins AS. Preventing Health Care-Associated Infections. In: Patient Safety and Quality: An Evidence-Based Handbook for Nurses. Hughes, RG (Ed. (Rockville (MD), 2008)

3. Emori TG, Gaynes RP. An overview of nosocomial infections, including the role of the microbiology laboratory. Clin Microbiol Rev, 6(4), 428-442 (1993).

4. Suljagic V, Jevtic M, Djordjevic B, Jovelic A. Surgical site infections in a tertiary health care center: prospective cohort study. Surg Today, 40(8), 763-771 (2010).

5. Ott E, Saathoff S, Graf K, Schwab F, Chaberny IF. The prevalence of nosocomial and community acquired infections in a university hospital: an observational study. Deutsches Arzteblatt international, 110(31-32), 533540 (2013).

6. Leaper DJ, van Goor H, Reilly J et al. Surgical site infection - a European perspective of incidence and economic burden. Int Wound J, 1(4), 247-273 (2004).

7. Broex EC, van Asselt AD, Bruggeman CA, van Tiel FH. Surgical site infections: how high are the costs? J Hosp Infect, 72(3), 193-201 (2009).

8. Harrop JS, Styliaras JC, Ooi YC, Radcliff KE, Vaccaro AR, Wu C. Contributing factors to surgical site infections. J Am Acad Orthop Surg, 20(2), 94-101 (2012).

9. Owens CD, Stoessel K. Surgical site infections: epidemiology, microbiology and prevention. J Hosp Infect, 70 Suppl 2, 3-10 (2008).

10. Jenks PJ, Laurent M, McQuarry S, Watkins R. Clinical and economic burden of surgical site infection (SSI) and predicted financial consequences of elimination of SSI from an English hospital. J Hosp Infect, 86(1), 24-33 (2014).

11. National Nosocomial Infections Surveillance (NNIS) report, data summary from October 1986-April 1996, issued May 1996. A report from the 
National Nosocomial Infections Surveillance (NNIS) System. Am J Infect Control, 24(5), 380-388 (1996).

12. Mangram AJ, Horan TC, Pearson ML, Silver LC, Jarvis WR. Guideline for Prevention of Surgical Site Infection, 1999. Centers for Disease Control and Prevention (CDC) Hospital Infection Control Practices Advisory Committee. Am J Infect Control, 27(2), 97-132; quiz 133-134; discussion 196 (1999).

13. Kirby JP, Mazuski JE. Prevention of surgical site infection. Surg Clin North Am, 89(2), 365-389, viii (2009).

14. Mangram AJ, Horan TC, Pearson ML, Silver LC, Jarvis WR. Guideline for prevention of surgical site infection, 1999. Hospital Infection Control Practices Advisory Committee. Infect Control Hosp Epidemiol, 20(4), 250278; quiz 279-280 (1999).

15. PREZIES. [PREventie ZIEkenhuisinfecties door Surveillance. Bilthoven: PREZIES; 2012]. Available at http://www.prezies.nl/zkh/prev/ref_cijfers/Referentiecijfers\%20Prevalent ie\%20tm\%20maart\%202012.pdf. Bilthoven)

16. Ruden H, Gastmeier P, Daschner FD, Schumacher M. Nosocomial and community-acquired infections in Germany. Summary of the results of the First National Prevalence Study (NIDEP). Infection, 25(4), 199-202 (1997).

17. Klavs I, Bufon Luznik T, Skerl M et al. Prevalance of and risk factors for hospital-acquired infections in Slovenia-results of the first national survey, 2001. J Hosp Infect, 54(2), 149-157 (2003).

18. Di Pietrantonj C, Ferrara L, Lomolino G. Multicenter study of the prevalence of nosocomial infections in Italian hospitals. Infect Control Hosp Epidemiol, 25(1), 85-87 (2004).

19. Pittet D, Harbarth $S$, Ruef $C$ et al. Prevalence and risk factors for nosocomial infections in four university hospitals in Switzerland. Infect Control Hosp Epidemiol, 20(1), 37-42 (1999).

20. Reilly J, Stewart S, Allardice GA et al. Results from the Scottish National HAI Prevalence Survey. J Hosp Infect, 69(1), 62-68 (2008).

21. Pellizzer $G$, Mantoan $P$, Timillero $L$ et al. Prevalence and risk factors for nosocomial infections in hospitals of the Veneto region, north-eastern Italy. Infection, 36(2), 112-119 (2008).

22. Moucha CS, Clyburn TA, Evans RP, Prokuski L. Modifiable risk factors for surgical site infection. Instr Course Lect, 60, 557-564 (2011). 
23. Limon E, Shaw E, Badia JM et al. Post-discharge surgical site infections after uncomplicated elective colorectal surgery: impact and risk factors. The experience of the VINCat Program. J Hosp Infect, 86(2), 127-132 (2014).

24. Kirchhoff $P$, Clavien PA, Hahnloser D. Complications in colorectal surgery: risk factors and preventive strategies. Patient Saf Surg, 4(1), 5 (2010).

25. Korol E, Johnston K, Waser $\mathrm{N}$ et al. A Systematic Review of Risk Factors Associated with Surgical Site Infections among Surgical Patients. PLoS One, 8(12), e83743 (2013).

26. Kirchhoff $P$, Dincler $S$, Buchmann P. A multivariate analysis of potential risk factors for intra- and postoperative complications in 1316 elective laparoscopic colorectal procedures. Ann Surg, 248(2), 259-265 (2008).

27. Wang Y, Wang JQ. Standard definition of child overweight and obesity worldwide. Authors' standard compares well wil WHO standard. BMJ, 321(7269), 1158 (2000).

28. Olsen MA, Nepple JJ, Riew KD et al. Risk factors for surgical site infection following orthopaedic spinal operations. J Bone Joint Surg Am, 90(1), 6269 (2008).

29. Obesity: preventing and managing the global epidemic. Report of a WHO consultation. World Health Organization technical report series, 894, i-xii, 1-253 (2000).

30. Mullen JT, Moorman DW, Davenport DL. The obesity paradox: body mass index and outcomes in patients undergoing nonbariatric general surgery. Ann Surg, 250(1), 166-172 (2009).

31. Mullen JT, Davenport DL, Hutter MM et al. Impact of body mass index on perioperative outcomes in patients undergoing major intra-abdominal cancer surgery. Ann Surg Oncol, 15(8), 2164-2172 (2008).

32. Turrentine FE, Wang H, Simpson VB, Jones RS. Surgical risk factors, morbidity, and mortality in elderly patients. J Am Coll Surg, 203(6), 865877 (2006).

33. Cruz-Jentoft AJ, Baeyens JP, Bauer JM et al. Sarcopenia: European consensus on definition and diagnosis: Report of the European Working Group on Sarcopenia in Older People. Age and ageing, 39(4), 412-423 (2010). 
34. Thomas DR. Loss of skeletal muscle mass in aging: examining the relationship of starvation, sarcopenia and cachexia. Clin Nutr, 26(4), 389399 (2007).

35. Ata A, Valerian BT, Lee EC, Bestle SL, Elmendorf SL, Stain SC. The effect of diabetes mellitus on surgical site infections after colorectal and noncolorectal general surgical operations. Am Surg, 76(7), 697-702 (2010).

36. Drosdeck J, Harzman A, Suzo A, Arnold M, Abdel-Rasoul M, Husain S. Multivariate analysis of risk factors for surgical site infection after laparoscopic colorectal surgery. Surg Endosc, 27(12), 4574-4580 (2013).

37. Alavi K, Sturrock PR, Sweeney WB et al. A simple risk score for predicting surgical site infections in inflammatory bowel disease. Dis Colon Rectum, 53(11), 1480-1486 (2010).

38. Uchino M, Ikeuchi H, Tsuchida T, Nakajima K, Tomita N, Takesue Y. Surgical site infection following surgery for inflammatory bowel disease in patients with clean-contaminated wounds. World J Surg, 33(5), 1042-1048 (2009).

39. Valentijn TM, Galal W, Tjeertes EK, Hoeks SE, Verhagen HJ, Stolker RJ. The obesity paradox in the surgical population. Surgeon, 11(3), 169-176 (2013).

40. Jaspers I. Cigarette smoke effects on innate immune mechanisms in the nasal mucosa. Potential effects on the microbiome. Annals of the American Thoracic Society, 11 Suppl 1, S38-42 (2014).

41. Birrell MA, Wong S, Catley MC, Belvisi MG. Impact of tobacco-smoke on key signaling pathways in the innate immune response in lung macrophages. J Cell Physiol, 214(1), 27-37 (2008).

42. Daabiss M. American Society of Anaesthesiologists physical status classification. Indian J Anaesth, 55(2), 111-115 (2011).

43. Khan M, Rooh ul M, Zarin M, Khalil J, Salman M. Influence of ASA-score and Charlson Comorbidity Index on the surgical site infection rates. J Coll Physicians Surg Pak, 20(8), 506-509 (2010).

44. Cohen B, Choi YJ, Hyman S, Furuya EY, Neidell M, Larson E. Gender differences in risk of bloodstream and surgical site infections. J Gen Intern Med, 28(10), 1318-1325 (2013).

45. Sorensen LT, Hemmingsen $U$, Kallehave $F$ et al. Risk factors for tissue and wound complications in gastrointestinal surgery. Ann Surg, 241(4), 654658 (2005). 
46. Konishi T, Watanabe $\mathrm{T}$, Morikane $\mathrm{K}$ et al. Prospective surveillance effectively reduced rates of surgical site infection associated with elective colorectal surgery at a university hospital in Japan. Infect Control Hosp Epidemiol, 27(5), 526-528 (2006).

47. Tang $\mathrm{R}$, Chen $\mathrm{HH}$, Wang $\mathrm{YL}$ et al. Risk factors for surgical site infection after elective resection of the colon and rectum: a single-center prospective study of 2, 809 consecutive patients. Ann Surg, 234(2), 181-189 (2001).

48. Smith RL, Bohl JK, McElearney ST et al. Wound infection after elective colorectal resection. Ann Surg, 239(5), 599-605; discussion 605-597 (2004).

49. Hagihara $M$, Suwa $M$, Ito $Y$ et al. Preventing surgical-site infections after colorectal surgery. J Infect Chemother, 18(1), 83-89 (2012).

50. Petrosillo N, Drapeau CM, Nicastri E et al. Surgical site infections in Italian Hospitals: a prospective multicenter study. BMC Infect Dis, 8, 34 (2008).

51. Tatterton MR, Homer-Vanniasinkam S. Infections in vascular surgery. Injury, 42 Suppl 5, S35-41 (2011).

52. Culver DH, Horan TC, Gaynes RP et al. Surgical wound infection rates by wound class, operative procedure, and patient risk index. National Nosocomial Infections Surveillance System. Am J Med, 91(3B), 152S-157S (1991).

53. Bandyk DF. Vascular surgical site infection: risk factors and preventive measures. Semin Vasc Surg, 21(3), 119-123 (2008).

54. Richet HM, Chidiac C, Prat A et al. Analysis of risk factors for surgical wound infections following vascular surgery. Am J Med, 91(3B), 170S-172S (1991).

55. Ott E, Bange FC, Sohr D, Teebken O, Mattner F. Risk factors associated with surgical site infections following vascular surgery at a German university hospital. Epidemiol Infect, 1-7 (2012).

56. Sax $H$, Pittet $D$, Swiss NN. Interhospital differences in nosocomial infection rates: importance of case-mix adjustment. Arch Intern Med, 162(21), 2437-2442 (2002).

57. Mioton LM, Jordan SW, Hanwright PJ, Bilimoria KY, Kim JY. The Relationship between Preoperative Wound Classification and Postoperative Infection: A Multi-Institutional Analysis of 15, 289 Patients. Archives of plastic surgery, 40(5), 522-529 (2013). 
58. Brandt C, Sohr D, Behnke M, Daschner F, Ruden H, Gastmeier P. Reduction of surgical site infection rates associated with active surveillance. Infect Control Hosp Epidemiol, 27(12), 1347-1351 (2006).

59. Haridas $M$, Malangoni MA. Predictive factors for surgical site infection in general surgery. Surgery, 144(4), 496-501; discussion 501-493 (2008).

60. Cruse PJ, Foord R. The epidemiology of wound infection. A 10-year prospective study of 62, 939 wounds. Surg Clin North Am, 60(1), 27-40 (1980).

61. Olson M, O'Connor M, Schwartz ML. Surgical wound infections. A 5-year prospective study of 20, 193 wounds at the Minneapolis VA Medical Center. Ann Surg, 199(3), 253-259 (1984).

62. Berard F, Gandon J. Postoperative Wound Infections: The Influence of Ultraviolet Irradiation of the Operating Room and of Various Other Factors. Ann Surg, 160(Suppl 2), 1-192 (1964).

63. NNIS. Nosocomial infection rates for interhospital comparison: limitations and possible solutions. A Report from the National Nosocomial Infections Surveillance (NNIS) System. Infect Control Hosp Epidemiol, 12(10), 609621 (1991).

64. Mayhall CG. Hospital Epidemiology and Infection Control (Lippincott Williams \& Wilkins 2011).

65. Gaynes RP, Culver DH, Horan TC, Edwards JR, Richards C, Tolson JS. Surgical site infection (SSI) rates in the United States, 1992-1998: the National Nosocomial Infections Surveillance System basic SSI risk index. Clin Infect Dis, 33 Suppl 2, S69-77 (2001).

66. Levy PY, Ollivier M, Drancourt M, Raoult D, Argenson JN. Relation between nasal carriage of Staphylococcus aureus and surgical site infection in orthopedic surgery: the role of nasal contamination. A systematic literature review and meta-analysis. Orthop Traumatol Surg Res, 99(6), 645-651 (2013).

67. Wertheim HF, Melles DC, Vos MC et al. The role of nasal carriage in Staphylococcus aureus infections. Lancet Infect Dis, 5(12), 751-762 (2005).

68. Bode LG, Kluytmans JA, Wertheim HF et al. Preventing surgical-site infections in nasal carriers of Staphylococcus aureus. N Engl J Med, 362(1), 9-17 (2010).

69. Kluytmans JA, Mouton JW, VandenBergh MF et al. Reduction of surgicalsite infections in cardiothoracic surgery by elimination of nasal carriage of 
Staphylococcus aureus. Infect Control Hosp Epidemiol, 17(12), 780-785 (1996).

70. Simor AE. Staphylococcal decolonisation: an effective strategy for prevention of infection? Lancet Infect Dis, 11(12), 952-962 (2011).

71. Camus C, Sebille V, Legras A et al. Mupirocin/chlorexidine to prevent methicillin-resistant Staphylococcus aureus infections: post hoc analysis of a placebo-controlled, randomized trial using mupirocin/chlorhexidine and polymyxin/tobramycin for the prevention of acquired infections in intubated patients. Infection, (2014).

72. Bergstrom KG. News, views, and reviews. Less may be more for MRSA: the latest on antibiotics, the utility of packing an abscess, and decolonization strategies. J Drugs Dermatol, 13(1), 89-92 (2014).

73. Kim DH, Spencer M, Davidson SM et al. Institutional prescreening for detection and eradication of methicillin-resistant Staphylococcus aureus in patients undergoing elective orthopaedic surgery. J Bone Joint Surg Am, 92(9), 1820-1826 (2010).

74. Kaye KS, Schmader KE, Sawyer R. Surgical site infection in the elderly population. Clin Infect Dis, 39(12), 1835-1841 (2004).

75. Khullar D, Maa J. The impact of smoking on surgical outcomes. J Am Coll Surg, 215(3), 418-426 (2012).

76. Culebras JM. Malnutrition in the twenty-first century: an epidemic affecting surgical outcome. Surg Infect (Larchmt), 14(3), 237-243 (2013).

77. Waitzberg DL, Ravacci GR, Raslan M. [Hospital hyponutrition]. Nutricion hospitalaria : organo oficial de la Sociedad Espanola de Nutricion Parenteral y Enteral, 26(2), 254-264 (2011).

78. Di Carlo V, Gianotti L, Balzano G, Zerbi A, Braga M. Complications of pancreatic surgery and the role of perioperative nutrition. Dig Surg, 16(4), 320-326 (1999).

79. Martindale RG, McClave SA, Taylor B, Lawson CM. Perioperative nutrition: what is the current landscape? JPEN J Parenter Enteral Nutr, 37(5 Suppl), 5S-20S (2013).

80. van Kasteren ME, Gyssens IC, Kullberg BJ, Bruining HA, Stobberingh EE, Goris RJ. [Optimizing antibiotics policy in the Netherlands. V. SWAB guidelines for perioperative antibiotic prophylaxis. Foundation Antibiotics Policy Team]. Ned Tijdschr Geneeskd, 144(43), 2049-2055 (2000). 
81. Hemani ML, Lepor $H$. Skin preparation for the prevention of surgical site infection: which agent is best? Reviews in urology, 11(4), 190-195 (2009).

82. Tokarski AT, Blaha D, Mont MA et al. Perioperative skin preparation. J Arthroplasty, 29(2 Suppl), 26-28 (2014).

83. $\mathrm{Pu} \mathrm{Y,} \mathrm{Cen} \mathrm{G,} \mathrm{Sun} \mathrm{J} \mathrm{et} \mathrm{al.} \mathrm{Warming} \mathrm{with} \mathrm{an} \mathrm{underbody} \mathrm{warming} \mathrm{system}$ reduces intraoperative hypothermia in patients undergoing laparoscopic gastrointestinal surgery: a randomized controlled study. Int J Nurs Stud, 51(2), 181-189 (2014).

84. Erasmus V, Huis A, Oenema A et al. The ACCOMPLISH study. A cluster randomised trial on the cost-effectiveness of a multicomponent intervention to improve hand hygiene compliance and reduce health care associated infections. BMC Public Health, 11, 721 (2011).

85. Crolla RM, van der Laan L, Veen EJ, Hendriks Y, van Schendel C, Kluytmans J. Reduction of surgical site infections after implementation of a bundle of care. PLoS One, 7(9), e44599 (2012).

86. Yoshida M, Nabeshima T, Gomi H, Lefor AT. Technology and the prevention of surgical site infections. J Surg Educ, 64(5), 302-310 (2007).

87. Galway UA, Parker BM, Borkowski RG. Prevention of postoperative surgical site infections. Int Anesthesiol Clin, 47(4), 37-53 (2009).

88. Boyce JM, Larson EL, Pittet D. Hand hygiene must be enabled and promoted. Am J Infect Control, 40(4 Suppl 1), S2 (2012).

89. Pincock T, Bernstein P, Warthman S, Holst E. Bundling hand hygiene interventions and measurement to decrease health care-associated infections. Am J Infect Control, 40(4 Suppl 1), S18-27 (2012).

90. Al-Tawfiq JA, Pittet D. Improving hand hygiene compliance in health care settings using behavior change theories: reflections. Teaching and learning in medicine, 25(4), 374-382 (2013).

91. Gould DJ, Moralejo D, Drey N, Chudleigh JH. Interventions to improve hand hygiene compliance in patient care. Cochrane Database Syst Rev, (9), CD005186 (2010).

92. van Tiel FH, Elenbaas TW, Voskuilen BM et al. Plan-do-study-act cycles as an instrument for improvement of compliance with infection control measures in care of patients after cardiothoracic surgery. J Hosp Infect, 62(1), 64-70 (2006).

93. Leung Wai Sang S, Chaturvedi R, Alam A, Samoukovic G, de Varennes B, Lachapelle K. Preoperative hospital length of stay as a modifiable risk 
factor for mediastinitis after cardiac surgery. J Cardiothorac Surg, 8, 45 (2013).

94. Gastmeier P, Sohr D, Breier A, Behnke M, Geffers C. Prolonged duration of operation: an indicator of complicated surgery or of surgical (mis)management? Infection, 39(3), 211-215 (2011).

95. Cheadle WG. Risk factors for surgical site infection. Surg Infect (Larchmt), 7 Suppl 1, S7-11 (2006).

96. Pomorska-Mol M, Pejsak Z. Effects of antibiotics on acquired immunity in vivo--current state of knowledge. Polish journal of veterinary sciences, 15(3), 583-588 (2012).

97. Hunter $P$. Where next for antibiotics? The immune system and the nature of pathogenicity are providing vital clues in the fight against antibioticresistant bacteria. EMBO Rep, 13(8), 680-683 (2012).

98. Adegoke, A A, Mvuyo T, Okoh, Anthony, Steve J. Studies on multiple antibiotic resistant bacterial isolated from surgical site infection. Academic journals, 3876-3881 (2012).

99. Bowler PG, Duerden BI, Armstrong DG. Wound microbiology and associated approaches to wound management. Clin Microbiol Rev, 14(2), 244-269 (2001).

100.Boyce JM, Pittet D, Health care Infection Control Practices Advisory Committee. Society for Health care Epidemiology of America. Association for Professionals in Infection Control. Infectious Diseases Society of America. Hand Hygiene Task F. Guideline for Hand Hygiene in Health-Care Settings: recommendations of the Health care Infection Control Practices Advisory Committee and the HICPAC/SHEA/APIC/IDSA Hand Hygiene Task Force. Infect Control Hosp Epidemiol, 23(12 Suppl), S3-40 (2002).

101. Reichman DE, Greenberg JA. Reducing surgical site infections: a review. Reviews in obstetrics and gynecology, 2(4), 212-221 (2009).

102.Stevens DL, Bisno AL, Chambers HF et al. Practice guidelines for the diagnosis and management of skin and soft-tissue infections. Clin Infect Dis, 41(10), 1373-1406 (2005).

103. Bratzler DW, Dellinger EP, Olsen KM et al. Clinical practice guidelines for antimicrobial prophylaxis in surgery. Surg Infect (Larchmt), 14(1), 73-156 (2013). 
104.Smith RG, Joseph WS. Antibiotic stewardship: the lower-extremity physician's prescription for effectively treating infection. J Am Podiatr Med Assoc, 104(1), 77-84 (2014).

105. Reuland EA, Overdevest IT, Al Naiemi N et al. High prevalence of ESBLproducing Enterobacteriaceae carriage in Dutch community patients with gastrointestinal complaints. Clin Microbiol Infect, 19(6), 542-549 (2013).

106. Bull A, Wilson J, Worth $\mathrm{LJ}$ et al. A bundle of care to reduce colorectal surgical infections: an Australian experience. J Hosp Infect, 78(4), 297-301 (2011).

107. Wille J, Kluytmans J, Vos G, van den Broek PJ. [Interventiebundel wondinfecties hoopgevend, maar te weinig nageleefd. Infectiepreventie vergt meer inzet]. Medisch Contact 76 nr. 38: 2103-2105. 2012).

108.VMS. VMS veiligheidsprogramma, Utrecht. Voorkomen van wondinfecties na een operatie; 2009.

109. Wille J, Kluytmans J, Vos G, van den Broek PJ. Interventiebundel wondinfecties hoopgevend, maar te weinig nageleefd. Infectiepreventie vergt meer inzet. Medisch Contact 76 nr. 38: 2103-2105. 2012 ).

110.W.I.P. Richtlijnen Werkgroep Infectiepreventie. Chapter "Ziekenhuizen". Preventie van postoperatieve wondinfecties. www.wip.nl.).

111.Tanner J, Norrie P, Melen K. Preoperative hair removal to reduce surgical site infection. Cochrane Database Syst Rev, (11), CD004122 (2011).

112. Niel-Weise BS, Wille JC, van den Broek PJ. Hair removal policies in clean surgery: systematic review of randomized, controlled trials. Infect Control Hosp Epidemiol, 26(12), 923-928 (2005).

113.Ng RS, Chong CP. Surgeons' adherence to guidelines for surgical antimicrobial prophylaxis - a review. The Australasian medical journal, 5(10), 534-540 (2012).

114. Kurz A, Sessler DI, Lenhardt R. Perioperative normothermia to reduce the incidence of surgical-wound infection and shorten hospitalisation. Study of Wound Infection and Temperature Group. N Engl J Med, 334(19), 12091215 (1996).

115. Melling AC, Ali B, Scott EM, Leaper DJ. Effects of preoperative warming on the incidence of wound infection after clean surgery: a randomised controlled trial. Lancet, 358(9285), 876-880 (2001).

116.Geubbels EL, Nagelkerke NJ, Mintjes-De Groot AJ, Vandenbroucke-Grauls $\mathrm{CM}$, Grobbee DE, De Boer AS. Reduced risk of surgical site infections 
through surveillance in a network. Int J Qual Health Care, 18(2), 127-133 (2006).

117. Haley RW, Culver DH, White JW et al. The efficacy of infection surveillance and control programs in preventing nosocomial infections in US hospitals. Am J Epidemiol, 121(2), 182-205 (1985).

118. Coello R, Charlett A, Wilson J, Ward V, Pearson A, Borriello P. Adverse impact of surgical site infections in English hospitals. J Hosp Infect, 60(2), 93-103 (2005).

119. Bruce J, Russell EM, Mollison J, Krukowski ZH. The quality of measurement of surgical wound infection as the basis for monitoring: a systematic review. J Hosp Infect, 49(2), 99-108 (2001).

120. Mu Y, Edwards JR, Horan TC, Berrios-Torres SI, Fridkin SK. Improving riskadjusted measures of surgical site infection for the national health care safety network. Infect Control Hosp Epidemiol, 32(10), 970-986 (2011).

121. Mannien J, Wille JC, Kloek JJ, van Benthem BH. Surveillance and epidemiology of surgical site infections after cardiothoracic surgery in The Netherlands, 2002-2007. J Thorac Cardiovasc Surg, 141(4), 899-904 (2011).

122. Haley RW, Quade D, Freeman HE, Bennett JV. The SENIC Project. Study on the efficacy of nosocomial infection control (SENIC Project). Summary of study design. Am J Epidemiol, 111(5), 472-485 (1980).

123.PREZIES. [PREventie ZIEkenhuisinfecties door Surveillance. Bilthoven: PREZIES; 2012]. Available at http://www.prezies.nl.

124.Limon E, Shaw E, Badia JM et al. Post-discharge surgical site infections after uncomplicated elective colorectal surgery: impact and risk factors. The experience of the VINCat Program. J Hosp Infect, (2013).

125. Mannien J, Wille JC, Snoeren RL, van den Hof S. Impact of postdischarge surveillance on surgical site infection rates for several surgical procedures: results from the nosocomial surveillance network in The Netherlands. Infect Control Hosp Epidemiol, 27(8), 809-816 (2006).

126. Reilly J, Allardice G, Bruce J, Hill R, McCoubrey J. Procedure-specific surgical site infection rates and postdischarge surveillance in Scotland. Infect Control Hosp Epidemiol, 27(12), 1318-1323 (2006).

127. de Oliveira AC, Carvalho DV. Evaluation of underreported surgical site infection evidenced by post-discharge surveillance. Rev Lat Am Enfermagem, 15(5), 992-997 (2007). 
128. Avato JL, Lai KK. Impact of postdischarge surveillance on surgical-site infection rates for coronary artery bypass procedures. Infect Control Hosp Epidemiol, 23(7), 364-367 (2002).

129.Trampuz A, Widmer AF. Infections associated with orthopedic implants. Curr Opin Infect Dis, 19(4), 349-356 (2006).

130.Geubbels EL, Mintjes-de Groot AJ, van den Berg JM, de Boer AS. An operating surveillance system of surgical-site infections in The Netherlands: results of the PREZIES national surveillance network. Preventie van Ziekenhuisinfecties door Surveillance. Infect Control Hosp Epidemiol, 21(5), 311-318 (2000).

131.Petherick ES, Dalton JE, Moore PJ, Cullum N. Methods for identifying surgical wound infection after discharge from hospital: a systematic review. BMC Infect Dis, 6, 170 (2006).

132. Birgand G, Lepelletier D, Baron G et al. Agreement among health care professionals in ten European countries in diagnosing case-vignettes of surgical-site infections. PLoS One, 8(7), e68618 (2013).

133.Seaman M, Lammers R. Inability of patients to self-diagnose wound infections. J Emerg Med, 9(4), 215-219 (1991).

134. Whitby M, McLaws ML, Collopy B et al. Post-discharge surveillance: can patients reliably diagnose surgical wound infections? J Hosp Infect, 52(3), 155-160 (2002).

135. Ramcharan A, Penders J, Smeets E et al. Cross-sectional study on surveillance of surgical site infections after vascular surgery. Future Microbiol, 8(11), 1373-1380 (2013).

136.Jonkers D, Elenbaas T, Terporten P, Nieman F, Stobberingh E. Prevalence of 90-days postoperative wound infections after cardiac surgery. Eur J Cardiothorac Surg, 23(1), 97-102 (2003).

137. Medina-Cuadros M, Sillero-Arenas M, Martinez-Gallego G, DelgadoRodriguez M. Surgical wound infections diagnosed after discharge from hospital: epidemiologic differences with in-hospital infections. Am J Infect Control, 24(6), 421-428 (1996). 


\section{Chapter 2
what determines the (in-) efficacy of a}

\section{surveillance system to reduce surgical site}

\section{infections after gastrointestinal surgery?}

Ramcharan A, Smeets E, Rouflart M, van Tiel F, Bruggeman C, Breukink S, Tordoir J, Baeten C, Stobberingh E International Journal of Infection Control 2014, v10:i2 
What determines the (in-) efficacy of a surveillance system to reduce surgical site infections after gastrointestinal surgery?

\section{Abstract}

Aims: A surgical site infection (SSI) is a serious and costly complication with the highest rates being reported after gastrointestinal surgery. The objective of this cross sectional study was to assess the incidence and risk factors for SSIs after gastrointestinal surgery during and after hospitalisation, and to evaluate the effect of the VMS (Dutch acronym: VeiligheidsManagementSysteem) safety programme on the SSI rate.

Materials \& methods: We assessed the SSI rate from July 2008 until December 2011, according to the criteria of the Centers for Disease Control and Prevention $(C D C)$, before and after implementation of the VMS safety programme, which includes a bundle of four interventions. We differentiated between the SSI rate during and after hospitalisation and between superficial, deep and organ/space infections. The incidence of SSI in relation to the wound class, risk factors for SSI, and the compliance with the programme were assessed. Data were obtained during a thirty-day follow-up period after surgery.

Results: Surveillance after discharge significantly increased the overall SSI rate. An age higher than fifty years and contaminated or dirty wounds were risk factors for SSIs. Despite increased compliance with the safety programme, no significant decrease in SSI rate was found after implementation.

Conclusion: The Dutch VMS safety programme did not show a significant effect on the decrease in incidence of SSI. Surveillance, during and after hospitalisation, is essential for a reliable assessment of the SSI rate. 
What determines the (in-) efficacy of a surveillance system to reduce surgical site infections after gastrointestinal surgery?

\section{Introduction}

A surgical site infection (SSI) is a serious and costly complication resulting in prolonged hospital stay, increased antibiotic use, increased morbidity, and even mortality [1-4]. SSIs affect up to $5 \%$ of surgical patients, with the highest rates being reported after gastrointestinal surgery [5-9]. The negative effect that SSI has on patient safety depends partly on whether the infection is superficial or deep or whether it concerns organ or space, i.e., any part of the body, excluding the skin incision, fascia, or muscle layers, that is opened or manipulated during the operative procedure $[8,10]$. Since the risk of an SSI is amongst others associated with the degree of intrinsic microbial contamination of the surgical wound, wounds are classified into four wound classes [11]. Patients with advanced stages of disease and multiple co-morbid diagnoses are often referred to a tertiary care hospital for further treatment [12]. In addition, since shorter hospitalisation after surgery has become common practice, it is to be expected that an increased number of SSIs will be diagnosed after discharge [11, 13, 14]. Surveillance of SSI is an important strategy to reduce the risk for developing an SSI [15]. It consists of registration, analysis of patients' clinical data and feedback to health care workers [11, 16-19]. In the Netherlands, hospitals currently participate in a national programme intended at improving patient safety, i.e., the patient safety programme VMS (Dutch acronym: VeiligheidsManagementSysteem). The programme consists of ten themes, one of which focuses on the reduction of SSI, and was developed with the aim at reducing the occurrence of preventable deaths with $50 \%$ by the end of 2012 . It was initiated by the Society of Hospitals (NVZ), the Dutch Federation of University Medical Centres (NFU), and the Dutch Association of Medical Specialists and Nurses \& Carers (V\&VN). The theme to reduce SSI contains a bundle of four interventions. The goal is to improve the compliance with these preventive measures [20]. However, it remains uncertain which factors affect the successfulness of safety measures to reduce SSIs and whether extensive efforts result in the desired outcome, i.e., reducing SSIs. The objective of this study was to assess the incidence of SSI after gastrointestinal surgery during and after hospitalisation, and to evaluate the (in-) efficacy of the VMS safety programme, designed at an academic medical centre, on the incidence of SSI. We performed an analysis based on a logistic regression model to determine risk factors for SSIs after gastrointestinal surgery. 
What determines the (in-) efficacy of a surveillance system to reduce surgical site infections after gastrointestinal surgery?

\section{Methods}

\section{Study setting and patients}

The study was carried out from July 2008 until December 2011 in a 715-bed tertiary care hospital in the Netherlands, the Maastricht University Medical Centre (MUMC+). The study was divided in a pre-test period and a post-test period. In the pre-test period, from July 2008 till April 2010, surveillance was only performed during hospitalisation from July 2008 till July 2009. Half way during this pre-test period, the surveillance period was extended to a follow-up period of thirty days after surgery. The postdischarge surveillance was only performed for patients visiting the outpatient clinic within the thirty days after surgery. There was no systematic follow-up of all patients over the full thirty days period. April 2010 until December 2011 was the post-test period during which the VMS safety programme had been introduced and implemented at the surgical department. The effectiveness of the VMS programme was evaluated, using the incidence of SSI as indicator parameter.

\section{Surgical site infection}

All wounds after surgery were classified into four classes: clean, cleancontaminated, contaminated or dirty. The presence of superficial, deep and organ/space SSI was assessed according to the criteria of the Centres for Disease Control and Prevention (CDC) [8]. The index-surgery was defined as the first surgical intervention in this hospital. All SSIs diagnosed within thirty days after the index-surgery were registered according to the criteria of the CDC and the Dutch PREZIES (Dutch acronym: Preventie van Ziekenhuisinfecties door Surveillance) national guidelines $[8,21,22]$. An infection was considered as an SSI linked to the index-surgery, unless a surgical intervention in another hospital had been performed at the same surgical site within thirty days before the index-surgery. Resurgeries in this hospital, performed at the same surgical site and within thirty days after the index-surgery, were considered to be related to this surgery, and were therefore not included in the analysis. Surgery more than thirty days after the previous surgical intervention was registered as a new index-surgery and included in the analysis. An independent experienced infection control nurse (ICN), who was trained in the assessment of SSI, collected demographic data of the patient and clinical data of the surgical procedure over the course of the study: sex, age, wound class, elective versus urgent, admission date, date of surgery, discharge date, 
What determines the (in-) efficacy of a surveillance system to reduce surgical site infections after gastrointestinal surgery?

readmission within the postdischarge period, presence and type of SSI, and history of previous surgery. The inter-rater reliability (IRR) was evaluated by discussing difficult cases of SSI with independent physicians and checking print outs of the database every half year. The sources of information were medical records and consultations of independent physicians. Postdischarge surveillance (PDS) was assessed by examining patients' wounds during follow-up visits at the outpatient clinic within thirty days after surgery. This surveillance method included additional surgeon notes from the outpatient medical record to pre-existing clinical data, and was validated by the PREZIES network [23].

\section{The VMS safety programme}

The VMS safety programme has been developed for Dutch hospitals. One of the ten themes includes a bundle of four interventions with the aim at reducing SSIs. The bundle was intended to reach a compliance rate of at least $90 \%$, using the Plan-Do-Study-Act-cycle as developed by the American Institute for health care Improvement $[24,25]$. The SSI rate was measured to quantify the effect of the intervention measures. The elements of the bundle are peri-operative antibiotic prophylaxis, no hair removal before surgery, normothermia, and discipline in the operating room (OR), measured as the number of door movements during surgery [24]. Concerning the PDSA cycle, in the 'Plan' phase we determined the number of surgical index-surgeries and the SSI rate during the study period. In the 'Do'- phase surveillance was performed to collect, analyse and interpret the relevant data. During the 'Study'- phase trends over time in SSI rate and risk factors were investigated. In the 'Act'-phase, the putative interventions which should be made to improve compliance with the infection prevention policy in the future, were determined.

\section{Compliance with the VMS safety programme}

Random observation of infection control practices was yearly performed at the OR for gastrointestinal procedures. This was done by infection control personnel, using a specifically developed checklist that consisted of infection control practices related to surgical and anaesthesia procedures. Monitoring at the OR was performed throughout all activities related to the same procedure. OR personnel were not notified in advance of which surgical procedures were about to be monitored. The number of door movements was measured from the start of the incision until the surgical wound was closed. Antimicrobial therapy was provided 
according to the hospital-specific guidelines of the Dutch working party on Antibiotic policy (Dutch: Stichting Werkgroep AntibioticaBeleid, SWAB) [26]. Cefuroxime, 1500mg intravenous, or cefazoline $500 \mathrm{mg}$ with $500 \mathrm{mg}$ metronidazole intravenous or 2.2 gram amoxicillin-clavulanic acid intravenous for patients who underwent colorectal surgery, within 30 minutes to 1 hour before incision. Patients who underwent other laparotomies (clean procedures) did not receive antimicrobial treatments. For a morbidly obese patient two grams of a second generation cephalosporin or one gram ertapenem was more appropriate. Hair removal was omitted, if necessary a clipper was used instead. Normothermia was defined as a body temperature between $36^{\circ} \mathrm{C}$ and $38^{\circ} \mathrm{C}$ at the end of the surgery. This was achieved with intravenous fluids and a forced-air cover [27]. Between the monitoring events no specific interventions were established to improve compliance other than increasing awareness of the guidelines.

\section{Statistical Analysis}

The incidence of SSI was defined as the number of SSIs per number of surgical procedures and was calculated for the pre-test and the post-test periods. The SSI rate during hospitalisation in the post-test period was compared to that of the pretest period, using the Pearson's chi-square test. The univariate relationship between each independent variable and SSI was evaluated using a logistic model for continuous variables. Variables with the lowest infection risk were taken as reference group (clean wounds, age less than thirty years and elective procedures). Logistic regression was performed to assess the impact of a number of factors on the likelihood that an SSI during hospitalisation in the pre-test and post-test periods occurred. The model contained ten independent variables: sex (female or male), age groups (<30 year, 30-50 year, 50-70 year or >70 year), wound classes (clean-contaminated, contaminated or dirty), previous surgery and urgency of surgery (acute or emergent). Results were considered to be significant at a $p$-value of $\leq 0.05$. Unadjusted, adjusted odds ratios (OR) and the $95 \%$ confidence intervals (CI) were calculated for each independent variable. All statistical analysis of the data was done using the SPSS programme for Windows, PASW Statistics 18. 
What determines the (in-) efficacy of a surveillance system to reduce surgical site infections after gastrointestinal surgery?

\section{Results}

\section{Study population}

Of the 2546 surgical procedures (including 390 re-surgeries within thirty days), 2156 index-surgeries were included in the analysis. The gender ratio was 1067 (49.5\%) male and 1089 (50.5\%) female. The patients' ages ranged from 18 to 98 years with a mean of 63 years for male and 62 years for female patients. Surgical procedures were classified as clean ( $n=254,11.8 \%$ ), clean-contaminated ( $n=857$ $39.7 \%)$, contaminated $(n=518,24.0 \%)$ and dirty $(n=413,19.2 \%)$. The wound class of 114 procedures (5.3\%) was unknown. In total, 485 SSIs were diagnosed (22.5\%) during and after hospitalisation, of which 243 (50.1\%) were superficial, 216 deep (44.5\%) and 26 organ/space (5.4\%). Most superficial and deep SSIs were classified as clean-contaminated wounds $(47.7 \%$ and $37.5 \%$ respectively). The organ/space SSIs were mainly classified as dirty wounds (65.4\%). We observed an overall trend towards a higher incidence of SSI when progressing from clean to dirty wound procedures: $7 \%$ (clean), 24\% (clean-contaminated; OR 4.0, 95\% Cl 2.4-6.7), 23\% (contaminated; OR 1.0, 95\% Cl 0.7-1.2) and 32\% (dirty; OR 1.6, 95\% Cl 1.2-2.1). For statistical analysis, 1224 surgical procedures in the pre-test period and 932 procedures in the post-test period were examined (Table I). SSI rates of contaminated and dirty wounds were significantly higher than in clean and cleancontaminated wounds, both in the pre-test as well as in the post-test period. In the post-test period patients aged fifty and higher were more likely to get an SSI. In both periods a significant longer duration of hospitalisation was found in patients with an SSI compared to those without an SSI (mean additional length of stay (LOS): 11.5 and 5.5 days respectively). 
What determines the (in-) efficacy of a surveillance system to reduce surgical site infections after gastrointestinal surgery?

\begin{tabular}{|c|c|c|c|c|c|c|c|}
\hline \multicolumn{4}{|c|}{ Pre-test $(\mathrm{N}=1224)$} & \multicolumn{4}{|c|}{ Post-test (N=932) } \\
\hline Characteristics & $\begin{array}{l}\text { SSI } \\
(+)\end{array}$ & SSI (-) & $\mathrm{OR}, 95 \% \mathrm{Cl}$ & Characteristics & $\begin{array}{l}\text { SSI } \\
(+)\end{array}$ & SSI (-) & OR, $95 \% \mathrm{Cl}^{ \pm}$ \\
\hline Number & $\begin{array}{l}177 \\
(14.5)\end{array}$ & $\begin{array}{l}1047 \\
(85.5)\end{array}$ & & Number & $\begin{array}{l}179 \\
(19.2)\end{array}$ & $\begin{array}{l}753 \\
(80.8)\end{array}$ & \\
\hline Sex & & & $\begin{array}{c}1.30,0.94- \\
1.79\end{array}$ & Sex & & & $\begin{array}{c}1.30,0.94- \\
1.81\end{array}$ \\
\hline Female & $\begin{array}{l}81 \\
(45.8)\end{array}$ & $\begin{array}{l}547 \\
(52.2)\end{array}$ & & Female & $\begin{array}{l}79 \\
(44.1)\end{array}$ & $\begin{array}{l}382 \\
(50.7)\end{array}$ & \\
\hline Male & $\begin{array}{l}96 \\
(54.2)\end{array}$ & $\begin{array}{l}500 \\
(47.8)\end{array}$ & & Male & $\begin{array}{l}100 \\
(55.9)\end{array}$ & $\begin{array}{l}371 \\
(49.3)\end{array}$ & \\
\hline Age & & & $\begin{array}{c}0.78,0.52- \\
1.17\end{array}$ & Age & & & $\begin{array}{c}0.57,0.36- \\
0.91\end{array}$ \\
\hline$\geq 50$ & $\begin{array}{l}143 \\
(80.8)\end{array}$ & $\begin{array}{l}803 \\
(76.7)\end{array}$ & & $\geq 50$ & $\begin{array}{l}155 \\
(86.6)\end{array}$ & $\begin{array}{l}593 \\
(78.8)\end{array}$ & \\
\hline$<50$ & $\begin{array}{l}34 \\
(19.2)\end{array}$ & $\begin{array}{l}244 \\
(23.3)\end{array}$ & & $<50$ & $\begin{array}{l}24 \\
(13.4)\end{array}$ & $\begin{array}{l}160 \\
(21.2)\end{array}$ & \\
\hline Wound class ${ }^{\S}$ & & & $\begin{array}{c}1.54,1.11- \\
2.13\end{array}$ & Wound class & & & $\begin{array}{c}1.54,1.10- \\
2.15\end{array}$ \\
\hline $1+2$ & $\begin{array}{l}79 \\
(44.6)\end{array}$ & $\begin{array}{l}554 \\
(52.9)\end{array}$ & & $1+2$ & $\begin{array}{l}78 \\
(43.6)\end{array}$ & $\begin{array}{l}400 \\
(53.1)\end{array}$ & \\
\hline $3+4$ & $\begin{array}{l}95 \\
(53.7)\end{array}$ & $\begin{array}{l}433 \\
(41.4)\end{array}$ & & $3+4$ & $\begin{array}{l}93 \\
(52.0)\end{array}$ & $\begin{array}{l}310 \\
(41.2)\end{array}$ & \\
\hline $\begin{array}{l}\text { Previous } \\
\text { operation }^{\dagger}\end{array}$ & & & $\begin{array}{c}0.84,0.54- \\
1.30\end{array}$ & $\begin{array}{l}\text { Previous } \\
\text { operation }\end{array}$ & & & $\begin{array}{c}0.79,0.52- \\
1.22\end{array}$ \\
\hline Yes & $\begin{array}{l}28 \\
(15.8)\end{array}$ & $\begin{array}{l}142 \\
(13.6)\end{array}$ & & Yes & $\begin{array}{l}32 \\
(17.8)\end{array}$ & $\begin{array}{l}111 \\
(14.7)\end{array}$ & \\
\hline No & $\begin{array}{l}149 \\
(84.2)\end{array}$ & $\begin{array}{l}905 \\
(86.4)\end{array}$ & & No & $\begin{array}{l}147 \\
(82.1)\end{array}$ & $\begin{array}{l}642 \\
(85.3)\end{array}$ & \\
\hline Procedure & & & $\begin{array}{c}1.13,0.81- \\
1.57\end{array}$ & Procedure & & & $\begin{array}{c}0.85,0.61- \\
1.18\end{array}$ \\
\hline Emergency & $\begin{array}{l}63 \\
(35.6)\end{array}$ & $\begin{array}{l}402 \\
(38.4)\end{array}$ & & Emergency & $\begin{array}{l}72 \\
(40.2)\end{array}$ & $\begin{array}{l}273 \\
(36.3)\end{array}$ & \\
\hline Elective & $\begin{array}{l}114 \\
(64.4)\end{array}$ & $\begin{array}{l}645 \\
(61.6)\end{array}$ & & Elective & $\begin{array}{l}107 \\
(59.8)\end{array}$ & $\begin{array}{l}480 \\
(63.7)\end{array}$ & \\
\hline $\begin{array}{l}\text { Hospitalisation } \\
\text { (days) }\end{array}$ & $\begin{array}{l}28.9 \\
\pm \\
21.5\end{array}$ & $\begin{array}{l}23.4 \\
\pm \\
29.2\end{array}$ & $\begin{array}{c}p=0.018 \\
95 \% \mathrm{Cl} 0.9- \\
10-0\end{array}$ & $\begin{array}{l}\text { Hospitalisation } \\
\text { (days) }\end{array}$ & $\begin{array}{l}25.5 \\
\pm \\
23.7\end{array}$ & $\begin{array}{l}14.0 \\
\pm \\
18.5\end{array}$ & $\begin{array}{c}p=0.000 \\
95 \% \mathrm{Cl} \text { 8.3- } \\
14.7\end{array}$ \\
\hline
\end{tabular}


Observation of practice at the $O R$ was performed for twenty-three randomly selected gastrointestinal surgeries. In the pre-test period the compliance rate for the four measures was less than $90 \%$. In the post-test period a significant increase of compliance with the measures regarding antibiotic prophylaxis, shaving policy and the number of door movements was observed. No increase in compliance with normothermia measures was found. Despite this increase, compliance with measures regarding the number of door movements remained low. Overall compliance with all four preventive measures increased in the post-test period with $10 \%$ (data not shown).

Number of SSI in the Pre-test versus post-test period

The number of SSI diagnosed during hospitalisation significantly increased in time, from $14.5 \%$ in the pre-test period to $19.2 \%$ in the post-test period (OR $1.41,95 \% \mathrm{Cl}$ 1.12-1.77, Table II). The proportion of SSIs diagnosed after discharge slightly increased in the post-test period, from $27.6 \%$ to $35.8 \%$. The LOS of all patients (with and without an SSI) was lower in the post-test period than the pre-test period (16.2 days and 24.2 days respectively). The number of superficial SSI classified as dirty was higher in the pre-test period as compared to the post-test period (OR 5.76, 95\% Cl 2.92-11.34, Table III).

Results from the logistic regression analysis showed that in the pre-test period three independent variables contributed significantly to get an SSI. The strongest predictor being dirty wounds had a 23.6 times higher chance to develop an SSI than clean wounds. In the post-test period only two of the independent variables contributed significantly to get an SSI, i.e., patients older than seventy years and wounds classified as dirty. The strongest predictor for developing an SSI was again a dirty wound class which had a 4.8-fold higher risk for developing an SSI compared to clean wounds. 
What determines the (in-) efficacy of a surveillance system to reduce surgical site infections after gastrointestinal surgery?

\begin{tabular}{|c|c|c|c|c|}
\hline \multicolumn{2}{|l|}{ Pre-test } & \multicolumn{3}{|l|}{ Post-test } \\
\hline Characteristics & SSI (+) & Characteristics & SSI (+) & OR, $95 \%-\mathrm{Cl}^{ \pm}$ \\
\hline Number & $\begin{array}{l}177 \\
(14.5)\end{array}$ & Number & $\begin{array}{l}179 \\
(19.2)\end{array}$ & $1.41,1.12-1.77$ \\
\hline Superficial & $\begin{array}{l}88 \\
(49.7)\end{array}$ & Superficial & $\begin{array}{l}88 \\
(49.2)\end{array}$ & $0.98,0.65-1.48$ \\
\hline Deep/Organ space & $\begin{array}{l}89 \\
(50.3)\end{array}$ & $\begin{array}{l}\text { Deep/Organ } \\
\text { space }\end{array}$ & $\begin{array}{l}91 \\
(50.8)\end{array}$ & $1.02,0.68-1.55$ \\
\hline Sex & & Sex & & \\
\hline Female & $\begin{array}{l}81 \\
(45.8)\end{array}$ & Female & $\begin{array}{l}79 \\
(44.1)\end{array}$ & $0.94,0.62-1.42$ \\
\hline Male & $\begin{array}{l}96 \\
(54.2)\end{array}$ & Male & $\begin{array}{l}100 \\
(55.9)\end{array}$ & $1.07,0.70-1.62$ \\
\hline Age & & Age & & \\
\hline$>70$ & $\begin{array}{l}76 \\
(42.9)\end{array}$ & $\geq 70$ & $\begin{array}{l}76 \\
(42.4)\end{array}$ & $0.98,0.64-1.49$ \\
\hline $50-70$ & $\begin{array}{l}67 \\
(37.9)\end{array}$ & $50-70$ & $\begin{array}{l}79 \\
(44.1)\end{array}$ & $1.30,0.85-1.98$ \\
\hline $30-50$ & $\begin{array}{l}26 \\
(14.7)\end{array}$ & $30-50$ & $\begin{array}{l}21 \\
(11.7)\end{array}$ & $0.77,0.42-1.43$ \\
\hline$<30$ & $8(4.5)$ & $\leq 30$ & $3(1.7)$ & $0.36,0.09-1.38$ \\
\hline Wound class $^{\S}$ & & Wound class & & \\
\hline 1 & $2(1.1)$ & 1 & $6(3.4)$ & $3.03,0.60-15.2$ \\
\hline 2 & $\begin{array}{l}77 \\
(43.5)\end{array}$ & 2 & $\begin{array}{l}72 \\
(40.2)\end{array}$ & $0.87,0.57-1.33$ \\
\hline 3 & $\begin{array}{l}49 \\
(27.7)\end{array}$ & 3 & $\begin{array}{l}36 \\
(20.1)\end{array}$ & $0.66,0.40-1.08$ \\
\hline 4 & $\begin{array}{l}46 \\
(26.0)\end{array}$ & 4 & $\begin{array}{l}57 \\
(31.8)\end{array}$ & $1.33,0.84-2.11$ \\
\hline Previous operation $^{\dagger}$ & $\begin{array}{l}28 \\
(15.8)\end{array}$ & $\begin{array}{l}\text { Previous } \\
\text { operation }\end{array}$ & $\begin{array}{l}32 \\
(17.9)\end{array}$ & $1.16,066-2.02$ \\
\hline $\begin{array}{l}\text { Emergent } \\
\text { procedure }^{\ddagger}\end{array}$ & $\begin{array}{l}63 \\
(35.6)\end{array}$ & $\begin{array}{l}\text { Emergent } \\
\text { procedure }\end{array}$ & $\begin{array}{l}72 \\
(40.2)\end{array}$ & $1.22,0.79-1.87$ \\
\hline Proportion PDS SSI ${ }^{*}$ & $\begin{array}{l}29 \\
(27.6)\end{array}$ & $\begin{array}{l}\text { Proportion PDS } \\
\text { SSI }\end{array}$ & $\begin{array}{l}100 \\
(35.8)\end{array}$ & $1.46,0.89-2.40$ \\
\hline
\end{tabular}

${ }^{ \pm}$Characteristics of patients with SSI: comparison between the Pre-test and Post-test.

${ }^{\S}$ Wound class: 1 (clean), 2 (clean-contaminated), 3 (contaminated), 4 (dirty)

${ }^{+}$Previous operation within 30 days at the same surgical site

${ }^{\ddagger}$ Not elective

${ }^{*}$ In the Pre-test PDS was only performed from July 2009 - Apr 2010, 76 inpatient SSIs and 29 outpatient SSIS 
Table III: Comparison of patients with superficial and deep/organ space SSI during hospitalisation, Pre-test versus Post-test

\begin{tabular}{|c|c|c|c|c|c|c|c|}
\hline & Pre-test & & & & Post-test & & \\
\hline Variables & $\begin{array}{l}\text { Number } \\
\text { with } \\
\text { superficial }\end{array}$ & $\begin{array}{l}\text { Number } \\
\text { with } \\
\text { deep/organ }\end{array}$ & Variables & $\begin{array}{l}\text { Number } \\
\text { with } \\
\text { superficial }\end{array}$ & $\begin{array}{l}\text { Number } \\
\text { with } \\
\text { deep/organ }\end{array}$ & $\begin{array}{l}\text { OR, 95\%- } \\
\mathrm{Cl} \\
\text { Superficial }\end{array}$ & $\begin{array}{l}\text { OR, } 95 \%-\mathrm{Cl}^{ \pm} \\
\text {Deep/Organ } \\
\text { space SSI }\end{array}$ \\
\hline & SSI $(n=88)$ & $\begin{array}{ll}\text { space } & \text { SSI } \\
(n=89) & \end{array}$ & & SSI $(n=88)$ & $\begin{array}{ll}\text { space } & \text { SSI } \\
(n=91) & \end{array}$ & SSI & \\
\hline Sex & & & Sex & & & & \\
\hline Female & $39(44.3)$ & $42(47.2)$ & Female & $37(42.0)$ & $42(46.2)$ & $\begin{array}{c}0.91,0.50- \\
1.66\end{array}$ & $\begin{array}{c}0.96,0.53- \\
1.72\end{array}$ \\
\hline Male & 49 (55.7) & $47(52.8)$ & Male & 51 (58.0) & $49(53.8)$ & $\begin{array}{c}1.10,0.60- \\
1.99\end{array}$ & $\begin{array}{c}1.04,0.58- \\
1.87\end{array}$ \\
\hline Age & & & Age & & & & \\
\hline$>70$ & 41 (46.6) & 35 (39.3) & $\geq 70$ & $38(43.2)$ & $38(41.8)$ & $\begin{array}{c}0.87,0.48- \\
1.58\end{array}$ & $\begin{array}{c}1.11,0.61- \\
2.01\end{array}$ \\
\hline $50-70$ & $38(43.2)$ & $29(32.6)$ & $50-70$ & $39(44.3)$ & $40(44.0)$ & $\begin{array}{c}1.05,0.58- \\
1.90\end{array}$ & $\begin{array}{c}1.62,0.89- \\
2.98\end{array}$ \\
\hline $30-50$ & $7(8.0)$ & $19(21.3)$ & $30-50$ & $11(12.5)$ & $10(11.0)$ & $\begin{array}{c}1.65,0.61- \\
4.48\end{array}$ & $\begin{array}{c}0.46,0.20- \\
1.04\end{array}$ \\
\hline$<30$ & $2(2.3)$ & $6(6.7)$ & $\leq 30$ & 0 & $3(3.3)$ & $\begin{array}{c}0.49,0.43- \\
0.57\end{array}$ & $\begin{array}{c}0.47,0.11- \\
1.95\end{array}$ \\
\hline $\begin{array}{l}\text { Wound } \\
\text { class }^{\S}\end{array}$ & & & $\begin{array}{l}\text { Wound } \\
\text { class }\end{array}$ & & & & \\
\hline 1 & 0 & $2(2.2)$ & 1 & $3(3.4)$ & $3(3.3)$ & $\begin{array}{c}0.49,0.43- \\
0.57\end{array}$ & $\begin{array}{c}1.48,0.24- \\
9.09\end{array}$ \\
\hline 2 & 41 (46.6) & $36(40.4)$ & 2 & 43 (48.9) & 29 (31.9) & $\begin{array}{c}1.10,0.61- \\
1.98\end{array}$ & $\begin{array}{c}0.69,0.37- \\
1.27\end{array}$ \\
\hline 3 & $29(33.0)$ & $20(22.5)$ & 3 & $23(26.1)$ & $13(14.3)$ & $\begin{array}{c}0.72,0.38- \\
1.38\end{array}$ & $\begin{array}{c}0.58,0.27- \\
1.24\end{array}$ \\
\hline 4 & $17(19.3)$ & $29(32.6)$ & 4 & $51(58.0)$ & $42(46.2)$ & $\begin{array}{c}5.76,2.92- \\
11.34\end{array}$ & $\begin{array}{c}1.77,0.97- \\
3.25\end{array}$ \\
\hline $\begin{array}{l}\text { Previous } \\
\text { operation }^{+}\end{array}$ & 14 (15.9) & $14(15.7)$ & $\begin{array}{l}\text { Previous } \\
\text { operation }\end{array}$ & $11(12.5)$ & $21(23.1)$ & $\begin{array}{c}0.76,0.32- \\
1.77\end{array}$ & $\begin{array}{c}1.61,0.76- \\
3.40\end{array}$ \\
\hline $\begin{array}{l}\text { Emergent } \\
\text { procedure }\end{array}$ & $28(31.8)$ & 35 (39.3) & $\begin{array}{l}\text { Emergent } \\
\text { procedure }\end{array}$ & 33 (37.5) & 39 (42.9) & $\begin{array}{c}1.29,0.69- \\
2.40\end{array}$ & $\begin{array}{c}1.16,0.64- \\
2.10\end{array}$ \\
\hline
\end{tabular}

${ }^{ \pm}$Comparison of superficial and deep/organ space SSI between the Pre-test and Post-test.

${ }^{5}$ Wound class: 1 (clean), 2 (clean-contaminated), 3 (contaminated), 4 (dirty)

${ }^{+}$Previous operation within 30 days at the same surgical site

${ }^{\ddagger}$ Not elective 
What determines the (in-) efficacy of a surveillance system to reduce surgical site infections after gastrointestinal surgery?

\section{Discussion}

To evaluate the factors determining the effect of the VMS safety programme on the SSI rate after gastrointestinal surgery, we compared the incidence during the pre-test period with the incidence during the post-test period. We showed that for a reliable assessment of the SSI rate, surveillance, during and after hospitalisation, is crucial. Surveillance only during hospitalisation would result in an underestimation of SSI, as in our study the SSI rate that was diagnosed after discharge increased from $27.6 \%$ in the pre-test period to $35.8 \%$ in the post-test period. We further confirmed that older age and contaminated or dirty wounds were risk factors for developing an SSI. However, despite a trend of increasing mean overall compliance with the measures of the infection preventive bundle, no association was found with a significant decrease in SSIs. Similar observations were found by others monitoring their SSI rates [28-30]. Crolla et al. [31] implemented a comparable safety bundle and found higher compliance rates above $60 \%$ with a significant reduction of the SSI rates by $36 \%$. However, they used a zero-tolerance approach, a warning system for personnel who did not adhere to the prevention measures.

The safety bundle of the present study had been implemented from the second half of the pre-test period. The lowest compliance rate was observed with the number of door movements (39\%). Although discipline is considered important in terms of infection control, it is difficult to measure. Therefore, we decided to count the number of door movements as being representatives for discipline at the OR. The highest compliance rate was found with the shaving measures (87\%), but still not reached $90 \%$ as was the primary aim of the VMS programme. Our low overall compliance with the complete safety bundle can partly be explained by the complexity of the health care environment, the difficulty to change behaviour, and insufficient priority for infection prevention [24, 32].

The strengths of our study were the surveillance of SSI by a trained independent infection control nurse over the course of the study and the definitions of SSIs as well as the duration of the surveillance period that were defined according to the criteria of the CDC. According to the literature the assessment by an independent qualified person is the most reliable method for surveillance of SSI [33]. Correlation between the assessment by a surgical team involved in the operating procedure or the patients themselves and the infection control nurse were found to be low [33, 34]. 
What determines the (in-) efficacy of a surveillance system to reduce surgical site infections after gastrointestinal surgery?

For the postdischarge surveillance we assessed the surgical wounds during followup visits at the outpatient clinic. Using this "passive" PDS method the proportion of SSI diagnosed after discharge on the total percentage of SSI was $33.6 \%$. This percentage is higher than the $14 \%$ as described by Medina et al. [14]. Others who used active surveillance, which not only included the results of the patients' visits to the outpatient department, but also telephone calls to the patients and the general practitioners, found percentages of postdischarge SSI up to 46\% [13]. Surveillance after discharge will substantially contribute to the overall SSI rate, especially as there is an overall tendency to a decrease in hospitalisation periods resulting more often in diagnosis of an SSI after hospitalisation. However, some limitations of this study should be mentioned, that could explain the inefficacy of our surveillance system. The wound class of 114 procedures was unknown and therefore not included in the analysis. Another limitation was that some important risk factors were not included in the regression analysis, such as operative procedure, NNIS (National Nosocomial Infections Surveillance) risk index, duration of surgery and ASA-score. Instead, we used the older wound classification according to the $\mathrm{CDC}$, as it also predicts the risk of SSIs based on the bacterial load at the time of the operation. We acknowledge that for a good evaluation of a surveillance method, stratification using standard risk factors is crucial to be made. Regarding our SSI rate, we only calculated an overall incidence of SSI and did not differentiate between the different surgical gastrointestinal procedures. It is to be expected that the proportion of different procedures, with different risk factors, will influence the overall incidence. Furthermore, the number of patients between the pre- and post-test differed with $24 \%$. The lower number in the post-test period can be explained by the fact that in the post-test period patients were more intensively monitored in multidisciplinary meetings and therefore fewer patients needed to undergo an operation. Finally, the compliance with the bundle measures were based on a small number of OR observations, which might have influenced the reliability. However, it is not very likely that increasing the number of observations will result in a higher observed compliance rate. A more stringent approach (such as a zero-tolerance) is necessary to improve the compliance and to result in an improvement of patient safety.

Large variation, from $5 \%$ to $39 \%$, in the incidence of SSI has been reported $[19,35]$. Our overall SSI rate was $22.5 \%$. Narong et al. found an overall SSI rate of $5.8 \%$ [36]. However, the authors missed some infections, especially in patients who were discharged early and lost to follow-up. In the study by Suljagic et al., the SSI rates 
ranged from $0 \%$ to $14.3 \%$ [5]. Inter-study variation is further explained by different types of hospitals a study is based on, e.g., tertiary or local community hospitals [37], and definitions of surgical site infections that are used by researchers [38-40]. Some authors diagnosed an SSI only when the bacteriological culture of the wound was positive [41], whereas we used the CDC criteria [8].

There is also variation between studies in reported incidence of SSI within the different wound classes. The National Nosocomial Infection Surveillance (NNIS) system reported an incidence of $2.1 \%$ for clean wounds, $3.3 \%$ for cleancontaminated, $6.4 \%$ for contaminated and $7.1 \%$ for dirty wounds.8 Lichtenfels et al. showed incidences of $1.5-2.9 \%$ for clean wounds, $2.8-7.7 \%$ for clean and cleancontaminated, $6.4-15.2 \%$ for contaminated, and $7.1-40 \%$ for dirty wounds [42]. Similar figures were also described by others [5, 43, 44]. Likewise, we found a progressively higher incidence of SSI from clean to dirty wound procedures.

In conclusion, with this study we identified factors for the (in-) efficacy of a surveillance method, as it is difficult to predict an effect on SSI after gastrointestinal surgery in our academic hospital. We tried to point out that documentation of certain important factors is required and that compliance with safety measures is ensured to consume considerable resources that might be more effectively directed to other quality initiatives. Despite a slight increase of compliance with the measures of the VMS safety programme, the number of SSI did not show a reduction over time. Also, the too short period after implementation might have contributed to the lack of observed effect. Still, interventions to improve compliance with infection prevention guidelines should be enhanced, since other studies have shown a reduction of SSI rate after bundling interventions into a programme and thereby an improvement in the compliance of health care workers [31, 45, 46]. Most important is that resources and expenditures should be well adapted according to the setting. 
What determines the (in-) efficacy of a surveillance system to reduce surgical site infections after gastrointestinal surgery?

\section{References}

1. Geubbels EL, Nagelkerke NJ, Mintjes-De Groot AJ, Vandenbroucke-Grauls CM, Grobbee DE, De Boer AS. Reduced risk of surgical site infections through surveillance in a network. Int J Qual Health Care 2006; 18(2): 127-133.

2. Broex EC, van Asselt AD, Bruggeman CA, van Tiel FH. Surgical site infections: how high are the costs? J Hosp Infect 2009; 72(3): 193201.

3. Ortega G, Rhee DS, Papandria DJ, et al. An Evaluation of Surgical Site Infections by Wound Classification System Using the ACSNSQIP. J Surg Res 2012; 174(1): 33-38.

4. Meeks DW, Lally KP, Carrick MM, et al. Compliance with guidelines to prevent surgical site infections: As simple as 1-2-3? Am J Surg 2011; 201(1): 76-83.

5. Suljagic V, Jevtic M, Djordjevic B, Jovelic A. Surgical site infections in a tertiary health care center: prospective cohort study. Surg Today 2010; 40(8): 763-771.

6. Kirchhoff P, Clavien PA, Hahnloser D. Complications in colorectal surgery: risk factors and preventive strategies. Patient Saf Surg 2010; 4(1): 5.

7. Hubner M, Diana M, Zanetti G, Eisenring MC, Demartines N, Troillet N. Surgical Site Infections in Colon Surgery: The Patient, the Procedure, the Hospital, and the Surgeon. Arch Surg 2011; 146(11): 1240-1245.

8. Horan TC, Gaynes RP, Martone WJ, Jarvis WR, Emori TG. CDC definitions of nosocomial surgical site infections, 1992: a modification of CDC definitions of surgical wound infections. Infect Control Hosp Epidemiol 1992; 13(10): 606-608.

9. Tang $\mathrm{R}, \mathrm{Chen} \mathrm{HH}$, Wang $\mathrm{YL}$, et al. Risk factors for surgical site infection after elective resection of the colon and rectum: a single-center prospective study of 2, 809 consecutive patients.

10. Llanos Mendez A, Diaz Molina C, Fernandez-Crehuet Navajas R. [Surgical site infection in a tertiary hospital. A prospective surveillance study (2001-2004)]. Cir Esp 2010; 88(5): 319-327. 
11. Mangram AJ, Horan TC, Pearson ML, Silver LC, Jarvis WR. Guideline for Prevention of Surgical Site Infection, 1999. Centers for Disease Control and Prevention (CDC) Hospital Infection Control Practices Advisory Committee. Am J Infect Control 1999; 27(2): 97-132; quiz 133-134; discussion 196.

12. Weiss CA 3rd, Statz CL, Dahms RA, Remucal MJ, Dunn DL, Beilman GJ. Six years of surgical wound infection surveillance at a tertiary care center: review of the microbiologic and epidemiological aspects of 20, 007 wounds. Arch Surg 1999; 134(10): 1041-1048. http://dx.doi.org/10.1001/archsurg.134.10.1041

13. Delgado-Rodriguez M, Gomez-Ortega A, Sillero-Arenas M, Llorca J. Epidemiology of surgical-site infections diagnosed after hospital discharge: a prospective cohort study. Infect Control Hosp Epidemiol 2001; 22(1): 24-30.

14. Medina-Cuadros M, Sillero-Arenas M, Martinez-Gallego G, Delgado-Rodriguez M. Surgical wound infections diagnosed after discharge from hospital: epidemiologic differences with inhospital infections. Am J Infect Control 1996; 24(6): 421-428.

15. Mannien J, van der Zeeuw AE, Wille JC, van den Hof S. Validation of surgical site infection surveillance in the Netherlands. Infect Control Hosp Epidemiol 2007; 28(1): 36- 41.

16. Martone WJ, Nichols RL. Recognition, prevention, surveillance, and management of surgical site infections: introduction to the problem and symposium overview. Clin Infect Dis 2001; 33 Suppl 2: S67-68.

17. Haley RW, Culver DH, White JW, Morgan WM, Emori TG, Munn VP, Hooton TM. The efficacy of infection surveillance and control programs in preventing nosocomial infections in US hospitals. Am J Epidemiol 1985; 121(2): 182-205.

18. Delgado-Rodriguez $M$, Gomez-Ortega $A$, Sillero-Arenas $M$, Martinez-Gallego G, Medina-Cuadros M, Llorca J. Efficacy of surveillance in nosocomial infection control in a surgical service. Am J Infect Control 2001; 29(5): 289-294.

19. O'Neill E, Humphreys $H$. Use of surveillance data for prevention of health care-associated infection: risk adjustment and reporting dilemmas. Curr Opin Infect Dis 2009; 22(4): 359-363. 
20. Veiligheids Management Systeem (VMS). Voorkomen van wondinfecties na een operatie. Utrecht: VMS; 2009.

21. Wilson AP. Postoperative surveillance, registration and classification of wound infection in cardiac surgery-experiences from Great Britain. APMIS : acta pathologica, microbiologica, et immunologica Scandinavica 2007; 115(9): 996-1000.

22. PREventie ZIEkenhuisinfecties door Surveillance. Bilthoven: PREZIES; 2012.

23. Geubbels EL, Mintjes-de Groot AJ, van den Berg JM, de Boer AS. An operating surveillance system of surgical-site infections in The Netherlands: results of the PREZIES national surveillance network. Preventie van Ziekenhuisinfecties door Surveillance. Infect Control Hosp Epidemiol 2000; 21(5): 311-318.

24. Wille J, Kluytmans J, Vos G, van den Broek PJ. Interventiebundel wondinfecties hoopgevend, maar te weinig nageleefd. Infectiepreventie vergt meer inzet. Medisch Contact 76 nr. 38: 2103-2105. 2012

25. American Institute for Health care Improvement. PDSA-cycle. 2012.

26. Prins JM, Kullberg BJ, Gyssens IC. National guidelines for the use of antibiotics in hospitalised adult patients: the SWAB guidelines revisited. Neth J Med 2005; 63(8): 288-290.

27. VMS veiligheidsprogramma, Utrecht. Voorkomen van wondinfecties na een operatie; 2009.

28. Anthony T, Murray BW, Sum-Ping JT, et al. Evaluating an evidence-based bundle for preventing surgical site infection: a randomized trial. Arch Surg 2011; 146(3): 263-269.

29. Pastor C, Artinyan A, Varma MG, Kim E, Gibbs L, Garcia-Aguilar J. An increase in compliance with the Surgical Care Improvement Project measures does not prevent surgical site infection in colorectal surgery. Dis Colon Rectum 2010; 53(1): 24-30.

30. Poulsen KB, Jepsen OB. Failure to detect a general reduction of surgical wound infections in Danish hospitals. Dan Med Bull 1995; 42(5): 485-488. 
31. Crolla RM, van der Laan L, Veen EJ, Hendriks Y, van Schendel C, Kluytmans J. Reduction of surgical site infections after implementation of a bundle of care. PLoS One 2012; 7(9): e44599.

32. Pincock T, Bernstein P, Warthman S, Holst E. Bundling hand hygiene interventions and measurement to decrease health careassociated infections. Am J Infect Control 2012; 40(4 Suppl 1): S18-27.

33. Petherick ES, Dalton JE, Moore PJ, Cullum N. Methods for identifying surgical wound infection after discharge from hospital: a systematic review. BMC Infect Dis 2006; 6: 170.

34. Whitby M, Mclaws ML, Collopy B, et al. Post-discharge surveillance: can patients reliably diagnose surgical wound infections? J Hosp Infect 2002; 52(3): 155-160.

35. Mannien J, van den Hof S, Muilwijk J, van den Broek PJ, van Benthem B, Wille JC. Trends in the incidence of surgical site infection in the Netherlands. Infect Control Hosp Epidemiol 2008; 29(12): 1132-1138.

36. Narong MN, Thongpiyapoom S, Thaikul N, Jamulitrat S, Kasatpibal $N$. Surgical site infections in patients undergoing major operations in a university hospital: using standardized infection ratio as a benchmarking tool. Am J Infect Control 2003; 31(5): 274-279.

37. Heisler CA, Melton LJ, 3rd, Weaver AL, Gebhart JB. Complication rates between local and referral patients undergoing vaginal hysterectomy at an academic medical center. Mayo Clin Proc 2010; 85(2): 145-149.

38. Bruce J, Russell EM, Mollison J, Krukowski ZH. The measurement and monitoring of surgical adverse events. Health Technol Assess 2001;5(22): 1-194.

39. Turtiainen J, Saimanen E, Partio T, et al. Surgical wound infections after vascular surgery: prospective multicenter observational study. Scand J Surg 2010; 99(3): 167-172.

40. Gastmeier P. European perspective on surveillance. J Hosp Infect 2007; 65 Suppl 2: 159-164.

41. Rasnake MS, Dooley DP. Culture-negative surgical site infections. Surg Infect (Larchmt) 2006; 7(6): 555-565. http:// dx.doi.org/10.1089/sur.2006.7.555 
42. Lichtenfels EM, Marcio LL, Webster R, d'Azevedo PA. Antimicrobial Prophylaxis in peripheral vascular surgery: is cephalosporin still the gold standard? Journal Vascular Brasileiro 2007; 6(4): 378-387.

43. Culver DH, Horan TC, Gaynes RP, et al. Surgical wound infection rates by wound class, operative procedure, and patient risk index. National Nosocomial Infections Surveillance System. Am J Med 1991; 91(3B): 152S-157S.

44. Cruse PJ, Foord R. The epidemiology of wound infection. A 10year prospective study of 62, 939 wounds. Surg Clin North Am 1980; 60(1): 27-40.

45. Chaberny IF, Graf K. [Strategies to prevent surgical site infections]. Unfallchirurg 2011; 114(3): 236-240.

46. Bull A, Wilson J, Worth LJ, et al. A bundle of care to reduce colorectal surgical infections: an Australian experience. J Hosp Infect 2011; 78(4): 297-301. 


\title{
Chapter 3
}

\section{Microbiology of surgical site infections after}

\section{gastrointestinal surgery in the south}

\author{
region of the Netherlands
}

Ramcharan A, den Heijer C, Smeets E, Rouflart M, van Tiel F, Bruggeman C, Breukink S, Tordoir J, Baeten C, Stobberingh E

Future Microbiol, 9(3), 291-298 (2014) 


\section{Abstract}

Aims: To give an overview of the microbiology of blood and wound samples from surgical site infections (SSIs) after gastrointestinal surgery, as well as the antimicrobial susceptibility of the microorganisms involved, and to discuss the appropriateness of the prophylactic antibiotics administered.

Materials \& methods: During a 3.5-year study period, wound swabs and blood samples of patients with an SSI were taken in the first 48 hours after surgery until 30 days thereafter.

Results: Most pathogens were isolated from wound swabs. Escherichia coli (25\%) and Pseudomonas aeruginosa (10\%) were the most frequently found microorganisms. Both microorganisms showed a slight tendency towards a decrease in susceptibility for the tested antibiotics, although after correction, this was not significant.

Conclusion: The comparison between wound swabs taken in the first 48 hours after a surgical procedure and swabs in the 30 days thereafter provides important information concerning the microbiology of SSIs and the development of antibiotic resistance of the causative agents over time. 


\section{Introduction}

Hospital-acquired infections, also called nosocomial infections, are a frequent problem in health care facilities worldwide and contribute to longer hospital stays, prolonged periods of antimicrobial therapy, higher health care costs, higher morbidity and even mortality [1, 2]. Surgical site infections (SSIs) are one of the most frequently occurring nosocomial infections after gastrointestinal surgery, next to urinary tract, lower respiratory tract and bloodstream infections [3, 4]. Dutch hospitals aim to improve the quality of health care and patient safety by monitoring several infection control indicators and reporting incidence rates of SSI [5].

Various risk factors increase the chance of acquiring a SSI; for example, the patients' comorbidities, duration of the surgical procedure and the bacterial burden $[6,7]$. Most SSIs are caused by the commensal microbiota of the patient and/or facultative anaerobic Gram-negative and Gram-positive bacteria (e.g., Escherichia coli and Staphylococcus aureus, respectively) [8-11]. Since a prolonged period of antimicrobial therapy will contribute to a higher prevalence of resistance [12], optimal antibiotic choice for prophylaxis, as well as empiric therapy, need to be based on the antibiotic susceptibility pattern of the microorganisms isolated from SSIs [13]. Apart from antimicrobial therapy, SSIs can be treated successfully by opening the wound and performing dressing changes.

In this study, we analyse the microbiological results of the wounds after gastrointestinal surgery (i.e., the microorganisms isolated from wound swabs and blood samples), as well as discussing antimicrobial susceptibility and the appropriateness of the prophylactic antibiotic choice.

\section{Materials \& methods}

The study was performed from July 2008 until December 2011 in a 715-bed tertiary care hospital in the south of The Netherlands. Patients older than 18 years of age undergoing gastrointestinal surgery were included for analysis. Patients admitted with abdominal infections were excluded. The clinical data was registered by the same independent qualified infection control nurse over the course of the study. The microbiological results were retrospectively retrieved from the laboratory records at the Microbiology Department of the hospital. 


\section{Surgical site infection}

An infection was considered a SSI when it occurred within thirty days after the operative procedure and no implant was left in place. All SSIs were diagnosed according to the criteria of the CDC [3]. Only index operations were included for this analysis and were defined as the first surgical intervention for a certain gastrointestinal illness in our hospital. An infection was considered as a SSI linked to the index operation unless a surgical intervention in another hospital had been performed at the same surgical site within thirty days before the index operation.

An index operation was divided into two types, elective or emergency. Elective operations were scheduled in advance with good preparation. Emergency operations were performed without delay and under acute circumstances. All wounds were classified into four wound classes depending on the type of index operation: clean wounds (non-traumatic wounds without inflammation), cleancontaminated (wound opened for drainage or reopened for other surgical reasons), contaminated (a foreign body passing through a wound) and dirty wounds (wounds exposed to faecal matter or pus) [3].

Antimicrobial therapy was prescribed according to the hospital-specific guidelines of the Dutch Working Party on Antibiotic Policy (Stichting Werkgroep AntibioticaBeleid) [14]. For the prophylaxis, either $1500 \mathrm{mg}$ cefuroxime or cefazolin $1000 \mathrm{mg}$ with $500 \mathrm{mg}$ metronidazole intravenously was used for patients who underwent colorectal surgery, administered 30-60 min before surgery. For the empiric therapy, broad-spectrum penicillin, such as piperacillin in combination with tazobactam, was used, and in the case of severe infections, an aminoglycoside antibiotic, such as gentamicin, was added for 1-3 days. Based on culture results, the empiric therapy was adapted accordingly if necessary. Patients who underwent clean laparotomies did not receive antimicrobial treatments.

SSIs were divided into superficial (involving the skin and subcutaneous tissue), deep (involving deeper tissues of the muscle) and organ/space infections (involving organs or body spaces, outside the incision, that had been opened or manipulated during the surgery) [3].

\section{Microbiological analysis}

The inclusion criteria for the microbiological analysis were a diagnosis of SSI, a registered wound class and a wound or blood sample. Since surgical wound dressing protects primary closure incisions with sterile dressing within 48 hours 
postoperatively, the wound swabs and blood samples were processed according to standard microbiological methods [15] in the first 48 hours after surgery and during the thirty days thereafter. A period of $48 \mathrm{~h}$ was chosen to differentiate between community- $(<48 \mathrm{~h})$ and hospital-acquired infections ( $>48 \mathrm{~h})$. The swabs were either taken during surgery at the operation theatre, before the wound was closed or, in the case of an SSI during hospitalisation, at the ward.

Breakpoints for antibiotic susceptibility were determined according to the guidelines of the European Committee on Antimicrobial Susceptibility Testing [16]. Intermediate-resistant microorganisms were considered resistant.

In the first 48 hours after surgery, we were interested in the distribution of the microorganisms between the wound classes. In the thirty days thereafter, the main focus was on the differences between the microbiological results from wound swabs and blood samples.

Results of the antibiotic susceptibility were analysed for the most frequently isolated microorganisms from wound swabs only. The prevalence of resistance to a certain antibiotic was defined as the number of antibiotic-resistant isolates divided by the total number of isolates of that species isolated from wound swabs and multiplied by $100 \%$. To analyse the change in prevalence of resistance, we studied the microbial flora of the wound swabs taken in the first 48 hours after the operation and compared it with the microbial flora of wound swabs taken thirty days thereafter. Cultures were polymicrobial if more than one infectious agent was detected.

\section{Statistical methods}

Statistical analysis of the SSI rate, the proportion of emergency procedures and the proportion of isolated microorganisms between the wound classes were performed using binary logistic regression. The tendency in susceptibility of $E$. coli to amoxicillin/clavulanic acid, amoxicillin, cefuroxime, ciprofloxacin, gentamicin, piperacillin, piperacillin/tazobactam and cefazolin, isolated from the SSIs within the first 48 hours after surgery and those isolated after thirty days, was tested by univariable logistic regression. The same was performed for the susceptibility of Pseudomonas aeruginosa to ceftazidime, ciprofloxacin, gentamicin, piperacillin and piperacillin/tazobactam.

The multiple comparisons to test the susceptibility patterns of the most frequently isolated microorganisms were corrected by the false discovery rate control method. Statistical analyses were executed with SPSS software (PASW Statistics 18, 
SPSS Inc., IL, USA). All tests were two-tailed and statistical significance was defined as a $p$-value $<0.05$.

\section{Results}

During the 3.5-year study period, the surgical department of our hospital performed 2546 gastrointestinal surgical procedures, including 390 re-operations within thirty days. The re-operations were excluded for the analysis. The actual inhospital SSI rate was 356 out of 2156 surgical procedures (16.5\%). The wound class was unknown for 114 procedures (5.3\%), including 11 SSIs, and were therefore not included for further analysis. The remaining 2042 surgical procedures were classified into 254 clean (12\%), 857 clean-contaminated (42\%), 518 contaminated (25\%) and 413 dirty (20\%) procedures. The SSI rate was the highest in the cleancontaminated and the dirty procedures. Procedures classified as cleancontaminated included significantly fewer emergency ones compared with the clean procedures (odds ratio [OR]: $0.57 ; 95 \% \mathrm{Cl}$ : 0.43-0.76). Dirty procedures included more emergency ones (OR: 2.99; 95\% Cl: 2.16-4.13) (Table I).

The 345 SSIs of the 2042 procedures were classified into 171 superficial (49.6\%), 155 deep (44.9\%) and 19 organ/space (5.5\%) SSIs. For 141 out of 345 SSI cases (40.9\%), the surgical procedures were acute, and a similar proportion of procedures not resulting in a SSI was acute (41.9\%; 711 out of 1697).

From 264 of the 345 SSIs (77\%), wound swabs or blood samples were taken within the follow-up period of thirty days after surgery. A positive result of wound or blood during the follow-up period was found in 209 out of 264 SSIs (79\%). For the other 81 SSIs (23\%; mostly clean-contaminated or contaminated), other samples were taken (e.g., urine sample, drain tip or tissue of the incision) and therefore not included for the analysis. 


\begin{tabular}{|c|c|c|c|c|}
\hline & $\begin{array}{l}\text { Clean } \\
(n=254)\end{array}$ & $\begin{array}{l}\text { Clean- } \\
\text { contaminated } \\
(n=857)\end{array}$ & $\begin{array}{l}\text { Contaminated } \\
(n=518)\end{array}$ & $\begin{array}{l}\text { Dirty } \\
(n=413)\end{array}$ \\
\hline \multicolumn{5}{|l|}{ SSI } \\
\hline Yes & $8(3.1 \%)$ & $149(17.4 \%)$ & 85 (16.4\%) & 103 (24.9\%) \\
\hline OR $95 \% \mathrm{Cl}^{ \pm}$ & $\begin{array}{l}1.0 \\
\text { (reference) }\end{array}$ & $6.47(3.13-13.37)^{*}$ & $\begin{array}{l}6.04 \\
12.67)^{*}\end{array}$ & $\begin{array}{l}10.22 \\
21.38)^{*}\end{array}$ \\
\hline \multicolumn{5}{|l|}{ Surgical procedure } \\
\hline Acute/emergency & 105 & 275 (32.1\%) & 222 (42.9\%) & $280(67.8 \%)$ \\
\hline OR $95 \% \mathrm{Cl}$ & $\begin{array}{l}(41.3 \%) \\
1.0 \\
\text { (reference) }\end{array}$ & $0.57(0.43-0.76)^{*}$ & $\begin{array}{l}1.06 \quad(0.88- \\
1.44)\end{array}$ & $\begin{array}{l}2.99 \\
4.13)^{*}\end{array}$ \\
\hline
\end{tabular}

\footnotetext{
${ }^{ \pm}$Binary logistic regression with clean wound class as reference group =significant at $p \leq 0.05$

OR=Odds Ratio; $\mathrm{Cl}=$ Confidence Interval
}

Blood samples \& wound swabs in the first 48 hours after surgery

The microbiological analysis from the 264 SSIs included 96 blood samples and 168 wound swabs within the first 48 hours after surgery. Of the blood samples, 15 (15.6\%) were positive from patients with different types of wounds (one clean, eight clean-contaminated, three contaminated and three dirty) and yielded 16 isolates (i.e., E. coli $(n=4)$, Bacteroides fragilis $(n=2)$ and one of each of the following species: Candida species, Enterococcus faecium, Klebsiella oxytoca, Proteus mirabilis, P. aeruginosa, Enterobacter species, Klebsiella pneumoniae, Morganella morganni, coagulase-negative staphylococci and Staphylococcus aureus).

Of the 168 wound swabs, 118 (70\%) were positive from different types of wounds (three clean wounds, 43 clean-contaminated, 25 contaminated and 47 dirty wounds). The positive wound swabs yielded 212 isolates. The microorganisms most frequently found, irrespective of the wound class, were $E$. coli ( $n=52 ; 25 \%), B$. fragilis $(n=27 ; 13 \%), P$. aeruginosa $(n=22 ; 10 \%)$ and Enterobacter species $(n=18$; $9 \%)$, followed by a lower frequency of $E$. faecalis ( $n=14 ; 7 \%)$, Streptococcus species ( $n=14 ; 7 \%$ ) and $S$. aureus $(n=11 ; 5 \%$ ). The frequency of the isolated microorganisms did not significantly differ between the wound classes, except for 
Enterobacter species with a significantly lower number in dirty wounds compared with clean-contaminated wounds (OR: 0.29; 95\% Cl: 0.09-0.87) (Table II).

\begin{tabular}{|c|c|c|c|c|c|c|}
\hline 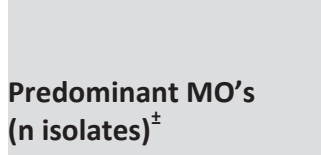 & $\begin{array}{l}\text { Wound class } \\
\text { Clean-Contaminated } \\
\qquad(n=67)\end{array}$ & Rank & $\begin{array}{l}\text { Contaminated } \\
\qquad(n=43)\end{array}$ & Rank & $\begin{array}{l}\text { Dirty } \\
(n=94)\end{array}$ & Rank \\
\hline $\begin{array}{l}\text { E. coli }(\mathrm{n}=52) \\
\text { OR; } 95 \% \mathrm{Cl}^{\S} \\
p \text {-value }\end{array}$ & $\begin{array}{c}15 / 67(22 \%) \\
1.0 \text { (reference) }\end{array}$ & 1 & $\begin{array}{c}10 / 43(23 \%) \\
1.05 ; 0.42-2.61 \\
0.916\end{array}$ & 1 & $\begin{array}{c}24 / 94(25 \%) \\
1.19 ; 0.57-2.49 \\
0.646\end{array}$ & 1 \\
\hline $\begin{array}{l}\text { B. fragilis }(\mathrm{n}=27) \\
\text { OR; } 95 \% \mathrm{Cl} \\
p \text {-value }\end{array}$ & $\begin{array}{c}8 / 67(12 \%) \\
1.0 \text { (reference) }\end{array}$ & 3 & $\begin{array}{c}7 / 43(16 \%) \\
1.43 ; 0.48-4.29 \\
0.519\end{array}$ & 2 & $\begin{array}{c}11 / 94(12 \%) \\
0.98 ; 0.37-2.58 \\
0.963\end{array}$ & 2 \\
\hline $\begin{array}{l}\text { Enterobacter sp. }(\mathrm{n}=18) \\
\text { OR; } 95 \% \mathrm{Cl} \\
p \text {-value }\end{array}$ & $\begin{array}{c}11 / 67(16 \%) \\
1.0 \text { (reference) }\end{array}$ & 2 & $\begin{array}{c}2 / 43(5 \%) \\
0.25 ; 0.05-1.18 \\
0.080\end{array}$ & 3 & $\begin{array}{c}5 / 94(5 \%) \\
0.29 ; 0.09-0.87^{*} \\
0.027\end{array}$ & 4 \\
\hline $\begin{array}{l}P \text {. aeruginosa }(\mathrm{n}=22) \\
\text { OR; } 95 \% \mathrm{Cl} \\
p \text {-value }\end{array}$ & $\begin{array}{c}7 / 67(10 \%) \\
1.0 \text { (reference) }\end{array}$ & 4 & $\begin{array}{c}7 / 43(16 \%) \\
1.67 ; 0.54-5.14 \\
0.374\end{array}$ & 2 & $\begin{array}{c}8 / 94(9 \%) \\
0.80 ; 0.27-2.32 \\
0.677\end{array}$ & 3 \\
\hline
\end{tabular}

The number of isolates in clean wounds was too low $(n=8)$

and therefore not included in the table

* =significant at $p \leq 0.05$

${ }^{ \pm}$MOs with $<15$ isolates were not included in the table

(E. faecalis ( $n=14)$, E. faecium ( $n=8)$, Streptococcus sp. $(n=14), K$. pneumoniae $(n=7)$, S. aureus $(n=11))$

${ }^{\delta}$ Binary logistic regression with clean-contaminated wound class as reference group

Abbreviations: OR, odds ratio; 95\%Cl, 95\% Confidence Interval; $\mathrm{MO}$, microorganism

Enterobacteriaceae susceptibility pattern in the first 48 hours after surgery

The susceptibility patterns of all Enterobacteriaceae isolated from the wound swabs taken in the first 48 hours after the surgical procedure ranged from $96 \%$ for gentamicin and $94 \%$ for ciprofloxacin to $30 \%$ for amoxicillin. The susceptibility for the agents commonly used in the prophylaxis (i.e., first- and second-generation cephalosporins), cefazolin, cefuroxime and amoxicillin/clavulanic acid, was 74, 67 and $57 \%$, respectively (Table III). 


\section{Table III: Resistant Enterobacteriaceae isolates in wound swabs in the first $48 \mathrm{~h}$ after surgery}

\begin{tabular}{llllll} 
& \multicolumn{2}{l}{ Wound class } & & \\
Antibiotic & $\begin{array}{l}\text { Clean } \\
(\mathbf{n}=\mathbf{4})\end{array}$ & $\begin{array}{l}\text { Clean- } \\
\text { contaminated } \\
(\mathbf{n = 3 3 )}\end{array}$ & $\begin{array}{l}\text { Contaminated } \\
(\mathbf{n}=\mathbf{1 6})\end{array}$ & $\begin{array}{l}\text { Dirty } \\
(\mathbf{n}=\mathbf{3 7})\end{array}$ & Resistance (\%) \\
\hline Amoxicillin & $2 / 4$ & $27 / 33$ & $12 / 16$ & $22 / 37$ & $63 / 90(70 \%)$ \\
Amoxicillin/clavulanic & $2 / 4$ & $19 / 33$ & $10 / 16$ & $8 / 37$ & $39 / 90(43 \%)$ \\
Piperacillin & $1 / 4$ & $13 / 33$ & $6 / 16$ & $12 / 37$ & $32 / 90(35 \%)$ \\
Piperacillin/tazobactam & $0 / 4$ & $6 / 33$ & $2 / 16$ & $1 / 37$ & $9 / 90(10 \%)$ \\
Tobramicin & $0 / 4$ & $2 / 33$ & $1 / 16$ & $0 / 37$ & $3 / 90(3 \%)$ \\
Gentamicin & $1 / 4$ & $1 / 33$ & $1 / 16$ & $1 / 37$ & $4 / 90(4 \%)$ \\
Ciprofloxacin & $1 / 4$ & $0 / 33$ & $1 / 16$ & $3 / 37$ & $5 / 90(6 \%)$ \\
Co-trimoxazole & $2 / 4$ & $5 / 33$ & $2 / 16$ & $9 / 37$ & $18 / 90(20 \%)$ \\
Cefazolin & $2 / 4$ & $11 / 33$ & $5 / 16$ & $5 / 37$ & $23 / 90(26 \%)$ \\
Cefuroxime & $1 / 4$ & $13 / 33$ & $7 / 16$ & $9 / 37$ & $30 / 90(33 \%)$ \\
Ceftriaxon & $1 / 4$ & $6 / 33$ & $1 / 16$ & $0 / 37$ & $8 / 90(9 \%)$ \\
Ceftazidime & $1 / 4$ & $5 / 33$ & $1 / 16$ & $0 / 37$ & $7 / 90(8 \%)$
\end{tabular}

Blood samples \& wound swabs from 48 hours after surgery until 30 days thereafter Of the 264 SSIs, 117 SSIs (66\%) were cultured more than once and resulted in a total of 1337 wound and blood isolates during the 30-day follow-up period. Of these isolates, 531 (39.7\%) were culture-negative. In 117 SSIs (44\%), the infection was polymicrobial.

Both blood samples and wound swabs were taken from 116 of the 264 SSIs (44\%); from 26 of these SSIs (22\%), both wound swabs and blood samples yielded a positive result, of which in almost all cases $(n=25)$ different microorganisms were found in the blood samples and the wound swabs. In one case, two wound swabs and two blood samples were taken and showed twice a positive sample with E. coli and twice a negative sample. In 56 out of the 116 SSIs (48\%), E. coli was found in the wound swab, of which from seven SSIs (12.5\%) this microorganism was also found in the blood sample. Furthermore, in 72 out of 116 SSIs (62\%), the blood samples were negative whereas the wound swabs yielded a positive result, mostly with E. coli, B. fragilis, P. aeruginosa, E. faecium and Streptococcus species. In four out of the 116 SSIs (3\%), the blood samples yielded E. coli, Candida species or coagulase-negative staphylococci, whereas the wound swabs showed no growth. 
Trend in antibiotic susceptibility of E. coli \& P. aeruginosa

The antibiotic susceptibilities during the follow-up period of the most frequently found microorganisms from wound swabs, E. coli and $P$. aeruginosa, are depicted in Tables IV \& V. After correction for comparisons, E. coli $(n=209)$ slightly decreased in susceptibility during the study period for most antibiotics tested, although the decrease was not significant. Gentamicin susceptibility fluctuated at approximately 95\% and ciprofloxacin at approximately 90\%. After correction, a decrease in susceptibility of $P$. aeruginosa $(n=68)$ over time was observed for all antibiotics tested; nevertheless, no significant results were found.

\begin{tabular}{lllll}
\multicolumn{2}{l}{ Table IV: Antibiotic susceptibility of Escherichia coli } & & & \\
& First isolate $^{ \pm}$(N=52) & Other isolates $^{\dagger}$ (N=157) & $\boldsymbol{p}$-value & $\boldsymbol{Q}_{\text {-value }}^{\S}$ \\
\hline Amoxicillin/cluvalanic acid & $37(71 \%)$ & $105(67 \%)$ & 0.567 & 0.851 \\
Amoxicillin & $23(44 \%)$ & $51(32 \%)$ & 0.125 & 0.375 \\
Cefuroxime & $44(85 \%)$ & $134(85 \%)$ & 0.897 & 0.897 \\
Ciprofloxacin & $47(90 \%)$ & $144(92 \%)$ & 0.766 & 0.862 \\
Gentamicin & $49(94 \%)$ & $146(93 \%)$ & 0.757 & 0.973 \\
Piperacillin & $32(62 \%)$ & $64(41 \%)$ & $0.009^{*}$ & 0.081 \\
Piperacillin/Tazobactam & $48(92 \%)$ & $129(82 \%)$ & 0.078 & 0.351 \\
Co-trimoxazol & $41(79 \%)$ & $109(69 \%)$ & 0.191 & 0.344 \\
Cefazolin & $46(88 \%)$ & $124(79 \%)$ & 0.128 & 0.288
\end{tabular}

"Significant at $p \leq 0.05$

${ }^{ \pm}$Wound swabs cultured in the first 48 hours after the surgical procedure

${ }^{+}$Wound swabs cultured after the first 48 hours after the surgical procedure until 30 days thereafter

${ }^{s}$ False Discovery Rate correction for multiple comparisons (significant at $p \leq 0.05$ )

\section{Table V: Antibiotic susceptibility of Pseudomonas aeruginosa}

$\begin{array}{lllll} & \text { First isolate }(\mathbf{N}=22)^{ \pm} & \text {Other isolates }(\mathbf{N}=46)^{+} & p \text {-value } & Q_{\text {-value }} \\ \text { Ceftazidime } & 21(95 \%) & 40(87 \%) & 0.281 & 0.562 \\ \text { Ciprofloxacin } & 22(100 \%) & 44(96 \%) & 0.716 & 0.716 \\ \text { Gentamicin } & 22(100 \%) & 43(93 \%) & 0.512 & 0.683 \\ \text { Piperacillin } & 22(100 \%) & 41(89 \%) & 0.261 & 1.044 \\ \text { Piperacillin/Tazobactam } & 22(100 \%) & 41(89 \%) & 0.261 & 1.044\end{array}$

\footnotetext{
${ }^{ \pm}$Wound swabs cultured in the first 48 hours after the surgical procedure

${ }^{+}$Wound swabs cultured after the first 48 hours after the surgical procedure until 30 days thereafter

${ }^{\S}$ False Discovery Rate correction for multiple comparisons (significant at $p \leq 0.05$ )
} 


\section{Discussion}

For this study, we determined the prevalence of the microorganisms isolated from SSIs after gastrointestinal surgery in relation to the wound classification of the surgical procedures (i.e., clean, clean-contaminated, contaminated and dirty). In addition, we assessed the antibiotic susceptibility during a follow-up period of thirty days for the most frequently isolated microorganisms from wound swabs (i.e., Escherichia coli and Pseudomonas aeruginosa). The antibiotic susceptibility showed a decreasing tendency over time, although not significant. In all wound categories, E. coli was the most frequently isolated microorganism, followed by Bacteroides fragilis after contaminated and dirty classified procedures and Enterobacter species after clean-contaminated procedures. The distribution of the different species did not differ between the wound classes, except for the significantly higher number of Enterobacter species found in clean-contaminated wounds compared with dirty wounds. Polymicrobial results were mainly observed in SSIs after contaminated procedures.

Our most frequently isolated microorganisms are in accordance to the literature $[10,17-18]$. Our low number of Staphylococcus aureus can be explained by the distribution of the wound types (i.e., a low number of clean wounds [12\%]) in which the most common pathogen is $S$. aureus, and the highest number of cleancontaminated wounds (42\%) in which E. coli is the most prevalent [10].

The strength of the study is that all microbiological analysis was performed in one laboratory, in contrast to others who performed the antimicrobial susceptibility testing by laboratories collaborating with the hospital, not by a central laboratory [17]. Our data were therefore not biased by differences in methodology. Moreover, data regarding the presence of SSIs were registered by the same independent qualified infection control nurse over the course of the study. In addition, in contrast to others, we investigated the wound cultures taken in the first 48 hours at the operation theatre (before the wound was closed) and compared the results with the wound cultures taken after thirty days. This allowed us to detect the decreasing tendency in antibiotic susceptibility during hospitalisation, which might be due to the use of agents for therapy if indicated (e.g., in case of spill).

Some limitations should be mentioned. In 81 cases of SSI (23\%), no wound swabs or blood samples were taken and therefore not included in the bacteriological analysis. These SSIs included mostly clean-contaminated and contaminated wounds. Furthermore, we had no information regarding the antimicrobial therapy 
the patients received (apart from the antimicrobial prophylaxis) for the treatment of infections during hospitalisation or after discharge. Moreover, we were unable to classify the wounds according to the National Nosocomial Infections Surveillance patient risk index, because it was not registered and therefore unknown. Instead, we used the older wound classification according to the $C D C$, as that also predicts the risk of SSIs. Finally, due to the low number of $P$. aeruginosa isolates, we were not able to detect a difference in the antibiotic susceptibility of this pathogen.

In $62 \%$ of the cases, the blood samples were negative whereas the wound swabs yielded a positive result, and in $3 \%$ of the cases, this was the other way around (positive blood sample and negative wound swab). These results are in accordance with the recommendations of the Expert Panel of the Surgical Infection Society and the Infectious Diseases Society of America to refrain from taking blood samples in case of a putative SSI [19].

In gastrointestinal surgery, short course antimicrobial prophylaxis is generally accepted as an effective mean to reduce the incidence of SSI [20]. The choice of the agent should be based on the microorganisms associated with the procedures performed. In our hospital, cefuroxime or cefazolin is used as a prophylactic agent and, depending on the type of surgery, in combination with metronidazole. As the antibiotic susceptibility percentages of the Gram-negative isolates of the first swabs in the first 48 hours could be used as a proxy for an effective prophylactic choice, cefazolin showed, in comparison with the other potential prophylactic agents amoxicillin/clavulanic acid and cefuroxime, the highest susceptibility of $74 \%$. The safety of cefazolin and its favourable pharmacokinetic parameters makes this agent an appropriate prophylaxis agent [21-23]. Amoxicillin alone and in combination with clavulanic acid is widely used in our hospital, since they are active against Gram-positive and a limited range of Gram-negative organisms. Owing to the prolonged use of these antimicrobial drugs in our hospital, the resistance rate to both agents is relatively high. Some compounds, such as piperacillin/tazobactam, are given for therapy only if indicated; however, they are not generally recommended for antimicrobial prophylaxis. We do not have a clear explanation for the decrease in susceptibility to these agents. The increase in resistance to piperacillin/tazobactam might be explained by the choice of this drug in our hospital, among other reasons. The high susceptibility of $E$. coli to ciprofloxacin and gentamicin was similar to Kusachi et al. who found that all E. coli isolates in their study were susceptible to ciprofloxacin [24]. The 26-33\% resistance to potential prophylactic agents is mainly due to the presence of Enterobacter species and $P$. 
aeruginosa in the first wound swabs of the SSIs after clean-contaminated and dirty procedures.

\section{Conclusion}

To conclude, this study gives an overview of the causative pathogens of SSIs and their susceptibility patterns after gastrointestinal surgery. This information is important to guide clinicians to make an optimal empiric antimicrobial choice and it also reflects putative changes in types of pathogens isolated in SSIs.

\section{Future perspective}

The aim of this study was to examine the most common causative agents from wound swabs and blood samples of SSIs, and to guide the choice of empiric antimicrobial treatment appropriately in the case of a SSI after gastrointestinal surgery. Since the incorrect use of antibiotics will contribute to increase resistance, all efforts to optimize correct choice of empiric therapy are warranted. 


\section{References}

1. Dohmen PM. Antibiotic resistance in common pathogens reinforces the need to minimise surgical site infections. J. Hosp. Infect. 70(Suppl. 2), 1520 (2008).

2. Krein SL, Kowalski CP, Hofer TP, Saint S. Preventing hospital-acquired infections: a national survey of practices reported by US hospitals in 2005 and 2009. J. Gen. Intern. Med. 27(7), 773-779 (2012).

3. Horan TC, Gaynes RP, Martone WJ, Jarvis WR, Emori TG. CDC definitions of nosocomial surgical site infections, 1992: a modification of CDC definitions of surgical wound infections. Infect. Control Hosp. Epidemiol. 13(10), 606608 (1992).

4. Struthers KJ, Westran RP. Clinical Bacteriology. Manson Publishing Ltd, London, UK (2003).

5. Geubbels EL, Mintjes-de Groot AJ, van den Berg JM, de Boer AS. An operating surveillance system of surgical-site infections in The Netherlands: results of the PREZIES national surveillance network. Preventie van Ziekenhuisinfecties door Surveillance. Infect. Control Hosp. Epidemiol. 21(5), 311-318 (2000).

6. Harrop JS, Styliaras JC, Ooi YC, Radcliff KE, Vaccaro AR, Wu C. Contributing factors to surgical site infections. J. Am. Acad. Orthop. Surg. 20(2), 94-101 (2012).

7. Cruse PJ, Foord R. The epidemiology of wound infection. A 10-year prospective study of 62, 939 wounds. Surg. Clin. North Am. 60(1), 27-40 (1980).

8. Emori TG, Gaynes RP. An overview of nosocomial infections, including the role of the microbiology laboratory. Clin. Microbiol. Rev. 6(4), 428-442 (1993).

9. Jones RN. Resistance patterns among nosocomial pathogens: trends over the past few years. Chest 119(Suppl. 2), S397-S404 (2001).

10. Munez E, Ramos A, Espejo TA et al. Microbiology of surgical site infections in abdominal tract surgery patients. Cir. Esp. 89(9), 606-612. (2011).

11. Owens CD, Stoessel K. Surgical site infections: epidemiology, microbiology and prevention. J. Hosp. Infect. 70(Suppl. 2), 3-10 (2008). 
12. Bonomo RA. Multiple antibiotic-resistant bacteria in long-term-care facilities: an emerging problem in the practice of infectious diseases. Clin. Infect. Dis. 31(6), 1414-1422 (2000).

13. Mannien J, van Kasteren ME, Nagelkerke NJ et al. Effect of optimized antibiotic prophylaxis on the incidence of surgical site infection. Infect. Control Hosp. Epidemiol. 27(12), 1340-1346 (2006).

14. Prins JM, Kullberg BJ, Gyssens IC. National guidelines for the use of antibiotics in hospitalised adult patients: the SWAB guidelines revisited. Neth. J. Med. 63(8), 288-290 (2005).

15. Isenberg HD. Manual of Clinical Microbiology (4th Edition). ASM Press, Washington, DC, USA, 1-99 (1985).

16. EUCAST Definitive Document E.DEF 2.1, August 2000: Determination of antimicrobial susceptibility test breakpoints. Clin. Microbiol. Infect. 6(10), 570-572 (2000).

17. Hidron Al, Edwards JR, Patel J et al. NHSN annual update: antimicrobialresistant pathogens associated with health care-associated infections: annual summary of data reported to the National Health care Safety Network at the Centers for Disease Control and Prevention, 2006-2007. Infect. Control Hosp. Epidemiol. 29(11), 996-1011 (2008).

18. Misteli H, Widmer AF, Rosenthal R, Oertli D, Marti WR, Weber WP. Spectrum of pathogens in surgical site infections at a Swiss university hospital. Swiss Med. Wkly 140, w13146 (2011).

19. Solomkin JS, Mazuski JE, Bradley JS et al. Diagnosis and management of complicated intra-abdominal infection in adults and children: guidelines by the Surgical Infection Society and the Infectious Diseases Society of America. Surg. Infect. (Larchmt) 11(1), 79-109 (2010).

20. Song F, Glenny AM. Antimicrobial prophylaxis in colorectal surgery: a systematic review of randomised controlled trials. Health Technol. Assess. 2(7), 1-110 (1998).

21. Kusaba T. Safety and efficacy of cefazolin sodium in the management of bacterial infection and in surgical prophylaxis. Clin. Med. Ther. 1, 16071615 (2009).

22. van Kasteren ME, Gyssens IC, Kullberg BJ, Bruining $H$, Stobberingh E, Goris RJ. [Optimizing antibiotics policy in The Netherlands. V. SWAB guidelines 
for perioperative antibiotic prophylaxis. Foundation Antibiotics Policy Team]. Ned. Tijdschr. Geneeskd. 144(43), 2049-2055 (2000).

23. Bratzler DW, Dellinger EP, Olsen KM et al. Clinical practice guidelines for antimicrobial prophylaxis in surgery. Am. J. Health Syst. Pharm. 70(3), 195-283 (2013).

24. Kusachi $S$, Sumiyama $Y$, Arima $Y$ et al. Isolated bacteria and drug susceptibility associated with the course of surgical site infections. J. Infect. Chemother. 13(3), 166-171 (2007). 


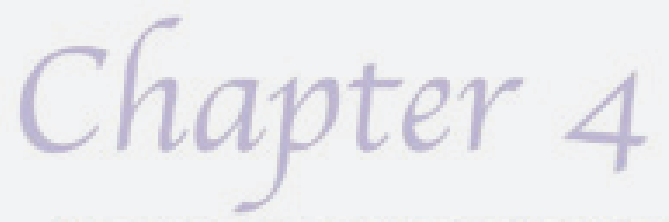

A cross-sectional study on surveillance

\section{of surgical site infections}

\section{after vascular}

\section{surgery}

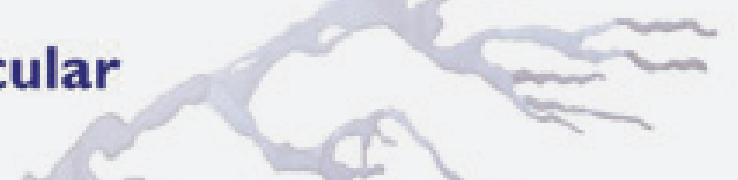

Ramcharan A, Penders J, Smeets E, Rouflart M, van Tiel F, Bruggeman C, Baeten C, Breukink S, Tordoir J, Stobberingh E

Future Microbiology 8(11), 1373-1380 (2013) 


\section{Abstract}

Aims: To determine the incidence and risk factors for surgical site infections (SSI) after vascular surgery, to evaluate the Dutch safety bundle to reduce adverse complications and to analyse causative microorganisms of SSIs.

Materials \& Methods: The 3.5-year study was divided into two periods: the control period (before bundle implementation) and intervention period (after implementation). Postdischarge surveillance was performed until 30 days after surgery. Causative microorganisms from in-hospital wound swabs were determined. SSI rates between both periods were compared and risk analysis was carried out by performing a logistic regression.

Results: The study included 1719 operations. The in-hospital SS rate increased significantly over time. Out of 140 SSIs, 39\% were diagnosed postdischarge. Risk factors were diabetes, age $>60$ years and operations classified as contaminated or dirty. Pseudomonas aeruginosa susceptibility was the highest for gentamicin (97\%). All Staphylococcus aureus were methicillin susceptible.

Conclusion: As patient-demographics are important to determine the effectiveness of infection preventive measures, (postdischarge) surveillance is important for developing SSI interventions. 


\section{Introduction}

Surgical site infections (SSIs) after vascular surgery are serious complications, increasing the risk of morbidity, mortality and health care costs [1-3] and accounting for approximately $38 \%$ of all nosocomial infections [4]. Most vascular operations are clean, aseptic procedures, in other words, elective, not acute, nontraumatic, primarily closed and without acute inflammation. The frequency of SSI after a vascular surgical procedure ranges from less than 1 to $43 \%$ worldwide [1, 2, 5-7].

Patient-related risk factors, such as gender, older age, obesity, previous operation history, nutritional status and diabetes mellitus [1, 2, 6, 8-10], as well as operationrelated factors, which include duration of operation (elective or acute) and location of incision (groin wound infection is a significant cause of postoperative complications [11]), influence the frequency of SSIs. Other factors, such as the correct use of antibiotic prophylaxis, may have an influence on the outcome. Correct use of antibiotic prophylaxis includes the correct choice of antibiotics, timing of administration and duration of treatment [9, 10, 12-14], and could prevent $40-60 \%$ of all SSIs [4, 8-11].

Although not all SSIs are preventable, many efforts have been reported worldwide to reduce the incidence of complications associated with surgery and especially SSIs $[9,15,16]$. Surveillance is an important tool to monitor the trend of SSIs. Since length of hospital stay is reduced, an increasing proportion of SSIs is diagnosed after discharge [17-21]. This proportion varies with the follow-up surveillance procedure adopted [17]; for example, active (using questionnaires or telephone interviews with patients) or passive (re-hospitalisation of patients with an SSI or follow-up visits at the outpatient clinic) [20].

From July 2010, the Maastricht University Medical Centre has been participating in the Dutch VeiligheidsManagementSystem (VMS) safety bundle to reduce adverse complications, including SSIs after surgery [48]. It has been demonstrated that optimal implementation of the program may result in a reduction of SSI [22].

We conducted a prospective cohort study to determine the incidence and risk factors for SSI after vascular surgery and evaluated the effect of the Dutch VMS safety bundle on the incidence of SSI. The most frequently isolated microorganisms involved were determined, as well as the antimicrobial susceptibility patterns of the bacteria associated with SSIs. 


\section{Materials \& methods}

\section{Setting}

The study was conducted at the surgical department of a 715-bed tertiary care hospital in the south of The Netherlands, the Maastricht University Medical Centre.

\section{Dutch VMS safety bundle}

The safety bundle, developed for Dutch hospitals, is a national initiative to improve surgical care by reducing postoperative complications, such as SSIs. The evidencebased measures of the bundle are preoperative antibiotic prophylaxis, no skin shaving before surgery, normothermia and hygiene discipline in the operating room, translated as the number of door movements during surgery $[15,23,48]$.

The bundle was introduced and implemented by using the Plan-Do-Study-Act cycle, as developed by the American Institute for Health care Improvement [23, 49]. In the 'plan' phase we determined the incidence of SSI during the study period. In the 'do' phase, relevant surveillance data were collected, analysed and interpreted. During the 'study' phase the trend of SSI over time and risk factors for SSI, along with the causative microorganisms were investigated. In the 'act' phase, the effect of the safety bundle on the SSI rate was determined.

\section{Timeline}

The study was carried out from July 2008 to December 2011 and was divided into a control period from July 2008 to April 2010 and an intervention period from April 2010 to December 2011. From July 2008 to July 2009, surveillance was only performed during hospitalisation. Thereafter, surveillance was also performed during a 30-day follow-up period after surgery, according to the criteria of the CDC. During the intervention period, from April 2010 to December 2011, the safety bundle was introduced and implemented. The effectiveness of the bundle was evaluated, using the incidence of SSI as an indicator parameter and a risk analysis was performed for risk-factor determination. No distinction was made between types of vascular surgical procedures. Wound swabs were taken for microbiological analysis during hospitalisation and during outpatient visits if deemed necessary by the physician in charge. 


\section{Surgical site infection}

All surgical procedures were classified into one of the following wound classes based on the expected bacterial load of the surgical wound: clean, cleancontaminated, contaminated or dirty, according to the criteria of the CDC and the Dutch Preventie van Ziekenhuisinfecties door Surveillance national guidelines [24, $25,50]$. The SSIs were categorized into superficial (only skin and subcutaneous tissue of the incision), deep (deep soft tissues of the incision) or anatomical infections (any part of the body that was opened during the operation, excluding the skin incision) [24].

An index operation was defined as the first surgical intervention in our hospital. All SSIs diagnosed within thirty days after the index operation were registered. An infection was considered as an SSI linked to the index surgery, unless a surgical intervention in another hospital had been performed at the same surgical site, within thirty days before the index surgery. Reoperations in our hospital, performed at the same surgical site and within thirty days after the index operation, were considered to be related to that index operation, and therefore not included in the analysis. If patients underwent surgery more than thirty days after the previous surgical intervention, this was registered as a new index operation and included in the analysis.

Demographic and clinical data of the surgical procedure, such as wound class and clinical symptoms of SSI (i.e., pain or tenderness, redness, localized warmth and swelling [50]), were collected by an experienced qualified infection control nurse over the course of the study. Other sources of information were medical records and consultations of physicians and nurses. Postdischarge surveillance to identify SSIs was conducted until thirty days following the operation during regular followup visits at the outpatient clinic or if the patient was re-hospitalised because of infectious complications.

\section{Microbiological analysis}

Wound swabs were processed according to standard microbiological methods [26]. Breakpoints for antibiotic susceptibility were according to the guidelines of the European Committee on Antimicrobial Susceptibility Testing [27]. Intermediately sensitive/resistant microorganisms were considered resistant. The prevalence of microorganisms resistant to a certain antibiotic was defined as the number of antibiotic-resistant isolates divided by the total number of isolates of that species isolated from blood cultures and/or wound swabs, multiplied by 100 . 


\section{Statistical analysis}

The incidence of in-hospital SSI was defined as the number of SSIs per total number of surgical procedures, and was calculated for the control and intervention period separately. To compare the in-hospital SSI in the control period with the intervention period, the Pearson's chi-square test was performed. The following risk factors were determined by uni- and multi-variate analysis and stratified by study period: contamination class, history of previous operation, type of procedure (acute or elective), sex, age, diabetes mellitus, total length of stay and hospital stay before surgery.

Results were considered to be significant at a $p$-value of $\leq 0.05$. All statistical analysis of the data was carried out using the SPSS programme for Windows, IBM SPSS Statistics 20 (NY, USA).

\section{Results}

\section{Study population}

During the 3.5-year study period a total of 1977 vascular surgical procedures were performed, of which 258 were reoperations within thirty days, finally resulting in 1719 index operations for the analysis. The absolute numbers of gender were 995 male (58\%) and 724 female (42\%). The age ranged from 22 to 98 years, with a mean of 67 years for both male and female patients.

\section{Patient demographics \& baseline characteristics}

Apart from the age and number of patients undergoing acute surgery, sex, contamination of the operation, type of SSI, previous operation history, diabetes mellitus, length of stay before surgery and the hospitalisation period after surgery significantly differed between the control period and the intervention period (Table I). In the intervention period, significantly more patients had had a previous operation before the initial operation, compared with the control period.

With regard to baseline characteristics, although more operations in the intervention period were classified as clean or clean- contaminated, more infections were deep or anatomical (3.5 vs $2 \% ; p<0.05)$. 
Table I: Demographics of the patients and baseline characteristics in the control and the intervention period

Patient and baseline characteristics

Male sex

Aged $>60$ years

Clean or clean-contaminated operation

Contaminated or dirty operation

Acute operation

Previous operation ${ }^{*}$

Diabetes mellitus

Length of stay before surgery (days)

Hospitalisation period after surgery (days)

$\begin{aligned} & \text { Control pe } \\ & \text { (n=857), n }\end{aligned}$
$539(63 \%)$
$644(75 \%)$
$688(80 \%)$
$138(16 \%)$
$243(28 \%)$
$77(9 \%)$
$153(18 \%)$
7.6
21.3

21.3

Intervention
(n=862), n
$456(53 \%)$
$668(77 \%)$
$742(86 \%)$
$106(12 \%)$
$245(28 \%)$
$165(19 \%)$
$53(6 \%)$
3.7
13.2

$p$-value

$<0.05$

0.252

$<0.05$

$<0.05$

0.957

$<0.05$

$<0.05$

$<0.05$

$<0.05$

*Previous operation in history at the same surgical site

Infections during hospitalisation

The surgical procedures were classified as clean ( $n=1402 ; 81.6 \%$ ), cleancontaminated $(n=28 ; 1.6 \%)$, contaminated $(n=110 ; 6.4 \%)$ and dirty ( $n=134$; $7.8 \%)$. In 45 out of 1719 surgical cases (2.6\%) the wound class was not registered and therefore unknown for the researchers.

Of all SSIs diagnosed during hospitalisation, the occurrence of deep/anatomical SSI ( $n=16+30 ; 54 \%$ ) was higher than superficial SSI ( $n=39 ; 46 \%)$. When stratifying by wound classification, most of the superficial SSIs (67\%) occurred after clean procedures. For all deep/anatomical SSIs, most infections (41\%) were diagnosed after dirty classified procedures.

Over time, we observed an increase in the incidence of SSIs during hospitalisation from $2.8 \%$ in the control period to $7.1 \%$ in the intervention period ( $p<0.05$; Table II).

$\begin{array}{lll}\text { Table II: Incidence of surgical site infections } & \text { before and after implementation of the Dutch VMS bundle } \\ \text { Outcome measures } & \begin{array}{l}\text { Control period } \\ \text { (July 2008-April 2010) }\end{array} & \begin{array}{l}\text { Intervention period } \\ \text { (April 2010-December 2011) }\end{array} \\ & 24 & 61 \\ \text { Number of SSI } & 857 & 862 \\ \text { Number of vascular index-operations } & 2.8 & 7.1 \\ \text { Incidence of SSI (\%) } & 1.9-4.1 & 5.5-9.0 \\ \text { 95\% Confidence interval } & \end{array}$

Abbreviation: SSI, surgical site infection 


\section{Surveillance after discharge}

After 1719 index operations, a total of 140 SSIs (8.1\%) were diagnosed during and after hospitalisation, within the follow-up period of thirty days after surgery. During this period surveillance was also performed after discharge (from July 2009 to December 2011), 130 SSIs were diagnosed during (58\%) and after (42\%) hospitalisation, when visiting the outpatient clinic. Of all SSIs diagnosed after hospitalisation, $73 \%$ were superficial.

\section{Risk-factor analysis}

The results of the risk-factor analysis are shown in Table III. In the adjusted analysis, we identified an age over 60 years (OR: $2.40 ; 95 \% \mathrm{Cl}: 1.23-4.68$ ) and an operation classified as contaminated or dirty (OR: $7.83 ; 95 \% \mathrm{Cl}: 4.71-13.01$ ) as significant risk factors for SSI development.

Since the patient characteristics between the two study periods were noticeably different (as shown in Table I), a test was performed to investigate the interactions between all risk factors and the study period. The results showed that the interaction between diabetes mellitus and the study period was statistically significant ( $p=0.005 ; 95 \% \mathrm{Cl}: 0.025-0.52$ ). As a consequence, we performed a stratified analysis for diabetes and found that patients with diabetes mellitus had an almost threefold higher risk for acquiring an SSI, compared with patients without diabetes in the intervention group (OR: 2.99; 95\% Cl: 1.32-6.77), but not in the control group. 
Table III: Unadjusted and adjusted odds ratios (OR) and $95 \%$ confidence intervals (95\% CI) of SSI by risk factors

\begin{tabular}{|c|c|c|c|c|}
\hline Factors & Discrete factors & $\begin{array}{l}\text { SSIs/operations } \\
\text { (n) }\end{array}$ & $\begin{array}{l}\text { Unadjusted OR } \\
\qquad(95 \% \mathrm{Cl})\end{array}$ & $\begin{array}{c}\text { Adjusted }{ }^{*} \text { OR } \\
95 \% \mathrm{Cl}\end{array}$ \\
\hline \multirow[t]{2}{*}{ Study period } & Control period $^{ \pm}$ & $24 / 857$ & 1.0 & 1.0 \\
\hline & Intervention period & $61 / 862$ & 2.64 (1.63-4.28) & $3.26(1.94-5.47)$ \\
\hline \multirow[t]{2}{*}{ Sex } & Female $^{ \pm}$ & $33 / 724$ & 1.0 & 1.0 \\
\hline & Male & $52 / 995$ & $1.16(0.74-1.81)$ & $1.12(0.70-1.79)$ \\
\hline \multirow[t]{2}{*}{ Age } & $<60$ years $^{ \pm}$ & $11 / 407$ & 1.0 & 1.0 \\
\hline & $>60$ years & $74 / 1312$ & $2.15(1.13-4.10)$ & $2.40(1.23-4.68)$ \\
\hline \multirow[t]{2}{*}{ Wound class $^{\S}$} & $1+2^{ \pm}$ & $45 / 1430$ & 1.0 & 1.0 \\
\hline & $3+4$ & $39 / 244$ & $5.86(3.72-9.21)$ & $7.83(4.71-13.01)$ \\
\hline \multirow[t]{2}{*}{ Operation } & Elective $^{ \pm}$ & $59 / 1231$ & 1.0 & 1.0 \\
\hline & Acute & $26 / 488$ & $1.12(0.67-1.80)$ & $0.59(0.34-1.00)$ \\
\hline \multirow[t]{2}{*}{ Previous operation } & $\mathrm{No}^{ \pm}$ & $64 / 1477$ & 1.0 & 1.0 \\
\hline & Yes & $21 / 242$ & $2.10(1.26-3.50)$ & $1.29(0.74-2.24)$ \\
\hline
\end{tabular}

"Multivariate logistic regression, adjusting for the factors shown in the table (no diabetes mellitus)

\pm =reference group

$\S=1$ (clean), 2 (clean-contaminated), 3 (contaminated), 4 (dirty)

Abbreviations: OR, odds ratio; SSI, surgical site infection

Microbiology \& susceptibility

Of the 85 SSIs detected during hospitalisation 44 (52\%) were diagnosed after clean procedures, one $(0.85 \%)$ as clean-contaminated, $14(16 \%)$ as contaminated, and 25 (29\%) as dirty wounds. The wound class was unknown for one SSI and therefore excluded for the microbiological analysis.

In 27 out of $84 \mathrm{SSI}$ cases (32\%), no bacteriological cultures were performed. Of the remaining 57 SSIs, 38 wound swabs (67\%) were taken for microbiological analysis, of which 13 samples (34\%) were considered negative as microorganisms were not isolated. From the remaining 25 wound swabs, 95 microorganisms were isolated, mainly Pseudomonas aeruginosa $(n=34 ; 36 \%$ ), Staphylococcus aureus $(n=19$; $20 \%)$, Bacteroides fragillis ( $n=8 ; 8 \%)$, Escherichia coli $(n=8 ; 8 \%)$ and Morganella morganii ( $\mathrm{n}=7 ; 7 \%)$.

The antimicrobial susceptibility of $P$. aeruginosa ranged from $73.5 \%$ for ciprofloxacin to $97 \%$ for gentamicin. The susceptibility for ceftazidime and piperacillin was $88 \%$ for both antibiotics. All S. aureus isolates were susceptible to methicillin, the susceptibility for the other antibiotics tested ranged from 90 to 100\%. 


\section{Discussion}

This study was performed to determine the risk factors, incidence and microbiology of SSI after vascular surgery and to evaluate the effect of the Dutch VMS safety bundle on the incidence of SSI. In this study, our overall incidence of SSI after vascular surgery, during and after hospitalisation, was $8 \%$. The postdischarge incidence fluctuated at approximately $4 \%$, indicating that almost half of all SSIs were found after discharge. Most operations were classified as clean procedures. Significant risk factors for SSI were diabetes, operations classified as contaminated or dirty and an age over 60 years. Regarding the microbiology, $66 \%$ of all wound swabs ( $n=38$ ) were culture positive, with $P$. aeruginosa and $S$. aureus as the most prevalent microorganisms and the latter being methicillin susceptible.

The validity of the study was increased by the surveillance being performed by an infection-control nurse, during and after hospitalisation, over the course of the study. Performing surveillance allowed us to identify risk factors for SSI and initiate preventive interventions for the future. The addition of postdischarge surveillance up to thirty days after surgery is an important feature, as it is known that infections after vascular surgery often manifest after discharge [28, 29]. Risk-factor analysis was performed for SSIs diagnosed during hospitalisation, as risk factors for postdischarge SSIs could differ from risk factors during hospitalisation [17]. Delgado-Rodríguez et al. found that patients with postdischarge SSI were more similar to non-infected patients (in terms of most classic risk factors for SSI) than to patients with in-hospital SSI, diagnosed during admission [17].

Finally, all microbiological analyses were performed in one laboratory, by contrast to other studies, where the antimicrobial susceptibility testing was performed by different laboratories collaborating with the hospital and not by a central laboratory [30]. Therefore, in this study, variation due to methodological differences can be excluded.

There were, however, limitations to the study that need to be addressed. First, as we did not differentiate between the different categories of vascular surgical procedures, the results might have been inaccurately interpreted. Since SSI rates following inguinal access generally vary $[2,31]$, it is difficult to develop targeted interventions to prevent vascular SSIs. Second, owing to our relatively small number of microbiologically positive wound swabs, the generalizability of the microbiological results could be questioned. Third, data on The American Society of Anaesthesiologists class and length of operation as risk factors for SSI were not 
retrospectively available. Instead, we used the older wound classification system according to the CDC [24], as it also predicts the risk of SSIs based on assessment of bacterial load at the time of the operation. Finally, spot checks to determine compliance with the bundle were randomly performed in the operating room. However, the number of operations was too small to draw a reliable conclusion regarding compliance with the safety bundle. Although an increasing trend in compliance was observed for the separate bundle measures (data not shown), compliance with the complete bundle was low $(<50 \%)$ and showed no increasing trend over time, for which we do not have an explanation. A study by van Tiel et al. showed that compliance with infection-control measures can significantly improve with repeated monitoring, even with a lower number of operations for which spotchecks were performed [32]. However, van Tiel's results are difficult to compare, as with their design the contribution of individual measures to the overall outcome were identified, instead of all measures together as one complete bundle.

We were not able to demonstrate a decreasing trend in SSI after implementation of the Dutch safety bundle, but our overall SSI incidence of $8 \%$ was similar to the $5-$ $10 \%$ found by Bandyk [31], and much lower than the $27 \%$ as described by Turtiainen et al. [1]. Our incidence of 4.4\% (85 SSIs after 1917 surgical procedures) found during hospitalisation was also in agreement with the $4.6 \%$ described by Delgado-Rodríguez et al. after vascular surgery in a tertiary hospital [17]. The variation found in the literature might be due to many factors; for example, different definitions of SSI used between hospitals [33], differentiation between vascular operation types, differences in surveillance methods (leading to e.g., under-reporting in hospitals) [33-35] and hospital characteristics. Regarding the latter, higher rates of postoperative complications were observed in major teaching hospitals compared with district hospitals [7]. The failure to detect a decrease in SSI might be due to insufficient implementation of the bundle and a short evaluation period. Even successful implementations of preventive measures are not always associated with a significant decrease in SSI [15, 36-40]. Furthermore, our study population differed in demographics between the control period and the intervention period, which significantly influenced the SSI rate. Over time, more severely ill patients, some with graft infections that were diagnosed years later, were admitted to our hospital for further treatment. The changes in demographics may also contribute to the lack of decrease in SSIs.

Our study stresses the importance of postdischarge surveillance to reliably assess the incidence of SSI. During the period when postdischarge surveillance was 
performed, $42 \%$ of all SSIs were diagnosed after discharge, which can be explained by our decrease in length of hospital stay [18]. Our postdischarge rate was similar to that of Delgado-Rodríguez et al. who found $45.6 \%$ of all SSIs after discharge [17]. Regarding the type of SSIs, more superficial infections compared with deep ones, were seen after discharge, as also found by others [41] and might be explained by the shorter hospitalisation, since superficial SSIs usually do not require antimicrobial therapy.

The results of our study confirmed the data described by others in terms of risk factors for SSI (i.e., diabetes, an age over 60 years and operations classified as contaminated or dirty). The incidence of SSI after dirty procedures is variable, both higher and lower percentages than the $18.7 \%$ we found have been described $[6,11$, $29,42,43]$. Also after clean-contaminated procedures, our incidence of SSI (3.6\%) was lower than described by Tatterton and Homer-Vanniasinkam (10\%) [10]. Concerning the microorganisms involved, $S$. aureus is frequently isolated $[1,10,44$, 45], whereas in our study $P$. aeruginosa was the most prevalent followed by $S$. aureus, probably owing to more patients suffering from a diabetic foot ulcer [46, 47].

Vascular operations carry significant risks due to complex surgery and long duration. As a result, the condition of the patient deteriorates. Therefore, reoperations are often necessary and a wide spectrum of antimicrobials is used. This may lead to increased antibiotic resistance, which nowadays raises concerns about antimicrobial prophylaxis practices, treatment, morbidity and mortality [15]. Information about the microorganisms involved in SSI and antibiotic resistance patterns will support an optimal choice for antibiotic prophylaxis.

\section{Conclusion}

Our study provided clinical and microbiological information on SSIs after vascular surgery. Despite evidence-based infection preventive measures, no beneficial impact was shown. Risk factors in this study, such as age of patients, diabetes and microbiological profile, must be better understood with the aim to control the frequency and morbidity associated with SSIs and to determine an optimal treatment plan. Therefore, surveillance, including postdischarge surveillance, remains important for developing timely intervention to reduce the incidence of SSI after vascular surgery in the future. 


\section{Future perspective}

As vascular operations vary, for example, in complexity, SSI risk, morbidity, surgical access, duration and technique, developing new and targeted interventions to reduce SSI is difficult and should continuously be promoted and updated. Also, with rising antibiotic resistance and emerging pathogens, research should be focused on protocols providing guidelines for daily practice and (antimicrobial) treatment. All information should be based on data regarding (postdischarge) surveillance and microorganisms involved in SSI with their antibiotic susceptibility patterns. 


\section{References}

1. Turtiainen J, Saimanen E, Partio T et al. Surgical wound infections after vascular surgery: prospective multicenter observational study. Scand. J. Surg. 99(3), 167-172 (2010).

2. Ott E, Bange FC, Sohr D, Teebken O, Mattner F. Risk factors associated with surgical site infections following vascular surgery at a German university hospital. Epidemiol. Infect. 141(6), 1-7 (2012).

3. Boltz MM, Hollenbeak CS, Julian KG, Ortenzi G, Dillon PW. Hospital costs associated with surgical site infections in general and vascular surgery patients. Surgery 150(5), 934-942 (2011).

4. National Nosocomial Infections Surveillance (NNIS) System Report, Data Summary from January 1992-June 2001, issued August 2001. Am. J. Infect. Control 29(6), 404-421 (2001).

5. Bunt TJ. Synthetic vascular graft infections. I. Graft infections. Surgery 93(6), 733-746 (1983).

6. Wipke-Tevis DD. Vascular infections: medical and surgical therapies. J. Cardiovasc. Nurs. 13(2), 70-81 (1999).

7. Vogel TR, Dombrovskiy VY, Carson JL, Haser PB, Lowry SF, Graham AM. Infectious complications after elective vascular surgical procedures. J. Vasc. Surg. 51(1), 122-129; discussion 129-130 (2010).

8. Richet HM, Chidiac C, Prat A et al. Analysis of risk factors for surgical wound infections following vascular surgery. Am. J. Med. 91(3B), S170S172 (1991).

9. Lobdell KW, Stamou S, Sanchez JA. Hospital-acquired infections. Surg. Clin. North Am. 92(1), 65-77 (2012).

10. Tatterton MR, Homer-Vanniasinkam S. Infections in vascular surgery. Injury 42(Suppl. 5), S35-S41 (2011).

11. Matatov T, Reddy KN, Doucet LD, Zhao CX, Zhang WW. Experience with a new negative pressure incision management system in prevention of groin wound infection in vascular surgery patients. J. Vasc. Surg. 57(3), 791-795 (2013).

12. Bandyk DF. Antibiotics - why so many and when should we use them? Semin. Vasc. Surg. 15(4), 268-274 (2002).

13. Salkind AR, Rao KC. Antiobiotic prophylaxis to prevent surgical site infections. Am. Fam. Physician 83(5), 585-590 (2011). 
14. Andrajati R, Vlcek J, Kolar M, Pípalová R. Survey of surgical antimicrobial prophylaxis in czech republic. Pharm. World Sci. 27(6), 436-441 (2005).

15. Schweizer ML, Herwaldt LA. Surgical site infections and their prevention. Curr. Opin. Infect. Dis. 25(4), 378-384 (2012).

16. Gastmeier P. European perspective on surveillance. J. Hosp. Infect. 65(Suppl. 2), 159-164 (2007).

17. Delgado-Rodríguez M, Gómez-Ortega A, Sillero-Arenas $M$, Llorca J. Epidemiology of surgical-site infections diagnosed after hospital discharge: a prospective cohort study. Infect. Control Hosp. Epidemiol. 22(1), 24-30 (2001).

18. Reed T Jr, Veith FJ, Gargiulo NJ 3rd et al. System to decrease length of stay for vascular surgery. J. Vasc. Surg. 39(2), 395-399 (2004).

19. O'Neill E, Humphreys $H$. Use of surveillance data for prevention of health care-associated infection: risk adjustment and reporting dilemmas. Curr. Opin. Infect. Dis. 22(4), 359-363 (2009).

20. Mannien J, Wille JC, Snoeren RL, van den Hof S. Impact of postdischarge surveillance on surgical site infection rates for several surgical procedures: results from the nosocomial surveillance network in The Netherlands. Infect. Control Hosp. Epidemiol. 27(8), 809-816 (2006).

21. Bruce J, Russell EM, Mollison J, Krukowski ZH. The measurement and monitoring of surgical adverse events. Health Technol. Assess. 5(22), 1194 (2001).

22. Geubbels EL, Nagelkerke NJ, Mintjes-De Groot AJ, Vandenbroucke-Grauls CM, Grobbee DE, De Boer AS. Reduced risk of surgical site infections through surveillance in a network. Int. J. Qual. Health care 18(2), 127-133 (2006).

23. Wille J, Kluytmans J, Vos G, van den Broek PJ. Interventiebundel wondinfecties hoopgevend, maar te weinig nageleefd. Infectiepreventie vergt meer inzet. Medisch Contact 76(38), 2103-2105 (2012).

24. Horan TC, Gaynes RP, Martone WJ, Jarvis WR, Emori TG. CDC definitions of nosocomial surgical site infections, 1992: a modification of CDC definitions of surgical wound infections. Infect. Control Hosp. Epidemiol. 13(10), 606608 (1992).

25. Wilson AP. Postoperative surveillance, registration and classification of wound infection in cardiac surgery - experiences from Great Britain. APMIS 115(9), 996-1000 (2007). 
26. Isenberg HD. Specimen Collection, Transport, and Acceptability. In: Clinical Microbiology Procedures Handbook (Volume 1, 2nd Edition). ASM Press, Washington, DC, USA, 2.1.1-2.1.28 (2008).

27. EUCAST Definitive Document E.DEF 2.1, August 2000: Determination of antimicrobial susceptibility test breakpoints. Clin. Microbiol. Infect. 6(10), 570-572 (2000).

28. Steckelberg JM, Osmon DR. Prosthetic joint infections. In: Division of Infectious Diseases. Bisno AL, Waldvogel FA (Eds). American Society for Microbiology, Washington, DC, USA, 259-289 (1994).

29. Orton DF, LeVeen RF, Saigh JA et al. Aortic prosthetic graft infections: radiologic manifestations and implications for management. Radiographics 20(4), 977-993 (2000).

30. Hidron Al, Edwards JR, Patel J et al. NHSN annual update: antimicrobialresistant pathogens associated with health care-associated infections: annual summary of data reported to the National Health care Safety Network at the Centers for Disease Control and Prevention, 2006-2007. Infect. Control Hosp. Epidemiol. 29(11), 996-1011 (2008).

31. Bandyk DF. Vascular surgical site infection: risk factors and preventive measures. Semin. Vasc. Surg. 21(3), 119-123 (2008).

32. van Tiel FH, Elenbaas TW, Voskuilen BM et al. Plan-do-study-act cycles as an instrument for improvement of compliance with infection control measures in care of patients after cardiothoracic surgery. J. Hosp. Infect. 62(1), 64-70 (2006).

33. Tanner J, Padley W, Kiernan M, Leaper D, Norrie P, Baggott R. A benchmark too far: findings from a national survey of surgical site infection surveillance. J. Hosp. Infect. 12, 405-407 (2013).

34. Gerbier-Colomban S, Bourjault M, Cetre JC, Baulieux J, Metzger MH. Evaluation study of different strategies for detecting surgical site infections using the hospital information system at Lyon University Hospital, France. Ann. Surg. 255(5), 896-900 (2012).

35. Mannien J, Wille JC, Kloek JJ, van Benthem BH. Surveillance and epidemiology of surgical site infections after cardiothoracic surgery in The Netherlands, 2002-2007. J. Thorac. Cardiovasc. Surg. 141(4), 899-904 (2011). 
36. Prospero E, Barbadoro P, Marigliano A, Martini E, D’Errico MM. Perioperative antibiotic prophylaxis: improved compliance and impact on infection rates. Epidemiol. Infect. 139(9), 1326-1331 (2011).

37. Stulberg JJ, Delaney CP, Neuhauser DV, Aron DC, Fu P, Koroukian SM. Adherence to surgical care improvement project measures and the association with postoperative infections. JAMA 303(24), 2479-2485 (2010).

38. Bratzler DW. The Surgical Infection Prevention and Surgical Care Improvement Projects: promises and pitfalls. Am. Surg. 72(11), 1010-1016 (2006).

39. Anthony T, Murray BW, Sum-Ping JT et al. Evaluating an evidence-based bundle for preventing surgical site infection: a randomized trial. Arch. Surg. 146(3), 263-269 (2011).

40. Poulsen KB, Jepsen OB. Failure to detect a general reduction of surgical wound infections in Danish hospitals. Dan. Med. Bull. 42(5), 485-488 (1995).

41. de Oliveira AC, Carvalho DV. Evaluation of underreported surgical site infection evidenced by post-discharge surveillance. Rev. Lat. Am. Enfermagem. 15(5), 992-997 (2007).

42. Cruse PJ, Foord R. The epidemiology of wound infection. A 10-year prospective study of 62, 939 wounds. Surg. Clin. North Am. 60(1), 27-40 (1980).

43. Culver DH, Horan TC, Gaynes RP et al. Surgical wound infection rates by wound class, operative procedure, and patient risk index. National Nosocomial Infections Surveillance System. Am. J. Med. 91(3B), S152-S157 (1991).

44. Lichtenfels EM, Webster LL, d'Azevedo R. Antimicrobial prophylaxis in peripheral vascular surgery: is cephalosporin still the gold standard? J. Vasc. Brasileiro 6(4), 378-387 (2007).

45. Homer-Vanniasinkam S. Surgical site and vascular infections: treatment and prophylaxis. Int. J. Infect. Dis. 11(Suppl. 1), S17-S22 (2007).

46. Pastar I, Nusbaum AG, Gil J et al. Interactions of methicillin resistant Staphylococcus aureus USA300 and Pseudomonas aeruginosa in polymicrobial wound infection. PLoS ONE 8(2), e56846 (2013). 
47. Muthu SE, Aberna RA, Mohan V et al. Phenotypes of isolates of Pseudomonas aeruginosa in a diabetes care center. Arch. Med. Res. 37(1), 95-101 (2006).

Websites

48. VMS veiligheidsprogramma, Utrecht. Voorkomen van wondinfectiesnaeenoperatie (2009). www.vmszorg.nl

49. American Institute for Health care Improvement. PDSA-cycle (2012). www.ihi.org

50. PREZIES. Preventie Ziekenbuisinfecties door Surveillance. Bilthoven (2012). www.prezies.nl 


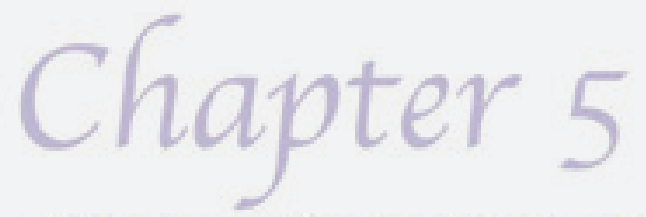

Does sarcopenia result in a higher risk for developing surgical site infections after colorectal surgery?

Ramcharan A, Ahmad A, Reisinger K, van Tiel F, Breukink S, Beets G, den Heijer C, Olde-Damink S

Submitted to Diseases of the Colon \& Rectum 


\section{Abstract}

Aims: The compromised host (immune) function of sarcopenic patients, in combination with clean-contaminated colorectal surgery, could contribute to the increased risk for surgical site infections (SSI). The aim of this study was to investigate the prevalence of sarcopenia, defined as age-related decline of muscle mass, and sarcopenic obesity in patients after a colorectal surgical procedure and the relationship of sarcopenia with gender-specific body composition and SSI. Next, to compare the microbial spectrum from SSI of sarcopenic and non-sarcopenic patients.

Materials \& methods: Patients undergoing colorectal surgery in the Maastricht University Medical Center, from July 2008 to December 2011. Clinical, infectious and microbiological parameters were collected and surveillance of SSI was performed until thirty days after surgery. Sarcopenia was diagnosed by Computed Tomography imaging. SSIs were defined according to criteria of the Centers for Disease Control and prevention.

Results: There was a strong tendency towards an association between sarcopenia and SSI. Sarcopenia was significantly more common for women, aged 65 year or above, a low Body Mass Index (BMI) category $\left(<20 \mathrm{~kg} / \mathrm{m}^{2}\right)$, and patients who received peri-operative blood transfusion. Significant factors for sarcopenic obesity were male gender, aged 65 year or above, BMI category between 25.0 and 29.9 $\mathrm{kg} / \mathrm{m}^{2}$, former smoking behaviour, and emergent operations. In all patients with an $\mathrm{SSI}$, Escherichia coli was the most frequently isolated microorganism, with a higher diversity of bacteria in sarcopenic patients.

Conclusion: Aging comes along with sarcopenia and a range of other independent predictors for surgical site infections. Because it is very likely that the underlying causes of sarcopenia are different in women and men, the identification of gender specific therapeutic interventions is strongly recommended. 


\section{Introduction}

Ageing comprises a decrease in skeletal muscle mass and may lead to decreased strength and functionality [1, 2]. For this status, Rosenberg introduced the term 'sarcopenia' in 1989 and defined it as "age-related loss of skeletal muscle mass and volume" [3].

Sarcopenia is a continuous process starting at an age of 30 to 40 years. Research has shown that the average muscle strength of an 80 -year old is almost half the muscle strength of a young adult2 and the prevalence of sarcopenia in this older population is over $50 \%$ [4].

Sarcopenia is negatively related to strength per unit muscle mass, also muscle quality (MQ), and is considered to be a better indicator of muscle function than strength alone5. A decrease in $\mathrm{MQ}$ is the result of several medical, behavioural and environmental factors that characterize the elderly [6], as well as lifestyle and behavioural changes. The (older) patient group often have nutritional problems, suffer from adverse effects of medication and changes in metabolism due to the aging process $[7,8]$. In some individuals, these changes are extreme and result in a combination of substantial overweight and muscle weakness, a condition recently termed "sarcopenic obesity" [9]. The combination of sarcopenia and obesity has been shown to be a greater risk for poor health related outcomes and disability than either obesity or sarcopenia alone $[10,11]$.

Several methods exist to diagnose sarcopenia. Next to magnetic resonance imaging (MRI), dual energy X-ray absorptiometry (DXA) and bio-impedance analysis (BIA), computed tomography (CT) imaging is a widely used method, as it accurately quantifies the skeletal muscle mass and is an objective test of physical functioning [12].

Several studies have shown that disturbances in body composition increase the risk for complications after surgery, dependent on gender [10, 13-15]. The aim of this study was to investigate the prevalence of sarcopenia and sarcopenic obesity in patients after a colorectal surgical procedure and the relationship of sarcopenia with gender-specific body composition and surgical site infections. Next, to compare the microbial spectrum of SSIs of sarcopenic patients to that of SSIs of patients without sarcopenia. 


\section{Material \& methods}

This study was conducted at the surgical department of a 715-bed tertiary care University hospital, the Maastricht University Medical Center in the Netherlands.

\section{Patient population}

The study was performed from July 2008 until October 2011. The study population included patients undergoing a colorectal surgical procedure. Patients from the age of eighteen were eligible for the study if the index-operation, defined as the first colorectal surgical intervention, was performed in our hospital and if the procedure included the rectal, anal, or colonic site or creation of colonic stomata.

Ethical approval for this study was granted by the Medical Ethics committee of the Maastricht University Medical Centre.

\section{Baseline patient characteristics}

Baseline characteristics of the patients included gender, age (in years), BMI (body mass index), previous colorectal surgery, patients' comorbidities, and complications after their colorectal surgery. All complications after surgery were reported according to the Clavien-Dindo classification [16].

\section{Computed Tomography (CT) image analysis and body composition by gender}

Muscle mass was assessed by electronically stored CT images within three months prior to surgery for diagnostic and staging purposes. Patients were not consented prior to obtaining the CT image. In order to identify only the skeletal muscle area Hounsefield Unit (HU) a threshold range between -30 and 110 was used.

Our standard landmark was a transverse slice of the third lumbar vertebral level (L3), because this correlates the strongest with whole-body tissue quantities [1719]. Two consecutive CT images extended from $L 3$ to the iliac crest and the costae were chosen to measure muscle cross-sectional area. The $\mathrm{L} 3$ muscle index $\left(\mathrm{cm}^{2}\right)$ was calculated by normalizing muscle areas for length $\left(\mathrm{cm}^{2} / \mathrm{m}^{2}\right)$.

Sarcopenia was defined as a L3 muscle index $<41 \mathrm{~cm}^{2} / \mathrm{m}^{2}$ in women, $<43 \mathrm{~cm}^{2} / \mathrm{m}^{2}$ in men with a $\mathrm{BMI}<25$ and $<53 \mathrm{~cm}^{2} / \mathrm{m}^{2}$ in men with a $\mathrm{BMI}>25$, based on the cut-off values associated with mortality [20].

Total fat-free body mass $(\mathrm{kg})$ was estimated as: $0.30 *$ (skeletal muscle surface area at L3 in $\mathrm{cm}^{2}$ ) +6.06 [21]. Body fat \% was calculated as: (body weight (kg) - fat free body mass (kg)) / body weight (kg). Obesity was based on body fat \%, with cut-off 
values for obesity to be $>49.6 \%$ for women and $>37.5 \%$ for men, based on studies evaluating sarcopenic obesity $[10,22]$. Patients were classified as obese or nonobese on the pre-operative admission date. Sarcopenic obesity was defined based on the presence of both sarcopenia and obesity.

\section{Features associated with sarcopenia and sarcopenic obesity}

Next to the clinical parameters, the influence of body composition on sarcopenia and sarcopenic obesity was tested. Sources of information were medical records and consultations of physicians and nurses. All data were obtained within the time window from the $\mathrm{CT}$ image until the surgical procedure.

\section{Surgical site infections}

An infection was considered a surgical site infection when it occurred within thirty days after the operative procedure if no implant was left in place or within one year if an implant was in place and the infection appeared to be related to the operative procedure [23].

Clinical data of the surgical procedure were collected prospectively by the same infection control nurse over the course of the study. To determine if sarcopenia was associated with SSI, potential predictors for SSI were selected based on the literature and availability in the patients' records. All data were obtained from medical records or retrieved after consultations of physicians and nurses. Postdischarge surveillance to identify SSIs was conducted by the same independent infection control nurse until thirty days following the operation.

\section{Microbiology and susceptibility patterns of the surgical wounds}

The microbiology of the surgical wounds of sarcopenic patients was compared to that of non-sarcopenic patients. The antibiotic susceptibility pattern was determined for the most frequently found microorganism. Breakpoints for antibiotic susceptibility were according to the guidelines of the European Committee on Antimicrobial Susceptibility Testing (EUCAST) [24]. Intermediate resistant microorganisms were considered resistant.

\section{Statistical analysis}

To be included in the analyses, patients needed to have a CT image within three months prior to surgery. In order to detect potential selection bias, the patient group included in further analyses was compared to the excluded patients with 
respect to the baseline characteristics. Body composition by gender and features associated with sarcopenia and sarcopenic obesity were determined. When parametric assumptions were met, an independent sample t-test was used for continuous variables and the Pearson's chi-square test was used for categorical characteristics.

To assess the association between sarcopenia and surgical site infections, initially the unadjusted relation was determined between sarcopenia and SSI. Subsequently, potential confounders were included in the multivariable analysis, when they change the beta-coefficient of sarcopenia by more than $5 \%$ individually. Multivariate analysis was performed after correction for confounders based on the univariate analysis. All statistical analyses were performed using the SPSS programme for Windows, IBM SPSS Statistics 20. $P$-values $\leq 0.05$ were considered statistically significant.

\section{Results}

\section{Patient population}

During the study period a total of 583 patients were registered. From 321 patients (55\%) CT scans were available. Baseline characteristics of the included group were compared to the remaining participants $(n=262)$, from whom no CT scan was available to determine the sarcopenic status. The former group was significantly older compared to the latter one. Significant differences were also observed concerning a previous colorectal operation, co-morbidities related to the gastrointestinal tract, cardiac and renal co-morbidities. An overview of our study population is presented in Table I. 


\section{Table I: Patients with CT scan vs. patients without CT scan}

\begin{tabular}{|c|c|c|c|}
\hline & $\begin{array}{l}\text { CT \% (n) } \\
(=321)\end{array}$ & $\begin{array}{l}\text { No CT \% (n) } \\
(n=262)\end{array}$ & $p$-value \\
\hline Male gender & $56.4(181)$ & $57.3(150)$ & 0.83 \\
\hline Age (yrs) (mean, SD) & $67.50 \pm 12.91$ & $58.33 \pm 16.24$ & $0.00^{*}$ \\
\hline BMI $\left(\mathrm{kg} / \mathrm{m}^{2}\right.$, mean, SD) & $25.25 \pm 4.17$ & $25.59 \pm 4.64$ & 0.37 \\
\hline Previous colorectal surgery & $11.8(38)$ & $19.1(50)$ & $0.02^{*}$ \\
\hline \multicolumn{4}{|l|}{ Co-morbidities } \\
\hline Diabetes & $15.0(48)$ & $11.1(29)$ & 0.17 \\
\hline Hypertension & $34.3(110)$ & $28.6(75)$ & 0.15 \\
\hline Hypercholesterolemia & $10.0(32)$ & $6.5(17)$ & 0.13 \\
\hline Lipid deficiency & $0.9(3)$ & $0.8(2)$ & 0.82 \\
\hline Pulmonary & $10.0(32)$ & $8.4(22)$ & 0.52 \\
\hline Cardiac & $21.5(69)$ & $13.4(35)$ & $0.01^{*}$ \\
\hline PAD (Fontaine) & $3.1(10)$ & $2.7(7)$ & 0.75 \\
\hline Gastro-intestinal & $15.6(50)$ & $30.5(80)$ & $0.00^{*}$ \\
\hline Renal & $8.4(27)$ & $3.8(10)$ & $0.02^{*}$ \\
\hline Hematologic disorder & $0.9(3)$ & $1.5(4)$ & 0.51 \\
\hline Musculoskeletal disorder & $10.9(35)$ & $8.8(23)$ & 0.39 \\
\hline \multicolumn{4}{|c|}{ Complications: Clavien-Dindo grade } \\
\hline$<3$ & $71.3(229)$ & $77.1(202)$ & 0.12 \\
\hline$\geq 3$ & $26.8(86)$ & $21.8(57)$ & 0.16 \\
\hline
\end{tabular}

\section{${ }^{*}$ Significant at $p \leq 0.05$ \\ Abbreviations: BMI, body mass index; SD, standard deviation}

Body composition by gender

Table II shows the difference between the female and male gender. First of all, men have a significantly higher weight than women $(p<0.001)$. Furthermore, there are significant differences between men and women with regard to body fat percentage, fat free body mass, length, lumbar total muscle cross-sectional area and skeletal muscle index (all $p<0.001$ ). Men and women did not differ in overall BMI (respectively $25.6 \mathrm{~kg} / \mathrm{m}^{2}$ and $24.8 \mathrm{~kg} / \mathrm{m}^{2}, p=0.06$ ). Men had a higher fat free body mass (52.1 kg vs. $38.2 \mathrm{~kg}$ ), length (176 vs. $163 \mathrm{~cm}$ ) and skeletal muscle index $\left(49.5\right.$ vs. $\left.40.1 \mathrm{~cm}^{2} / \mathrm{m}^{2}\right)$ than women. However, women showed a higher body fat percentage $(38.2 \%$ vs. $52.1 \%, p<0.001)$. 


\section{Table II: Body composition by gender}

\begin{tabular}{|c|c|c|c|}
\hline Characteristics & $\begin{array}{l}\text { Men }(n=181) \\
\text { No (\%) }\end{array}$ & $\begin{array}{l}\text { Women }(n=140) \\
\text { No (\%) }\end{array}$ & $p$-value \\
\hline Weight, kg & $<0.001$ & & \\
\hline Mean & 81.4 & 68.9 & \\
\hline SD & 11.7 & 13.4 & \\
\hline $\mathrm{BMI}, \mathrm{kg} / \mathrm{m}^{2+}$ & 0.06 & & \\
\hline Mean & 25.6 & 24.8 & \\
\hline SD & 3.7 & 4.7 & \\
\hline BMI category, $\mathrm{kg} / \mathrm{m}^{2+}$ & 0.01 & & \\
\hline$<20.0$ & $11(6.1)$ & $21(15.0)$ & \\
\hline 20.0 to 24.9 & $64(35.3)$ & $56(40.0)$ & \\
\hline 25.0 to 29.9 & 77 (42.5) & $37(26.4)$ & \\
\hline$\geq 30$ & $22(12.2)$ & $21(15.0)$ & \\
\hline Undetermined & $7(3.9)$ & $5(3.6)$ & \\
\hline Body fat \% & & & $<0.001$ \\
\hline Mean & 33.3 & 40.9 & \\
\hline SD & 9.3 & 9.6 & \\
\hline Fat-free body mass (kg) & & & $<0.001$ \\
\hline Mean & 52.1 & 38.2 & \\
\hline SD & 8.1 & 5.0 & \\
\hline Length, cm & $<0.001$ & & \\
\hline Mean & 176 & 163 & \\
\hline SD & 6.6 & 7.4 & \\
\hline Weight loss $^{\S}$ & 0.65 & & \\
\hline Mean & 2.3 & 2.6 & \\
\hline SD & 4.0 & 4.5 & \\
\hline CT image analysis & $<0.001$ & & \\
\hline $\begin{array}{l}\text { Lumbar total muscle cross- } \\
\text { sectional area, } \mathrm{cm}^{2}\end{array}$ & & & \\
\hline Mean & 153.4 & 107.1 & \\
\hline SD & 27.1 & 16.8 & \\
\hline Skeletal muscle index, $\mathrm{cm}^{2} / \mathrm{m}^{2}$ & $<0.001$ & & \\
\hline Mean & 49.5 & 40.1 & \\
\hline SD & 8.7 & 6.2 & \\
\hline
\end{tabular}

${ }^{\dagger} \mathrm{BMI}$ calculated as patient weight $(\mathrm{kg}) /$ length $\left(\mathrm{m}^{2}\right)$

${ }^{\S}$ Weight loss after surgery

${ }^{ \pm}$Skeletal muscle index calculated as lumbar total muscle cross-sectional area $\left(\mathrm{cm}^{2}\right) /$ length $\left(\mathrm{m}^{2}\right)$

Abbreviations: BMI, body mass index; $C T$, computed tomography; SD, standard deviation 
Features associated with sarcopenia and sarcopenic-obesity

From 318 patients all data was available to determine sarcopenia. The prevalence of sarcopenia was 54\%, (173 out of 318 patients). With regard to sarcopenic obesity, from 309 patients all data was available, resulting in $21 \%$ (66 out of 309 ) to be sarcopenic obese.

For this patient population, sarcopenia was more common in women, aged equal or above 65 year, and patients with the lowest BMI category $\left(<20 \mathrm{~kg} / \mathrm{m}^{2}\right)$. Also, more sarcopenic patients received peri-operative blood transfusion. Significant predictive factors for sarcopenic obesity were male gender, aged 65 year or above, BMI category between 25.0 and $29.9 \mathrm{~kg} / \mathrm{m}^{2}$, former smoking behaviour, and emergent operations (Table III).

With regard to body composition, patients with sarcopenia had a significantly lower weight and BMI compared to non-sarcopenic patients. Contrarily, sarcopenic obese patients had a significantly higher weight and BMI compared to nonsarcopenic obese patients (Table IV). 


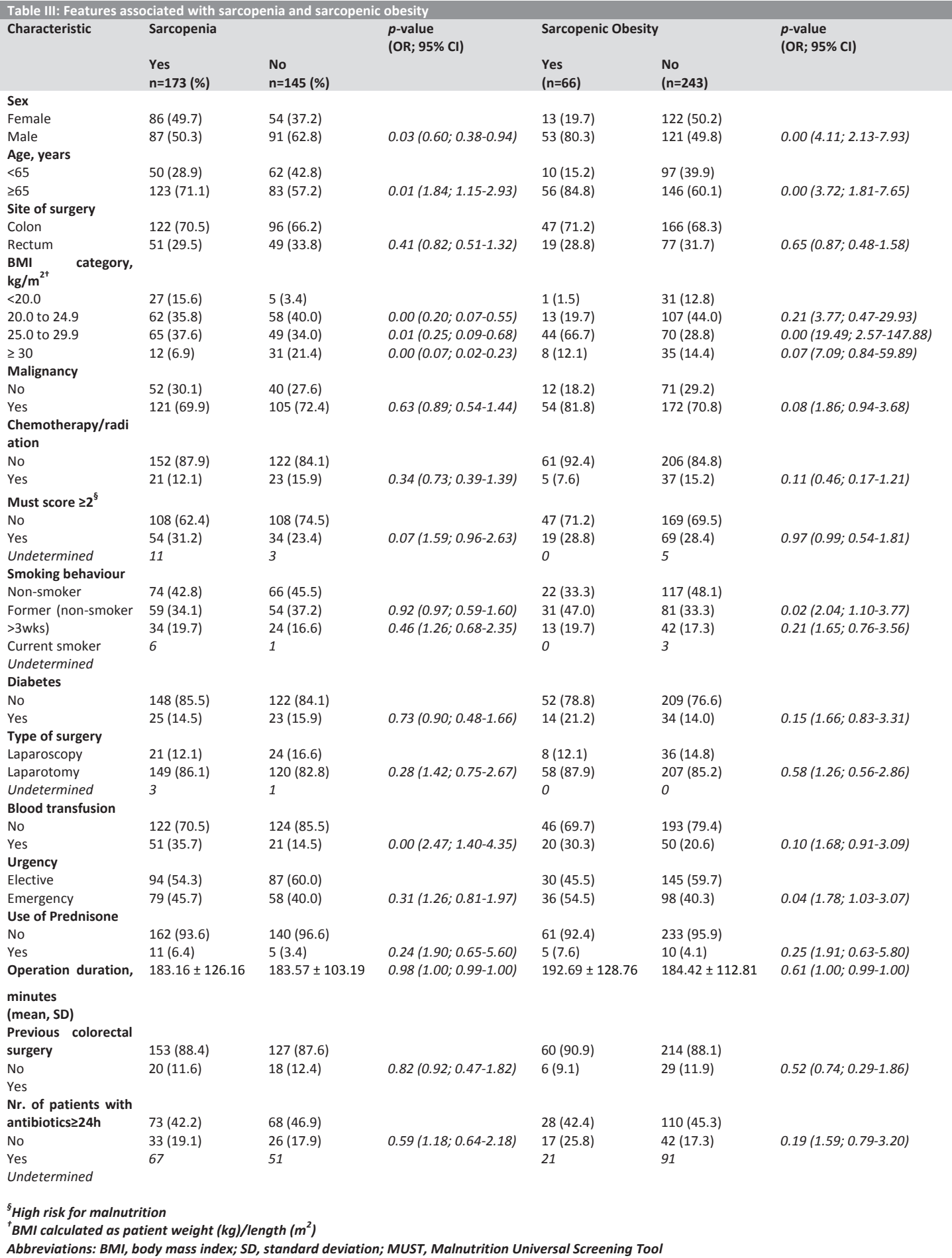




\begin{tabular}{|c|c|c|c|c|c|c|}
\hline \multirow[b]{2}{*}{ Characteristics } & \multicolumn{2}{|l|}{ Sarcopenia } & \multirow{2}{*}{$\begin{array}{l}p \text {-value } \\
\text { (OR; } 95 \% \mathrm{CI})\end{array}$} & \multicolumn{2}{|c|}{ Sarcopenic Obesity } & \multirow{2}{*}{$\begin{array}{l}p \text {-value } \\
\text { (OR; } 95 \% \mathrm{CI})\end{array}$} \\
\hline & $\begin{array}{l}\text { Yes } \\
n=173 \text { (\%) }\end{array}$ & $\begin{array}{l}\text { No } \\
n=145(\%)\end{array}$ & & $\begin{array}{l}\text { Yes } \\
(n=66)\end{array}$ & $\begin{array}{l}\text { No } \\
(n=243)\end{array}$ & \\
\hline Weight, kg & & & $\begin{array}{l}0.01 \\
(0.98 ; 0.96-0.99)\end{array}$ & & & $\begin{array}{l}<0.001 \\
(1.06 ; 1.04-1.08)\end{array}$ \\
\hline Mean \pm SD & $73.99 \pm 14.77$ & $78.38 \pm 12.44$ & & $84.09 \pm 10.37$ & $73.81 \pm 13.92$ & \\
\hline BMI, $\mathrm{kg} / \mathrm{m}^{2+}$ & & & $\begin{array}{l}<0.001 \\
(0.88 ; 0.83-0.93)\end{array}$ & & & $\begin{array}{l}<0.001 \\
(1.15 ; 1.07-1.23)\end{array}$ \\
\hline Mean \pm SD & $24.30 \pm 4.07$ & $26.37 \pm 4.01$ & & $27.07 \pm 2.58$ & $24.77 \pm 4.38$ & \\
\hline Body fat \% & & & $\begin{array}{l}<0.001 \\
(1.11 \pm 1.08-1.14)\end{array}$ & & & $\begin{array}{l}<0.001 \\
(1.16 ; 1.12-1.22)\end{array}$ \\
\hline Mean \pm SD & $40.57 \pm 8.65$ & $31.97 \pm 9.87$ & & $45.24 \pm 5.86$ & $34.24 \pm 9.83$ & \\
\hline Fat-free body mass (kg) & & & $\begin{array}{l}<0.001 \\
(0.87 ; 0.85-0.90)\end{array}$ & & & $\begin{array}{l}0.17 \\
(0.98 ; 0.95-1.01)\end{array}$ \\
\hline Mean \pm SD & $41.52 \pm 7.68$ & $51.42 \pm 9.49$ & & $44.61 \pm 7.39$ & $46.50 \pm 10.43$ & \\
\hline Length, cm & & & $\begin{array}{l}0.63 \\
(1.01 ; 0.98-1.03)\end{array}$ & & & $\begin{array}{l}0.00 \\
(1.05 ; 1.02-1.08)\end{array}$ \\
\hline Mean \pm SD & $170.44 \pm 9.08$ & $170.19 \pm 9.47$ & & $173.39 \pm 9.17$ & $169.49 \pm 9.11$ & \\
\hline Weight loss ${ }^{\S}$ & & & $\begin{array}{l}0.46 \\
(1.02 ; 0.97-1.08)\end{array}$ & & & $\begin{array}{l}0.42 \\
(1.03 ; 0.97-1.09)\end{array}$ \\
\hline Mean \pm SD & $2.60 \pm 4.37$ & $2.24 \pm 4.04$ & & $2.80 \pm 4.95$ & $2.33 \pm 3.99$ & \\
\hline CT image analysis & & & $<0.001$ & & & 0.17 \\
\hline $\begin{array}{l}\text { Lumbar total muscle cross- } \\
\text { sectional area, } \mathrm{cm}^{2}\end{array}$ & & & $(0.96 ; 0.95-0.97)$ & & & $(0.99 ; 0.99-1.00)$ \\
\hline Mean \pm SD & $118.19 \pm 25.60$ & $151.19 \pm 31.65$ & & $128.51 \pm 24.64$ & $134.81 \pm 34.77$ & \\
\hline $\begin{array}{l}\text { Skeletal muscle index, } \\
\mathrm{cm}^{2} / \mathrm{m}^{2 \pm}\end{array}$ & & & $\begin{array}{l}<0.001 \\
(0.77 ; 0.73-0.82)\end{array}$ & & & $\begin{array}{l}0.00 \\
(0.95 ; 0.91-0.98)\end{array}$ \\
\hline Mean \pm SD & $40.22 \pm 6.08$ & $51.80 \pm 7.90$ & & $42.45 \pm 5.93$ & $46.43 \pm 9.57$ & \\
\hline $\begin{array}{l}{ }^{*} \text { Significant at } p \leq 0.05 \\
{ }^{+} \text {BMI calculated as patient wei } \\
{ }^{8} \text { Weight loss after surgery }\end{array}$ & ght $(k g) / l e n g t h$ & & & & & \\
\hline
\end{tabular}


Association between sarcopenia and surgical site infections

Univariate analysis determined age, gender, wound class, BMI category, chemo- or radiotherapy, type of surgery (laparotomy or laparoscopy), and operation duration as potential confounders for the association between sarcopenia and SSI. Correction for confounders showed that, although there was a tendency towards a higher risk for SSI in sarcopenic patients, the association between in this study population was not significant ( $p=0.09$; OR, 95\% Cl: 1.75, 0.93-3.32) (Table V). 


\begin{tabular}{|c|c|c|c|}
\hline Characteristic & No. of patients & No. of SSI (\%) & $p$-value \\
\hline SMI & & & 0.09 \\
\hline Non-sarcopenic & 145 & $30(20.6)$ & \\
\hline Sarcopenic & 173 & $43(24.9)$ & \\
\hline Undetermined & 3 & 0 & \\
\hline Sex & & & 0.07 \\
\hline Female & 140 & $26(18.6)$ & \\
\hline Male & 181 & $47(26.0)$ & \\
\hline Age, years & & & 0.36 \\
\hline$<65$ & 114 & $24(21.1)$ & \\
\hline$\geq 65$ & 207 & $49(23.7)$ & \\
\hline Wound class & & & 0.44 \\
\hline Clean & 3 & 1 & \\
\hline Clean-contaminated & 203 & 49 & \\
\hline Contaminated & 63 & 11 & \\
\hline Dirty & 39 & 9 & \\
\hline Undetermined & 13 & 3 & \\
\hline BMI category, $\mathrm{kg} / \mathrm{m}^{2+}$ & & & 0.03 \\
\hline$<20.0$ & 32 & $2(6.3)$ & \\
\hline 20.0 to 24.9 & 120 & $26(21.7)$ & \\
\hline 25.0 to 29.9 & 114 & $27(23.7)$ & \\
\hline$\geq 30$ & 43 & $14(32.6)$ & \\
\hline Undetermined & 12 & 4 & \\
\hline Chemotherapy/radiation & & & $<0.001$ \\
\hline Yes & 45 & $23(51.1)$ & \\
\hline No & 276 & $50(18.1)$ & \\
\hline Type of surgery & & & 0.09 \\
\hline Laparoscopy & 45 & $4(8.9)$ & \\
\hline Laparotomy & 270 & $67(24.8)$ & \\
\hline Undetermined & 6 & 2 & \\
\hline $\begin{array}{l}\text { Operation duration, minutes } \\
\text { (mean, SD) }\end{array}$ & $190.70 \pm 119.60$ & $180.43 \pm 115.12$ & 0.69 \\
\hline
\end{tabular}

Microbiology and susceptibility patterns in sarcopenic patients with an SSI

Of all sarcopenic patients with an SSI $(n=43), 27$ wounds were clean-contaminated (63\%), 8 were contaminated (19\%) and 8 were dirty (19\%). There were no clean wounds. The most frequently found microorganism were Escherichia coli (20\%), 
followed by Pseudomonas aeruginosa (12\%), Bacteroides fragilis group (8\%), Candida albicans (8\%) and Enterococcus faecalis (7\%), independent of wound type. In the non-sarcopenic patients with an SSI ( $n=30), 1$ wound was clean, 22 wounds were clean-contaminated (73\%), 3 were contaminated (10\%) and 1 was dirty. In 3 cases the wound class was undetermined. The most frequently isolated microorganisms were Escherichia coli (53\%), followed by Bacteroides fragilis group (10\%), Enterococcus faecium (8\%) and Morganella morganii (3\%). E. coli was significantly more prevalent in non-sarcopenic patients compared to sarcopenic patients (OR $=4.56,95 \% \mathrm{Cl}: 2.14-9.82)$, but the diversity in microbial spectrum was higher in sarcopenic patients (19 different species in sarcopenic patients versus 11 different species in non-sarcopenic patients, data not shown).

Differences in the antibiotic susceptibility patterns between sarcopenic and nonsarcopenic patients were found for $E$. coli to ciprofloxacin $(16.7 \%$ versus $0 \%, p=$ 0.03 ) and piperacillin/tazobactam (5.6\% versus $30.8 \%, p=0.04)$.

\section{Discussion}

In the present study the prevalence of sarcopenia and sarcopenic obesity in patients after a colorectal surgical procedure and the relationship of sarcopenia with gender-specific body composition and surgical site infections were determined. Also, the microbial spectrum from SSIs of sarcopenic and nonsarcopenic patients was compared.

We found that sarcopenia in patients undergoing a colorectal operation was significantly more common in women than in men, in patients aged equal or above 65 year, and in patients with the lowest BMI category $\left(<20 \mathrm{~kg} / \mathrm{m}^{2}\right)$. Also, more sarcopenic patients received peri-operative blood transfusion. Significant factors for sarcopenic obesity were male gender, aged equal or above 65 year, BMI category between 25.0 and $29.9 \mathrm{~kg} / \mathrm{m}^{2}$, former smoking behaviour, and emergent operations. There was a tendency towards an association between sarcopenia and surgical site infections, although not significant. With regard to the microbial spectrum, Escherichia coli was the most frequently isolated microorganism from SSIs from both sarcopenic and non-sarcopenic patients, an organism that is generally found in lower tract surgery [25].

To our knowledge, this is the first study that analysed the microbiology of the wounds of sarcopenic patients with an SSI, combined with the association of sarcopenia in colorectal patients with surgical site infections. The second strength 
was that next to the standardization of data for length, degree of obesity, and age, standardization for gender effects was performed. It has been shown that significant gender differences in body composition were evident prior to the onset of puberty. In general, pre-pubertal girls have a higher total body fat and percentage body fat but lower fat-free mass compared to pre-pubertal boys [26, 27]. The gender differences could be explained by the sex hormones that produce different reactions in the fat metabolism. Although there was a tendency towards a higher risk for SSI in sarcopenic patients, the association was not significant after correction for potential confounders, in contrast to others who found a significant increased risk for postoperative infections in patients with sarcopenia [28]. We found a higher risk for sarcopenia in patients equal or older than 65 years, as was also found by others $[11,29,30]$. Although sarcopenic patients have a lower weight, sarcopenic obesity is associated with a higher weight. The increase in body weight is probably due to the decline in energy expenditure; decreased physical activity and reduced metabolism [31]. The lower weight in sarcopenic patients can be explained by anorexia of aging [32].

The third strength of this study is that patients were not selected to obtain a CT scan, a widely used method with high sensitivity and specificity that accurately measures a direct property of the muscle due to the high radiation exposure $[1,33$, 34]. Fourth, surveillance regarding SSIs was performed prospectively by an experienced infection control nurse during the course of the study and all measurements were done by a researcher who was blinded for clinical outcome to avoid bias. Finally, all microbiological analysis was performed in one laboratory, thus excluding interlaboratory variability.

The risk for sarcopenic patients to develop SSIs can be explained by their comorbid conditions that keep the patient nutritionally impaired and/or immunecompromised. However, the loss of muscle mass might also be deemed a normal phenomenon, in contrast to other circumstances where the process is obviously increased and disease related.

Several weaknesses in our study should be addressed. First, due to the retrospective data analysis of CT images within the thirty days prior to the surgical procedure, some data could not be captured and therefore patients without an available CT image to determine sarcopenia were excluded for the analysis, which could have come along with selection bias regarding the disease status of the patient. Second, possibly due to the absence of a WHO-classification for sarcopenia and consensus on the definition and diagnosis, the prevalence of sarcopenia (70\%) 
in our (specific) study population with a mean age of sixty-seven years was relatively high compared to the $5-13 \%$ in the general (healthy) population of $60-70$ year old people [29]. Thereby, because of the heterogeneity of populations studied throughout the literature, e.g., sarcopenic patients and muscle mass in relation to chemotherapy toxicities $[35,36]$, different cut-off point for sarcopenia are used and are still under debate. We assessed the best cut-off points for the definition of sarcopenia using the images at $\mathrm{L} 3$, related to increased morbidity and to wholebody tissue mass, corrected for gender [28]. Third, as our study population underwent different colorectal surgical procedures and different resection sites were involved [37, 38], patients had different (site-specific), risk factors, e.g., wound class, for developing an SSI [39]. Finally, we did not register data on use of medication, such as immunosuppressive drugs, of the patient.

Our findings with regard to the susceptibility pattern of $E$. coli and the diversity in microbial spectrum in sarcopenic patients can be explained by the sometimes compromised host (immune) function, e.g., due to malnutrition. Clinical malnutrition is a disorder that often coexists with infectious and inflammatory processes and environmental problems [40]. Combined with the more contaminated wounds and the different susceptibility patterns to ciprofloxacin and piperacillin/tazobactam, the higher diversity of the microbial spectrum in sarcopenic patients could be explained. The different susceptibility patterns to ciprofloxacin and piperacillin/tazobactam might be explained by the pharmacokinetic and pharmacodynamic implications that come along with the aging process.

As the analysis demonstrated a range of independent predictors of SSI alongside that of muscle loss, the reliability of the statistical association could be questioned due to confounding. This study population underwent surgery for different abdominal diseases such as colorectal cancer, IBD (inflammatory bowel disease, such as Crohn's disease and colitis ulcerosa), and diverticulitis and were thus different from the healthy elderly. Colorectal surgery remains a high-risk intervention and prognosis is multifactorial, especially in combination with sarcopenia. We underscore that it is necessary to reach a consensus on the definition of sarcopenia per clinical discipline, in order to make results from different studies comparable, particularly since study populations throughout the literature highly differ in terms of co-morbidities and medical background.

For feature research, more attention should be given to operative care, as the magnitude, duration, and consequences of postoperative complications are 
determined by the complex interplay between the indication for surgery, the resulting injury of the tissue, and patient factors (e.g., age and co-morbid disease). Knowledge of the microbial agents in the wounds of sarcopenic patients with an SSI might be useful to prescribe empirical antibiotic therapy and to develop interventions for daily care of sarcopenic patients. Finally, because the likelihood is high that the underlying causes of sarcopenia are different in women and men, the identification of gender specific therapeutic interventions is strongly recommended. 


\section{References}

1. Cruz-Jentoft AJ, Baeyens JP, Bauer JM, Boirie Y, Cederholm T, Landi F, Martin FC, Michel JP, Rolland Y, Schneider SM, Topinkova E, Vandewoude M, Zamboni M. Sarcopenia: European consensus on definition and diagnosis: Report of the European Working Group on Sarcopenia in Older People. Age and ageing 2010;39:412-23.

2. Beenakker KG, Ling CH, Meskers CG, de Craen AJ, Stijnen T, Westendorp RG, Maier AB. Patterns of muscle strength loss with age in the general population and patients with a chronic inflammatory state. Ageing research reviews 2010;9:431-6.

3. Rosenberg IH. Sarcopenia: origins and clinical relevance. J Nutr 1997;127:990S-1S.

4. Bijlsma AY, Meskers CG, Ling CH, Narici M, Kurrle SE, Cameron ID, Westendorp RG, Maier AB. Defining sarcopenia: the impact of different diagnostic criteria on the prevalence of sarcopenia in a large middle aged cohort. Age (Dordr) 2012.

5. Doherty TJ. Invited review: Aging and sarcopenia. J Appl Physiol 2003;95:1717-27.

6. Cederholm T, Cruz-Jentoft AJ, Maggi S. Sarcopenia and fragility fractures. European journal of physical and rehabilitation medicine 2013;49:111-7.

7. Bales CW, Ritchie CS. Sarcopenia, weight loss, and nutritional frailty in the elderly. Annual review of nutrition 2002;22:309-23.

8. Oh CA, Kim DH, Oh SJ, Choi MG, Noh JH, Sohn TS, Bae JM, Kim S. Nutritional risk index as a predictor of postoperative wound complications after gastrectomy. World J Gastroenterol 2012;18:673-8.

9. Roubenoff R. Sarcopenic obesity: does muscle loss cause fat gain? Lessons from rheumatoid arthritis and osteoarthritis. Ann N Y Acad Sci 2000;904:553-7.

10. Baumgartner RN, Wayne SJ, Waters DL, Janssen I, Gallagher D, Morley JE. Sarcopenic obesity predicts instrumental activities of daily living disability in the elderly. Obes Res 2004;12:1995-2004.

11. Stenholm S, Harris TB, Rantanen T, Visser M, Kritchevsky SB, Ferrucci L. Sarcopenic obesity: definition, cause and consequences. Curr Opin Clin Nutr Metab Care 2008;11:693-700. 
12. Pahor M, Manini T, Cesari M. Sarcopenia: clinical evaluation, biological markers and other evaluation tools. The journal of nutrition, health \& aging 2009;13:724-8.

13. Rolland Y, Lauwers-Cances V, Cristini C, Abellan van Kan G, Janssen I, Morley JE, Vellas B. Difficulties with physical function associated with obesity, sarcopenia, and sarcopenic-obesity in community-dwelling elderly women: the EPIDOS (EPIDemiologie de I'OSteoporose) Study. Am J Clin Nutr 2009;89:1895-900.

14. Chen H, Guo X. Obesity and functional disability in elderly Americans. J Am Geriatr Soc 2008;56:689-94.

15. Cohen B, Choi YJ, Hyman S, Furuya EY, Neidell M, Larson E. Gender differences in risk of bloodstream and surgical site infections. J Gen Intern Med 2013;28:1318-25.

16. Clavien PA, Barkun J, de Oliveira ML, Vauthey JN, Dindo D, Schulick RD, de Santibanes E, Pekolj J, Slankamenac K, Bassi C, Graf R, Vonlanthen R, Padbury R, Cameron JL, Makuuchi M. The Clavien-Dindo classification of surgical complications: five-year experience. Ann Surg 2009;250:187-96.

17. Shen W, Punyanitya M, Wang Z, Gallagher D, St-Onge MP, Albu J, Heymsfield SB, Heshka S. Visceral adipose tissue: relations between singleslice areas and total volume. Am J Clin Nutr 2004;80:271-8.

18. Shen W, Punyanitya M, Wang Z, Gallagher D, St-Onge MP, Albu J, Heymsfield SB, Heshka S. Total body skeletal muscle and adipose tissue volumes: estimation from a single abdominal cross-sectional image. J Appl Physiol 2004;97:2333-8.

19. Dello SA, Lodewick TM, van Dam RM, Reisinger KW, van den Broek MA, von Meyenfeldt MF, Bemelmans $\mathrm{MH}$, Olde Damink SW, Dejong $\mathrm{CH}$. Sarcopenia negatively affects preoperative total functional liver volume in patients undergoing liver resection. HPB (Oxford) 2013;15:165-9.

20. Martin L, Birdsell L, Macdonald N, Reiman T, Clandinin MT, McCargar LJ, Murphy R, Ghosh S, Sawyer MB, Baracos VE. Cancer cachexia in the age of obesity: skeletal muscle depletion is a powerful prognostic factor, independent of body mass index. J Clin Oncol 2013;31:1539-47.

21. Prado CM, Lieffers JR, McCargar LJ, Reiman T, Sawyer MB, Martin L, Baracos VE. Prevalence and clinical implications of sarcopenic obesity in patients with solid tumours of the respiratory and gastrointestinal tracts: a population-based study. Lancet Oncol 2008;9:629-35. 
22. Prado CM, Wells JC, Smith SR, Stephan BC, Siervo M. Sarcopenic obesity: A Critical appraisal of the current evidence. Clin Nutr 2012;31:583-601.

23. Horan TC, Gaynes RP, Martone WJ, Jarvis WR, Emori TG. CDC definitions of nosocomial surgical site infections, 1992: a modification of CDC definitions of surgical wound infections. Infect Control Hosp Epidemiol 1992;13:6068.

24. EUCAST Definitive Document E.DEF 2.1, August 2000: Determination of antimicrobial susceptibility test breakpoints. Clin Microbiol Infect 2000;6:570-2.

25. Munez E, Ramos A, Espejo TA, Vaque J, Sanchez-Paya J, Pastor V, Asensio A. Microbiology of surgical site infections in abdominal tract surgery patients. Cir Esp 2011.

26. Taylor RW, Gold E, Manning P, Goulding A. Gender differences in body fat content are present well before puberty. Int J Obes Relat Metab Disord 1997;21:1082-4.

27. Garnett SP, Hogler W, Blades B, Baur LA, Peat J, Lee J, Cowell CT. Relation between hormones and body composition, including bone, in prepubertal children. Am J Clin Nutr 2004;80:966-72.

28. Lieffers JR, Bathe OF, Fassbender K, Winget M, Baracos VE. Sarcopenia is associated with postoperative infection and delayed recovery from colorectal cancer resection surgery. Br J Cancer 2012;107:931-6.

29. von Haehling S, Morley JE, Anker SD. An overview of sarcopenia: facts and numbers on prevalence and clinical impact. Journal of cachexia, sarcopenia and muscle 2010;1:129-33.

30. Chapman IM. Obesity paradox during aging. Interdisciplinary topics in gerontology 2010;37:20-36.

31. Elia M, Ritz P, Stubbs RJ. Total energy expenditure in the elderly. Eur J Clin Nutr 2000;54 Suppl 3:S92-103.

32. Martone AM, Onder G, Vetrano DL, Ortolani E, Tosato M, Marzetti E, Landi F. Anorexia of aging: a modifiable risk factor for frailty. Nutrients 2013;5:4126-33.

33. Malafarina V, Uriz-Otano F, Iniesta R, Gil-Guerrero L. Sarcopenia in the elderly: diagnosis, physiopathology and treatment. Maturitas 2012;71:109-14.

34. Cesari M, Fielding RA, Pahor M, Goodpaster B, Hellerstein M, Van Kan GA, Anker SD, Rutkove S, Vrijbloed JW, Isaac M, Rolland Y, M'Rini C, Aubertin- 
Leheudre M, Cedarbaum JM, Zamboni M, Sieber CC, Laurent D, Evans WJ, Roubenoff R, Morley JE, Vellas B, International Working Group on S. Biomarkers of sarcopenia in clinical trials-recommendations from the International Working Group on Sarcopenia. Journal of cachexia, sarcopenia and muscle 2012;3:181-90.

35. Prado CM, Baracos VE, McCargar LJ, Mourtzakis M, Mulder KE, Reiman T, Butts CA, Scarfe AG, Sawyer MB. Body composition as an independent determinant of 5-fluorouracil-based chemotherapy toxicity. Clin Cancer Res 2007;13:3264-8.

36. Prado CM, Baracos VE, McCargar LJ, Reiman T, Mourtzakis M, Tonkin K, Mackey JR, Koski S, Pituskin E, Sawyer MB. Sarcopenia as a determinant of chemotherapy toxicity and time to tumor progression in metastatic breast cancer patients receiving capecitabine treatment. Clin Cancer Res 2009;15:2920-6.

37. Degrate L, Garancini M, Misani M, Poli S, Nobili C, Romano F, Giordano L, Motta V, Uggeri F. Right colon, left colon, and rectal surgeries are not similar for surgical site infection development. Analysis of 277 elective and urgent colorectal resections. Int J Colorectal Dis 2011;26:61-9.

38. Konishi T, Watanabe T, Kishimoto J, Nagawa H. Elective colon and rectal surgery differ in risk factors for wound infection: results of prospective surveillance. Ann Surg 2006;244:758-63.

39. Miki C, Inoue Y, Mohri Y, Kobayashi M, Kusunoki M. Site-specific patterns of surgical site infections and their early indicators after elective colorectal cancer surgery. Dis Colon Rectum 2006;49:S45-52.

40. Hughes S, Kelly P. Interactions of malnutrition and immune impairment, with specific reference to immunity against parasites. Parasite Immunol 2006;28:577-88. 


$$
=6
$$




\section{General discussion and summary - Introduction}

The treatment of nosocomial infections has been an increasing challenge worldwide. According to the literature, $10 \%-70 \%$ of nosocomial infections and $40 \%-60 \%$ of surgical site infections (SSIs) are preventable, depending on factors such as the study setting, study design, infection rates at baseline and type of infection [1-6]. Surveillance is an important instrument of an infection control program as the reporting of SSI rates to the surgeons reduces the rates significantly and contributes to an improvement of patient care $[2,7,8]$.

Several national and international surveillance systems have been set up to monitor and control SSIs [9-14]. The Centers for Disease Control and prevention (CDC) defines surveillance of nosocomial infections as "the on-going, systematic collection, analysis, and interpretation of health data essential to the planning, implementation, and evaluation of public health practice, closely integrated with the timely dissemination of these data to those who need to know" $[2,15,16]$. The aims of the CDC were to develop epidemiologically sound definitions, to stratify SSI rates according to risk factors associated with the development of SSI, and to provide feedback of data [7]. In the Netherlands, SSI surveillance was set up within the national PREZIES (Dutch acronym: PREventie van ZIEkenhuisinfecties door Surveillance) network in 1996 [17]. They also defined surveillance according to the original definition of the CDC. The goals of PREZIES were to enable voluntarily participating hospitals to obtain insight into nosocomial infection rates, to offer benchmarking to hospitals, and to provide a basic infrastructure for further intervention research [18].

For a surveillance system to be reliable and effective in reducing $\mathrm{SSI}$, it should meet the criteria, according to the Plan-Do-Study-Act cycle of the American Institute for health care Improvement $[19,20]$ : clear and standardised definitions, registration of clinical and laboratory data by trained and qualified infection control personnel, risk factor analysis, and feedback of data to the surgeon [2, 21, 22].

This thesis describes the evaluation of SSI surveillance in a Dutch hospital within two different patient populations, i.e., gastrointestinal (including the sarcopenic colorectal elderly patients) in chapters 2, 3 and $\mathbf{5}$ and vascular patient groups in chapter 4. Our surveillance was performed before and after implementation of the Dutch VMS (Dutch acronym: VeiligheidsManagementSysteem [23]) safety bundle. Trends in SSI were calculated and risk factors for developing SSIs in the patient populations were analysed. We showed the importance of postdischarge 
surveillance (PDS), until thirty days after surgery (without an implant), for reliable data. Furthermore, procedure-specific risk factors for SSI were observed in the different high-risk populations. However, evaluation of the VMS bundle by measuring the effect on the SSI rates showed no significant decrease in SSI over time.

\section{Surveillance of SSI}

Essential in the studies included in this thesis, was the prospective surveillance of SSI was performed by one trained independent infection control nurse. According to the literature the assessment by an independent qualified person is the most reliable method for surveillance of SSI to have a consistent interpretation of the criteria to diagnose an SSI $[22,24,25]$. Some studies have shown that lower SSI rates were found when the registration was only performed by the surgeons who are involved in the operation, compared to rates when registration was performed by an infection control nurse [25-30]. A study by Rosenthal et al. demonstrated an underreporting by the surgical staff of more than $50 \%$ of all SSIs during hospitalisation [27]. And a study by van Ramshorst et al. showed that more than $60 \%$ of all SSIs were underreported when registration of SSI was performed by surgeons [28]. On the other hand, others explained their high SSI rate by careful surveillance by a surgeon in the general surgery ward, compared to a patient's selfreport through the telephone [21].

We defined SSIs based on a standard set of clinical national criteria of the Dutch nosocomial infection surveillance network PREZIES (Dutch acronym: Preventie van Ziekenhuisinfecties door Surveillance) and international criteria of the Centers for Disease Control and prevention (CDC) [15, 17]. For our sarcopenic patient population in chapter $\mathbf{5}$ we assessed cut-off points to define sarcopenia, after correcting for gender differences and body compositions [31, 32].

The way surveillance is performed can be active or passive, previously mentioned in the introduction of this thesis [8]. During hospitalisation, our surveillance was active. All surgical sites were directly observed by the surgeon, and confirmed by the independent infection control nurse through review of laboratory reports, patient electronic records, and meetings with surgical personnel.

We also performed passive postdischarge surveillance (PDS), i.e., surveillance of SSI after the patient has been discharged from the hospital, until thirty days after surgery. Our overall SSI rate increased after the introduction of PDS, which 
increased the reliability of the study, as well as the reliable assessment of SSIs. Our data underline the importance of PDS to avoid underestimation of the actual SSI rate $[8,33]$. This is especially important since the current trends show a shortened postoperative hospital stay, more outpatient surgery, and same-day surgery [8, 3436]. A surveillance period of thirty days after surgery (or one year when an implant is left) is recommended by PREZIES and the $\operatorname{CDC}[15,17]$. The question remains whether a follow-up period of thirty days (without an implant is left) or one year (when an implant is left) is sufficient for reliable data. Studies have shown that the onset of SSIs can occur long after a patient has been discharged [37-39]. For instance, a deep prosthetic graft infection can become manifest months to years after the operation [40].

Finally, we categorized all infections into those that affect superficial tissues (skin and subcutaneous layer) of the incision and those that affect the deeper tissues (deep incisional or anatomical) [41]. This distinction is important because deep SSIs are more severe, often require intravenous antibiotic treatment, longer hospitalisation and wound dressing. Superficial SSIs can more often be treated locally and shorter courses of oral antibiotics are generally sufficient [42-44]. Furthermore, other microorganisms are found in superficial infections compared to deeper SSIs $[18,42]$. In our study, we stratified the infections according to the four different wound classes [15]. In chapter 2, we showed that in our gastrointestinal population $50 \%$ was superficial, $45 \%$ deep and $5 \%$ was an anatomical SSI. The superficial and deep SSIs developed largely after surgical procedures that were classified as clean-contaminated, most anatomical SSI after dirty procedures. In chapter 4 we determined that in the vascular population most SSIs were deep/anatomical SSIs (54\%) and most frequently developed after procedures classified as dirty (41\%). Most superficial SSIs (67\%) occurred after clean procedures. Ortega et al. [45] also stratified by wound class and found most superficial SSIs occurred after clean-contaminated procedures, most deep SSIs after clean procedures, and most of the organ/space SSIs also after clean-contaminated procedures.

Some authors state that the diagnosis of superficial SSI is subjective and inconsistent and are the cause of the wide range of reported SSI rate throughout the literature $[25,46,47]$. Therefore, others have suggested excluding superficial SSIs from reporting altogether, because data related to superficial SSIs would be subjective, inconsistent and therefore uncertain $[41,48]$. Yokoe et al. , who studied patients after, amongst others, coronary artery bypass graft procedures, 
questioned the lower sensitivity of superficial SSIs compared to the more complex SSIs [49]. Generally, the hospitalisation period of patients with superficial SSIs is brief, and they are readmitted less frequently compared to the patients with deep SSIs. The Efficiency of routine surveillance could therefore be limited. Instead, Kao et al. concluded that superficial SSIs after colon resections are a reliable indicator of hospital quality when the number of cases is acceptable [50]. However, it could be questioned if the reliability of the superficial SSI rate could become underestimated.

Our surveillance method has several limitations. First, our PDS method was passively performed instead of actively, meaning that the diagnosis of surgical wounds were based on laboratory results during follow-up visits at the outpatient clinic and electronic patient records by the infection control nurse. However, several studies have shown that not all patients visit the out-patient [51]. However, we chose this method because active PDS would have been more time-consuming and might have resulted in higher costs [52]. Other passive surveillance methods described in the literature are questionnaires sent to the patient or surgeon, or telephone interviews with patients by health care personnel. We did not choose for these methods, because not all questionnaires are returned, resulting in an underreporting of the SSI rate [51]. Also, due to time constraints, it might have been performed by others than our infection control nurse and thus have led to misclassification $[35,52]$. Additionally, it was shown that reporting by the surgeon is more efficient and reliable than reporting by the patient when using a questionnaire or a telephone interview by infection control personnel $[39,53,54]$. Second, for our risk analysis we did not differentiate between the three types of SSI separately. Similar to the methods used in several other studies of SSI, superficial, deep and anatomical SSI are combined together when analysing the risk factors [55-58]. In contrast, there are also studies that compared risk factors for the types of SSI. For instance, Lawson et al. found a variation in superficial and deep or anatomical risk factors for SSI [42]. Blumetti et al. found that Body Mass Index and creation of ostomy were associated with incisional SSI and that peri-operative transfusion and previous abdominal surgery were associated with anatomical SSI [59]. Ho et al. also found surgical outcomes and risks for SSI to be different by infection type [60].

In conclusion, the surveillance we performed has several strengths and limitations. The registration of SSI by one and the same experienced infection control nurse is an important strength. The inclusion of PDS is a strength, but as we used only a 
passive registration, this might be considered as a limitation. Also, the lack of compliance measurements with the VMS bundle is unfortunately a limitation.

\section{SSI rates during and after hospitalisation}

A reduction of SSI will result in significant advantages in terms of patient quality of life and reduced use of medical treatment. Therefore, we determined the SSI rates in different study populations during and after hospitalisation. For SSI rates to be reliable, a sufficient number of surgical procedures have to be evaluated [50]. With regard to our gastrointestinal patient population in chapter 2, 485 SSIs out of 2156 index operations (22.5\%) were diagnosed during the follow-up period of thirty days after surgery. In the literature, SSI rates between (including postdischarge surveillance) less than $1 \%$ and more than $40 \%$ are found. Narong et al. assessed an overall lower SSI rate of $5.8 \%$ in this patient group [61]. However, the authors did not include all infections; especially SSIs of patients who were discharged early and lost to follow-up were missed. Also, the National Nosocomial Infections Surveillance (NNIS) System reported lower rates after gastrointestinal surgery, i.e., between $0.67 \%$ and $11.3 \%$. Moro et al. [62] mentioned percentages up to $13.5 \%$. Although Suljagic et al. did not conduct postdischarge surveillance to detect SSIs, they reported a percentage of $44 \%$ after abdominal surgical procedures [63]. The variation in SSI rates depends on the surgical procedure, risk factors for SSIs, and surveillance. Several studies have identified different independent risk factors for developing SSI, including different patient characteristics and other health care associated risk factors [56, 64-70].

Using PDS, 36\% of all gastrointestinal SSIs were found after discharge, which was higher than the $14 \%$ as described by Medina et al. [71]. The difference might be explained by difference in (PDS) surveillance method. In their study, only patients were included who returned to their surgeon with a wound infection, assuming that if they did not come back the wound was healing. On the other hand, Tanner et al. found $41 \%$ of their total number of SSI after discharge. Although they also used a follow-up period of thirty days, they used an active method for the PDS surveillance, i.e., by telephone interviews and home visits [72].

Also for vascular surgery a great variation in the rates between studies of SSI has been found. In chapter 4 , our overall SSI rate was $8 \%$, which was similar to the 5$10 \%$ found by Bandyk et al. [56], but much lower than the $27 \%$ as described by Turtiainen et al. [73]. Their high rate can be explained by their diagnosis of SSI as an 
infection if there were signs of infection irrespective of the culture results. The NNIS System reported low rates between 0.9 and 4.3\% [10], Suljagic et al. found rates between $2.6 \%$ and $23.5 \%$ [63], and Moro et al. up to 5.4\% [62]. Regarding PDS, almost half of all our vascular SSIs were found after discharge, similar to the proportion found by other investigators [74]. Our infection rate was lower than the $61 \%$ by Mannien et al. [55]. However, they included different types of procedures and they used a longer follow-up period of 42 postoperative days.

In our sarcopenic elderly patients in chapter $\mathbf{5}$, we found an overall SSI rate of $23 \%$. The literature with regard to the association between sarcopenia and SSI is limited. However, the study by Lieffers et al. [31]. found the same percentage of SSI (23.7\%) as in our study.

Besides the surveillance methods used, other factors might explain the large variation in SSI rate. This may be accounted for by the experience of the surgeon in charge, type of hospital, i.e., types of surgical procedures and patient case-mix, the surveillance method used, and follow-up period [10, 75-79]. The variation in followup period between "only during hospitalisation" up to 90 days postoperatively or even longer has been described and makes the comparsion of the results even more difficult. As previously mentioned we followed our patients until thirty days after surgery, according to the criteria of the CDC. Whereas some studies only follow their patients during hospitalisation [80,81], others maintain longer followup periods of four to six weeks $[29,82,83]$, or up to ninety days postoperatively, also when no implant is left at the surgical site [37]. Occasionally, the follow-up period is not mentioned at all [84].

The skills of the surgeon in charge can also influence the risk of developing an SSI [70]. Wurtz et al. explained the increase in the overall SSI rates by the longer operating times and less technical skill among recently qualified surgeons [85]. Castro et al. showed a 4.5 times higher risk of SSI for surgeons who have less than 5 year experience, compared to surgeons with more than 10 year surgical experience [86]. The variation in SSI rates throughout the literature can further be explained by the type of hospital, the complexity of operation types or the patient case-mix with different risk factors. In this regard, it is known that post-operative complications are more often observed in major teaching hospitals compared to smaller district institutions [87, 88]. Patients with advanced stages of disease and multiple comorbid diagnoses are often referred to an academic hospital for further treatment [89]. Increased admissions of severely ill patients to our hospital over time may have occurred. Also, higher rates of health care-associated infections have been 
demonstrated in tertiary referral hospitals, such as academic hospitals, compared to primary or secondary health care centres [90].

In conclusion, several factors play a role in the variation between SSI rates in the literature compared to our results. Variations in method of registration, patient case-mix, experience of the surgeon in charge, type of operation, are among others relevant to explain the difference in SSI rates.

\section{Risk factors for SSI}

Risk factors for developing SSIs depend in part on the differences in patient case mix. Between hospitals, different surgical procedures are performed. Some are more complex or more urgent than the other. As patients carry different risks for developing surgical site infections, correcting for these differences is required to allow a reliable comparison between different surgical patient populations and hospitals [91-94].

This thesis discusses non-modifiable and modifiable risk factors, some are patientrelated, while others are surgery- or environment-related [95, 96]. We corrected for different risk factors or other potential factors for SSI in all patient groups, i.e., gender, age, wound classification, previous surgery and urgency of surgery, which are frequently found factors in the literature $[59,67,69,97]$.

In our gastrointestinal study population in chapter $\mathbf{2}$, older age and contaminated or dirty wounds were significant risk factors for developing an SSI. These risk factors were also found by others [66, 70, 97-99].

For our vascular population in chapter 4 , we additionally corrected for diabetes mellitus, total length of stay (LOS) and hospital stay before surgery [100-104]. The risk factor analysis was only performed for SSIs diagnosed during hospitalisation, because risk factors for postdischarge SSIs can differ from risk factors during hospitalisation as shown by Delgado-Rodriguez et al [105]. They found variables as emergency operation, duration of operation, type of surgical wound, wound drainage, need of admission to the intensive care, and administration of antibiotics according to written protocols associated with an increased in-hospital SSI risk. But none of the variables was associated with an increased risk of SSI after discharge. Significant risk factors for in-hospital SSI in our vascular study population were diabetes, operations classified as contaminated or dirty and an age over 60 years, similar to what other authors found [74, 100, 105-107]. 
For our sarcopenic patient group in chapter 5, we also corrected for BMI category, chemo- or radiotherapy, type of surgery (laparotomy or laparoscopy), and operation duration [108-111]. In patients with sarcopenia, the risk of SSIs can be explained by their comorbid conditions that keep the patient nutritionally impaired and/or immune-compromised. To find an association of sarcopenia and the development of SSIs, we standardized for length, degree of obesity, age, and gender effects in body composition. We found a higher risk of sarcopenia in patients 65 years of age or older. Although we showed a tendency towards a higher risk of SSI in sarcopenic patients, the association was not significant after correction for potential confounders. These results are in contrast to the study of Lieffers et al., describing a significant association between sarcopenia and postoperative infections [31]. Reasons for this can be different diagnostic methods, different methods of infection registration and/or different surveillance methods between both studies.

The risk factors we found in our patient populations were in part in accordance with those described in the literature [61, 64-66, 70, 107, 112-114]. However, a limitation of our risk factor analysis was the proportion of different procedures, with different risk factors, which might have influenced the trends of SSI rates. Furthermore, we were not able to gather data on The American Society of Anaesthesiologists (ASA) class and length of operation as risk factors for SSI for the risk analysis. Instead, we used the older wound classification system, i.e., clean, clean-contaminated, contaminated or dirty wound class, according to the CDC [15], because it also predicts the risk of SSIs based on the estimation of bacterial load in proximity to the wound area at the time of the operation.

\section{The VMS safety bundle}

Many interventions to prevent health care-associated infections that were implemented as a bundle have been shown to reduce infection rates [115-124]. The Dutch VMS safety bundle has been implemented at the surgical department of our hospital. In chapters $\mathbf{2}$ and $\mathbf{4}$, no decrease in SSIs was determined after the implementation. Similar observations were found by others monitoring their SSI rates [125-130]. On the other hand, Crolla et al. implemented a similar safety bundle and observed compliance rates above $60 \%$ with a zero-tolerance approach and a significant reduction of the SSI rate by $36 \%$ [131]. Hedrick et al. demonstrated a reduction of post-operative morbidity in patients undergoing 
colorectal operations after implementation of an active surveillance system and a multidisciplinary wound-management protocol [132].

To demonstrate and up-ward step change of compliance, regularly repeated measurements of compliance would have been required. We did not observe the compliance with the VMS safety bundle on a frequent basis. Although overall compliance with the entire bundle was measured as being above $80 \%$ (data not shown), overall compliance never reached $100 \%$ during the study period. Studies have shown that compliance with infection preventive measures reduces infection rates [133]. This was also observed by Van der Slegt et al., who showed that the implementation of a bundle of care was associated with improved compliance over time and a $51 \%$ reduction of the SSI-rate in vascular procedures [134]. Their findings were based on the measurements of bundle adherence every three months. Also, the results of the compliance with the bundle were communicated to all surgical personnel every three months.

Additionally, a too short evaluation period of one year of the measures might be reasons for our non-decreasing SSI rate. Furthermore, gradual change in patientmix, lack of awareness or knowledge of the bundle by health care personnel can account for an insufficient implementation. To increase knowledge and responsibility regarding the safety bundle, communication, understanding and collaboration between researchers and health care personnel is crucial [135]. It has also been described that the bundle is not tailored well enough to the needs and working strategies of the health care personnel and setting [136].

Thus, due to several factors, our implementation of the VMS bundle has several limitations. Inadequate frequency of compliance measurement with the bundle, a too short evaluation period, and no differentiation between the different surgical procedures, are by far the most important ones. As a result, the information for optimal feedback was incomplete.

\section{Microbiology of SSI}

It has been demonstrated that the involvement of the microbiology laboratory can be useful to control the incidence of SSI, to guide prescription of antibiotics and to limit the spread of antibiotic resistant pathogens [137-140]. Therefore, we included the results of wound and blood samples during our surveillance in chapters $\mathbf{3 , 4}$ and 5 [139]. In our gastrointestinal patient population, culture results of wound swabs taken in the first forty-eight hours after the surgical procedure, were 
compared with the culture results of the wound swabs taken within thirty days after surgery. This allowed us to observe which changes in antibiotic susceptibility during hospitalisation occurred. By examining the culture results in the first fortyeight hours, we were able to determine the antibiotic resistance of the empiric antibiotic treatment at time of surgery. We only reported results from wound samples, since blood samples do not add relevant information in this regard [141]. The number of (positive) blood samples ( $n=15$ ) was low [142]. In $62 \%$ of the cases, the blood samples were negative whereas the wound swabs yielded a positive result.

During hospitalisation, antibiotics are often part of the treatment, and can be used both for prophylaxis and therapy. As antibiotic use is the main risk factor for antibiotic resistance, it is to be expected that an increases in resistance will be observed [143-149]. However, no significant increase in resistance to the antibiotics tested was found for the most frequently isolated microorganisms, i.e., Escherichia coli, Pseudomonas aeruginosa and Staphylococcus aureus, in our gastrointestinal and vascular patient population. With regard to the microbial spectrum of our colorectal sarcopenic study population, Escherichia coli was the most frequently isolated microorganism from SSIs in both sarcopenic and nonsarcopenic patients. The National Health care Safety Network (NHSN) and others found similar microorganisms associated with SSI cases after these types of surgery [137, 150, 151].

Differences in pathogens and antibiotic resistance patterns can be explained by several factors. Although some studies diagnosed an SSI only when the bacteriological culture of the wound was positive [152], our SSI diagnosis was based on the CDC criteria, also when the culture was negative [15]. Furthermore, all our microbiological analyses were performed in one laboratory. This is in contrast to other studies, where the antimicrobial susceptibility testing was performed by different laboratories collaborating with the hospital and not by a central laboratory [150]. Therefore, variation due to methodological differences in our study can be excluded.

To conclude, the distribution of the microorganisms isolated from SSIs can vary between different patient populations, as shown in chapters $\mathbf{3 , 4}$ and $\mathbf{5}$. Collaboration with clinical laboratory staff is crucial to gather information about the isolated pathogens and antibiotic resistance patterns. This may guide the treatment for a surgical patient, in order to prevent SSI and the occurrence of resistant pathogens. 


\section{Future directions}

The prevention of surgical site infections is important for health care services, and more importantly for the patient. Methods of infection registration are therefore crucial to be evaluated. Fortunately, a significant number of SSIs is preventable. The Dutch VMS safety bundle has been implemented in our hospital with the aim to reduce SSIs, based on consistent and evidence-based measures of the bundle. For a bundle of infection preventive measures to be a useful tool for a safer operating environment, several aspects should be kept in mind and determined in order to analyse and disseminate surveillance results: the aetiology and severity of infections, high-risk populations and surgical procedures, goals of the surveillance system, standard definitions, the registration period, and appropriate personnel and tools for data collection.

Although this thesis demonstrated the importance of SSI surveillance (active and passive, during and after hospitalisation), we were not able to find a significant decrease of our SSI rate after the implementation of the VMS bundle. As discussed earlier, during the study period we have dealt with several implementation issues. In future studies, these issues should be evaluated according to the PDSA-cycle, i.e., a step-wise approach to successfully implement an intervention. Next, surveillance should be carried out according to the guidelines and all surgical staff should be involved by providing feedback of the results.

Feedback of infection rates to the involved health care professionals is highly important, because behaviour at the operating theatre is a risk factor for developing SSIs [153-155]. As already mentioned, studies have shown that compliance with infection preventive measures is not always optimal and needs to be improved in the future $[156,157]$. We believe that feedback may substantially affect behaviour and enables personnel to comply with the guidelines. A tool to change behaviour is education provided to the clinical team on the one hand, and the infection control team on the other. Teamwork and continuous verbal and electronic communication are critical for effective clinical care. The compliance with the bundle measures should intermittently be monitored. Unfortunately, we were unable to find an increase in compliance rate in our studies. Furthermore, to compare SSI results between reported studies, it should be ensured that the same and concise definitions have been used and the same guidelines have been followed, with regard to the diagnosis of SSIs. But also the patient population or medical condition is important. For sarcopenic patients, there is still no consensus 
about the skeletal muscle cut-off points, at which the condition is diagnosed. Therefore, we decided to calculate our own cut-off points for this particular colorectal population. However, these values cannot be used as a gold standard. Therefore, more research should be performed to diagnose sarcopenia in the aging population with different medical backgrounds. The results of studies to sarcopenia should provide further information for treatment options in order to reach the desired goals in this patient population.

Besides unambiguous definitions, the addition of microbiological analysis is also important, because the occurrence of resistant bacteria is increasing, among others by the prolonged and wide-spread use of antimicrobial prophylaxis and broadspectrum antibiotics [158]. As our sample size of the wound cultures was small, larger sample sizes should be included in the overall surveillance method. It is of great importance to identify the causative pathogens to discuss the type of surgical antimicrobial prophylaxis and to better handle therapeutic implications. To achieve this, clinical departments must implement adequate procedures for the collection and transport of samples to the laboratory and collaboration between the infection control team, the surgical team and the microbiologists should be optimal for analysis and feedback of surveillance data.

Finally, we have shown that variation in case mix, underlying disease and severity of illness at participating hospitals should be controlled for statistical analysis. Within our study populations significant risks for developing SSIs were found due to the long duration of the surgical procedure, different types of wounds and SSIs, and complex diseases, as also found by other others. Additionally, we are an academic hospital and we were more confronted with referral patients and medical backgrounds, compared to smaller district hospitals. Throughout the literature, many risk factors for SSIs have been identified that can be used individually or in combination as scoring indices. As it is already mentioned that several studies still show that an optimal risk score for all surgical procedures is difficult to quantify, more research should be performed to identify risk factors for SSI in different patient groups with different medical conditions.

To conclude, this manuscript describes elements for an accurate infection registration method. SSIs acquired after surgery may be serious and, in some cases, life threatening. These may result in higher morbidity and adversely affect recovery. Infections may be caused by organisms resistant to antibiotics. It is therefore important that clear information on the standards of infection prevention and control in hospitals is combined and easily available to allow 
adequate surveillance and to improve the quality of care. For the prevention and control of SSI, and a successful implementation of a safety bundle, a multidisciplinary approach is crucial. Activities based on infection prevention protocols should be imbedded in every day practices and adhered to by all health care workers. Through feedback they have to be made aware of the consequences for the patient when guidelines are not recognised and followed accurately. Besides the availability of tools, education, communication and support, leadership and active involvement are important aspects. We believe that the first steps in SSI prevention are the willingness, collaboration, and efforts to improve compliance with infection preventive measures. After all: an ounce of prevention is worth a pound of care! 


\section{References}

1. Harbarth S, Sax H, Gastmeier P. The preventable proportion of nosocomial infections: an overview of published reports. J Hosp Infect, 54(4), 258-266; quiz 321 (2003).

2. Haley RW, Culver DH, White JW et al. The efficacy of infection surveillance and control programs in preventing nosocomial infections in US hospitals. Am J Epidemiol, 121(2), 182-205 (1985).

3. McConkey SJ, L'Ecuyer PB, Murphy DM, Leet TL, Sundt TM, Fraser VJ. Results of a comprehensive infection control program for reducing surgical-site infections in coronary artery bypass surgery: further data from the authors. Infect Control Hosp Epidemiol, 20(12), 791-792 (1999).

4. Hacek DM, Suriano T, Noskin GA, Kruszynski J, Reisberg B, Peterson LR. Medical and economic benefit of a comprehensive infection control program that includes routine determination of microbial clonality. Am J Clin Pathol, 111(5), 647-654 (1999).

5. Yoo S, Ha M, Choi D, Pai H. Effectiveness of surveillance of central catheter-related bloodstream infection in an ICU in Korea. Infect Control Hosp Epidemiol, 22(7), 433-436 (2001).

6. Bandi S, Conway A. Question 2. Does regular cleaning of stethoscopes result in a reduction in nosocomial infections? Arch Dis Child, 97(2), 175177 (2012).

7. Consensus paper on the surveillance of surgical wound infections. The Society for Hospital Epidemiology of America; The Association for Practitioners in Infection Control; The Centers for Disease Control; The Surgical Infection Society. Infect Control Hosp Epidemiol, 13(10), 599-605 (1992).

8. Mangram AJ, Horan TC, Pearson ML, Silver LC, Jarvis WR. Guideline for prevention of surgical site infection, 1999. Hospital Infection Control Practices Advisory Committee. Infect Control Hosp Epidemiol, 20(4), 250 278; quiz 279-280 (1999).

9. Moro ML, Sommella L, Gialli $\mathrm{M}$ et al. Surgical infections surveillance: results of a six-month incidence study in two Italian hospitals. European journal of epidemiology, 7(6), 641-648 (1991).

10. National Nosocomial Infections Surveillance S. National Nosocomial Infections Surveillance (NNIS) System Report, data summary from January 
1992 through June 2004, issued October 2004. Am J Infect Control, 32(8), 470-485 (2004).

11. Ronveaux O, Mertens R, Dupont Y. Surgical wound infection surveillance: results from the Belgian hospital network. Acta Chir Belg, 96(1), 3-10 (1996).

12. Mertens R, Van den Berg JM, Veerman-Brenzikofer ML, Kurz X, Jans B, Klazinga N. International comparison of results of infection surveillance: The Netherlands versus Belgium. Infect Control Hosp Epidemiol, 15(9), 574-578 (1994).

13. Severijnen AJ, Verbrugh HA, Mintjes-de Groot AJ, Vandenbroucke-Grauls $\mathrm{CM}$, van Pelt $\mathrm{W}$. Sentinel system for nosocomial infections in The Netherlands: a pilot study. Infect Control Hosp Epidemiol, 18(12), 818-824 (1997).

14. Simchen E, Wax Y, Pevsner B et al. The Israeli Study of Surgical Infections (ISSI): I. Methods for developing a standardized surveillance system for a multicenter study of surgical infections. Infect Control Hosp Epidemiol, 9(6), 232-240 (1988).

15. Horan TC, Gaynes RP, Martone WJ, Jarvis WR, Emori TG. CDC definitions of nosocomial surgical site infections, 1992: a modification of CDC definitions of surgical wound infections. Infect Control Hosp Epidemiol, 13(10), 606608 (1992).

16. Garner JS, Jarvis WR, Emori TG, Horan TC, Hughes JM. CDC definitions for nosocomial infections, 1988. Am J Infect Control, 16(3), 128-140 (1988).

17. PREZIES. [PREventie ZIEkenhuisinfecties door Surveillance. Bilthoven: PREZIES; 2012]. Available at http://www.prezies.nl.

18. Geubbels EL, Mintjes-de Groot AJ, van den Berg JM, de Boer AS. An operating surveillance system of surgical-site infections in The Netherlands: results of the PREZIES national surveillance network. Preventie van Ziekenhuisinfecties door Surveillance. Infect Control Hosp Epidemiol, 21(5), 311-318 (2000).

19. American Institute for Health care Improvement. PDSA-cycle. Available at http://www.ihi.org.IHI/Topics/Improvement/ImprovementMethods/HowT olmprove/testingchanges.htm.

20. Wille J, Kluytmans J, Vos G, van den Broek PJ. [Interventiebundel wondinfecties hoopgevend, maar te weinig nageleefd. Infectiepreventie vergt meer inzet]. Medisch Contact 76 nr. 38: 2103-2105. 2012 ). 
21. Prospero E, Cavicchi A, Bacelli S, Barbadoro P, Tantucci L, D'Errico MM. Surveillance for surgical site infection after hospital discharge: a surgical procedure-specific perspective. Infect Control Hosp Epidemiol, 27(12), 1313-1317 (2006).

22. Platt R, Yokoe DS, Sands KE. Automated methods for surveillance of surgical site infections. Emerg Infect Dis, 7(2), 212-216 (2001).

23. VMS. Veiligheids Management Systeem (VMS). Voorkomen van wondinfecties na een operatie. Available at http://www.vmszorg.nl/Themas/POWI.

24. Donker JM, Kluytmans JA, Veen EJ, Ho GH, Hendriks YJ, van der Laan L. The registration of surgical site infections: a comparison of two different methods in vascular surgery. Surg Infect (Larchmt), 14(4), 397-400 (2013).

25. Petherick ES, Dalton JE, Moore PJ, Cullum N. Methods for identifying surgical wound infection after discharge from hospital: a systematic review. BMC Infect Dis, 6, 170 (2006).

26. Poulsen KB, Meyer $M$. Infection registration underestimates the risk of surgical wound infections. J Hosp Infect, 33(3), 207-215 (1996).

27. Rosenthal R, Weber WP, Marti WR et al. Surveillance of surgical site infections by surgeons: biased underreporting or useful epidemiological data? J Hosp Infect, 75(3), 178-182 (2010).

28. van Ramshorst GH, Vos MC, den Hartog D et al. A comparative assessment of surgeons' tracking methods for surgical site infections. Surg Infect (Larchmt), 14(2), 181-187 (2013).

29. Whitby M, McLaws ML, Collopy B et al. Post-discharge surveillance: can patients reliably diagnose surgical wound infections? J Hosp Infect, 52(3), 155-160 (2002).

30. Bilimoria KY, Kmiecik TE, DaRosa DA et al. Development of an online morbidity, mortality, and near-miss reporting system to identify patterns of adverse events in surgical patients. Arch Surg, 144(4), 305-311; discussion 311 (2009).

31. Lieffers JR, Bathe OF, Fassbender K, Winget M, Baracos VE. Sarcopenia is associated with postoperative infection and delayed recovery from colorectal cancer resection surgery. Br J Cancer, 107(6), 931-936 (2012).

32. Cruz-Jentoft AJ, Baeyens JP, Bauer JM et al. Sarcopenia: European consensus on definition and diagnosis: Report of the European Working 
Group on Sarcopenia in Older People. Age and ageing, 39(4), 412-423 (2010).

33. Visser A, Ubbink DT, Gouma DJ, Goslings JC. Surgeons are overlooking post-discharge complications: a prospective cohort study. World J Surg, 38(5), 1019-1025 (2014).

34. Perencevich EN, Sands KE, Cosgrove SE, Guadagnoli E, Meara E, Platt R. Health and economic impact of surgical site infections diagnosed after hospital discharge. Emerg Infect Dis, 9(2), 196-203 (2003).

35. Sands K, Vineyard G, Platt R. Surgical site infections occurring after hospital discharge. J Infect Dis, 173(4), 963-970 (1996).

36. Kent $\mathrm{P}$, McDonald M, Harris O, Mason T, Spelman D. Post-discharge surgical wound infection surveillance in a provincial hospital: follow-up rates, validity of data and review of the literature. ANZ J Surg, 71(10), 583589 (2001).

37. Jonkers D, Elenbaas T, Terporten P, Nieman F, Stobberingh E. Prevalence of 90-days postoperative wound infections after cardiac surgery. Eur J Cardiothorac Surg, 23(1), 97-102 (2003).

38. Mannien J, Wille JC, Snoeren RL, van den Hof S. Impact of postdischarge surveillance on surgical site infection rates for several surgical procedures: results from the nosocomial surveillance network in The Netherlands. Infect Control Hosp Epidemiol, 27(8), 809-816 (2006).

39. Huenger F, Schmachtenberg A, Haefner $H$ et al. Evaluation of postdischarge surveillance of surgical site infections after total hip and knee arthroplasty. Am J Infect Control, 33(8), 455-462 (2005).

40. Vogel TR, Symons R, Flum DR. The incidence and factors associated with graft infection after aortic aneurysm repair. J Vasc Surg, 47(2), 264-269 (2008).

41. Ming DY, Chen LF, Miller BA, Anderson DJ. The impact of depth of infection and postdischarge surveillance on rate of surgical-site infections in a network of community hospitals. Infect Control Hosp Epidemiol, 33(3), 276-282 (2012).

42. Lawson EH, Hall BL, Ko CY. Risk factors for superficial vs deep/organ-space surgical site infections: implications for quality improvement initiatives. JAMA surgery, 148(9), 849-858 (2013).

43. Knapp AG, Kamepalli RK, Martone WJ, Yankelev S. Prospective, noncomparative study of daptomycin for the treatment of superficial and 
deep incisional surgical site infections. Surg Infect (Larchmt), 12(2), 113118 (2011).

44. Ali SA, Tahir SM, Memon AS, Shaikh NA. Pattern of pathogens and their sensitivity isolated from superficial surgical site infections in a tertiary care hospital. J Ayub Med Coll Abbottabad, 21(2), 80-82 (2009).

45. Ortega G, Rhee DS, Papandria DJ et al. An evaluation of surgical site infections by wound classification system using the ACS-NSQIP. J Surg Res, 174(1), 33-38 (2012).

46. Haut ER, Pronovost PJ. Surveillance bias in outcomes reporting. JAMA, 305(23), 2462-2463 (2011).

47. Anderson DJ, Chen LF, Sexton DJ, Kaye KS. Complex surgical site infections and the devilish details of risk adjustment: important implications for public reporting. Infect Control Hosp Epidemiol, 29(10), 941-946 (2008).

48. Mannien J, van den Hof S, Brandt C, Behnke M, Wille JC, Gastmeier P. Comparison of the National Surgical Site Infection surveillance data between The Netherlands and Germany: PREZIES versus KISS. J Hosp Infect, 66(3), 224-231 (2007).

49. Yokoe DS, Noskin GA, Cunnigham SM et al. Enhanced identification of postoperative infections among inpatients. Emerg Infect Dis, 10(11), 19241930 (2004).

50. Kao LS, Ghaferi AA, Ko CY, Dimick JB. Reliability of superficial surgical site infections as a hospital quality measure. J Am Coll Surg, 213(2), 231-235 (2011).

51. Seaman M, Lammers R. Inability of patients to self-diagnose wound infections. J Emerg Med, 9(4), 215-219 (1991).

52. Heipel D, Ober JF, Edmond MB, Bearman GM. Surgical site infection surveillance for neurosurgical procedures: a comparison of passive surveillance by surgeons to active surveillance by infection control professionals. Am J Infect Control, 35(3), 200-202 (2007).

53. Fanning $\mathrm{C}$, Johnston $\mathrm{BL}$, MacDonald S, LeFort-Jost S, Dockerty $\mathrm{E}$. Postdischarge surgical site infection surveillance. The Canadian journal of infection control : the official journal of the Community \& Hospital Infection Control Association-Canada = Revue canadienne de prevention des infections / Association pour la prevention des infections a l'ho, 10(3), 75-79 (1995). 
54. Taylor G, McKenzie M, Kirkland T, Wiens R. Effect of surgeon's diagnosis on surgical wound infection rates. Am J Infect Control, 18(5), 295-299 (1990).

55. Mannien J, Wille JC, Kloek JJ, van Benthem BH. Surveillance and epidemiology of surgical site infections after cardiothoracic surgery in The Netherlands, 2002-2007. J Thorac Cardiovasc Surg, 141(4), 899-904 (2011).

56. Bandyk DF. Vascular surgical site infection: risk factors and preventive measures. Semin Vasc Surg, 21(3), 119-123 (2008).

57. Gailiene G, Gierasimovic Z, Petruseviciene D, Macijauskiene A. The prevalence of health care-associated infections and risk factors in a university hospital. Medicina, 48(8), 399-403 (2012).

58. Gaynes RP, Culver DH, Horan TC, Edwards JR, Richards C, Tolson JS. Surgical site infection (SSI) rates in the United States, 1992-1998: the National Nosocomial Infections Surveillance System basic SSI risk index. Clin Infect Dis, 33 Suppl 2, S69-77 (2001).

59. Blumetti J, Luu M, Sarosi G et al. Surgical site infections after colorectal surgery: do risk factors vary depending on the type of infection considered? Surgery, 142(5), 704-711 (2007).

60. Ho VP, Stein SL, Trencheva $\mathrm{K}$ et al. Differing risk factors for incisional and organ/space surgical site infections following abdominal colorectal surgery. Dis Colon Rectum, 54(7), 818-825 (2011).

61. Narong MN, Thongpiyapoom S, Thaikul N, Jamulitrat S, Kasatpibal N. Surgical site infections in patients undergoing major operations in a university hospital: using standardized infection ratio as a benchmarking tool. Am J Infect Control, 31(5), 274-279 (2003).

62. Moro ML, Morsillo F, Tangenti M et al. Rates of surgical-site infection: an international comparison. Infect Control Hosp Epidemiol, 26(5), 442-448 (2005).

63. Suljagic V, Jevtic M, Djordjevic B, Jovelic A. Surgical site infections in a tertiary health care center: prospective cohort study. Surg Today, 40(8), 763-771 (2010).

64. Sehgal R, Berg A, Figueroa R et al. Risk factors for surgical site infections after colorectal resection in diabetic patients. J Am Coll Surg, 212(1), 29-34 (2011).

65. Moucha CS, Clyburn TA, Evans RP, Prokuski L. Modifiable risk factors for surgical site infection. Instr Course Lect, 60, 557-564 (2011). 
66. Imai E, Ueda M, Kanao K et al. Surgical site infection risk factors identified by multivariate analysis for patient undergoing laparoscopic, open colon, and gastric surgery. Am J Infect Control, 36(10), 727-731 (2008).

67. Haridas $M$, Malangoni MA. Predictive factors for surgical site infection in general surgery. Surgery, 144 (4), 496-501; discussion 501-493 (2008).

68. Dominioni L, Imperatori A, Rotolo N, Rovera F. Risk factors for surgical infections. Surg Infect (Larchmt), 7 Suppl 2, S9-12 (2006).

69. Cheadle WG. Risk factors for surgical site infection. Surg Infect (Larchmt), 7 Suppl 1, S7-11 (2006).

70. Tang $\mathrm{R}$, Chen $\mathrm{HH}$, Wang $\mathrm{YL}$ et al. Risk factors for surgical site infection after elective resection of the colon and rectum: a single-center prospective study of 2, 809 consecutive patients. Ann Surg, 234(2), 181-189 (2001).

71. Medina-Cuadros M, Sillero-Arenas M, Martinez-Gallego G, DelgadoRodriguez M. Surgical wound infections diagnosed after discharge from hospital: epidemiologic differences with in-hospital infections. Am J Infect Control, 24(6), 421-428 (1996).

72. Tanner J, Khan D, Aplin C, Ball J, Thomas M, Bankart J. Post-discharge surveillance to identify colorectal surgical site infection rates and related costs. J Hosp Infect, 72(3), 243-250 (2009).

73. Turtiainen J, Saimanen E, Partio $T$ et al. Surgical wound infections after vascular surgery: prospective multicenter observational study. Scand J Surg, 99(3), 167-172 (2010).

74. Wojkowska-Mach J, Bulanda M, Cencora A et al. [Surgical site infections following vascular surgery]. Przeglad epidemiologiczny, 61(4), 683-691 (2007).

75. O'Neill E, Humphreys $H$. Use of surveillance data for prevention of health care-associated infection: risk adjustment and reporting dilemmas. Curr Opin Infect Dis, 22(4), 359-363 (2009).

76. Mannien J, van den Hof S, Muilwijk J, van den Broek PJ, van Benthem B, Wille JC. Trends in the incidence of surgical site infection in the Netherlands. Infect Control Hosp Epidemiol, 29(12), 1132-1138 (2008).

77. van Dishoeck $A M$, Koek $M B$, Steyerberg $E W$, van Benthem $B H$, Vos $M C$, Lingsma HF. Use of surgical-site infection rates to rank hospital performance across several types of surgery. Br J Surg, 100(5), 628-636; discussion 637 (2013). 
78. Lilani SP, Jangale N, Chowdhary A, Daver GB. Surgical site infection in clean and clean-contaminated cases. Indian J Med Microbiol, 23(4), 249-252 (2005).

79. Barie PS, Eachempati SR. Surgical site infections. Surg Clin North Am, 85(6), 1115-1135, viii-ix (2005).

80. Sisto T, Laurikka J, Tarkka MR. Ceftriaxone vs cefuroxime for infection prophylaxis in coronary bypass surgery. Scandinavian journal of thoracic and cardiovascular surgery, 28(3-4), 143-148 (1994).

81. Kollef MH, Sharpless L, Vlasnik J, Pasque C, Murphy D, Fraser VJ. The impact of nosocomial infections on patient outcomes following cardiac surgery. Chest, 112(3), 666-675 (1997).

82. Stockley JM, Allen RM, Thomlinson DF, Constantine CE. A district general hospital's method of post-operative infection surveillance including postdischarge follow-up, developed over a five-year period. J Hosp Infect, 49(1), 48-54 (2001).

83. Holtz TH, Wenzel RP. Postdischarge surveillance for nosocomial wound infection: a brief review and commentary. Am J Infect Control, 20(4), 206213 (1992).

84. Bruce J, Russell EM, Mollison J, Krukowski ZH. The measurement and monitoring of surgical adverse events. Health Technol Assess, 5(22), 1-194 (2001).

85. Wurtz R, Wittrock B, Lavin MA, Zawacki A. Do new surgeons have higher surgical-site infection rates? Infect Control Hosp Epidemiol, 22(6), 375-377 (2001).

86. Castro Pde T, Carvalho AL, Peres SV, Foschini MM, Passos AD. Surgical-site infection risk in oncologic digestive surgery. Braz J Infect Dis, 15(2), 109115 (2011).

87. Vogel TR, Dombrovskiy VY, Carson JL, Haser PB, Lowry SF, Graham AM. Infectious complications after elective vascular surgical procedures. J Vasc Surg, 51(1), 122-129; discussion 129-130 (2010).

88. Heisler CA, Melton LJ, 3rd, Weaver AL, Gebhart JB. Complication rates between local and referral patients undergoing vaginal hysterectomy at an academic medical center. Mayo Clin Proc, 85(2), 145-149 (2010).

89. Weiss CA, 3rd, Statz CL, Dahms RA, Remucal MJ, Dunn DL, Beilman GJ. Six years of surgical wound infection surveillance at a tertiary care center: 
review of the microbiologic and epidemiological aspects of 20, 007 wounds. Arch Surg, 134(10), 1041-1048 (1999).

90. Donker T, Wallinga J, Grundmann H. Patient referral patterns and the spread of hospital-acquired infections through national health care networks. PLoS Comput Biol, 6(3), e1000715 (2010).

91. Brandt C, Hansen S, Sohr D, Daschner F, Ruden H, Gastmeier P. Finding a method for optimizing risk adjustment when comparing surgical-site infection rates. Infect Control Hosp Epidemiol, 25(4), 313-318 (2004).

92. Anderson DJ, Kaye KS, Classen D et al. Strategies to prevent surgical site infections in acute care hospitals. Infect Control Hosp Epidemiol, 29 Suppl 1, S51-61 (2008).

93. Mu Y, Edwards JR, Horan TC, Berrios-Torres SI, Fridkin SK. Improving riskadjusted measures of surgical site infection for the national health care safety network. Infect Control Hosp Epidemiol, 32(10), 970-986 (2011).

94. Cohen ME, Ko CY, Bilimoria KY et al. Optimizing ACS NSQIP modeling for evaluation of surgical quality and risk: patient risk adjustment, procedure mix adjustment, shrinkage adjustment, and surgical focus. J Am Coll Surg, 217(2), 336-346 e331 (2013).

95. Kirchhoff $P$, Clavien PA, Hahnloser D. Complications in colorectal surgery: risk factors and preventive strategies. Patient Saf Surg, 4(1), 5 (2010).

96. Korol E, Johnston K, Waser N et al. A Systematic Review of Risk Factors Associated with Surgical Site Infections among Surgical Patients. PLoS One, 8(12), e83743 (2013).

97. Hubner M, Diana M, Zanetti G, Eisenring MC, Demartines N, Troillet N. Surgical Site Infections in Colon Surgery: The Patient, the Procedure, the Hospital, and the Surgeon. Arch Surg, (2011).

98. Raka L, Krasniqi A, Hoxha F et al. Surgical site infections in an abdominal surgical ward at Kosovo Teaching Hospital. World hospitals and health services : the official journal of the International Hospital Federation, 44(2), 32-36 (2008).

99. Kirchhoff $P$, Dincler $S$, Buchmann P. A multivariate analysis of potential risk factors for intra- and postoperative complications in 1316 elective laparoscopic colorectal procedures. Ann Surg, 248(2), 259-265 (2008).

100.Boltz MM, Hollenbeak CS, Julian KG, Ortenzi G, Dillon PW. Hospital costs associated with surgical site infections in general and vascular surgery patients. Surgery, (2011). 
101.Leung Wai Sang S, Chaturvedi R, Alam A, Samoukovic G, de Varennes B, Lachapelle K. Preoperative hospital length of stay as a modifiable risk factor for mediastinitis after cardiac surgery. J Cardiothorac Surg, 8, 45 (2013).

102. Neumayer L, Hosokawa P, Itani K, El-Tamer M, Henderson WG, Khuri SF. Multivariable predictors of postoperative surgical site infection after general and vascular surgery: results from the patient safety in surgery study. J Am Coll Surg, 204(6), 1178-1187 (2007).

103. Ata A, Lee J, Bestle SL, Desemone J, Stain SC. Postoperative hyperglycemia and surgical site infection in general surgery patients. Arch Surg, 145(9), 858-864 (2010).

104.Ata A, Valerian BT, Lee EC, Bestle SL, Elmendorf SL, Stain SC. The effect of diabetes mellitus on surgical site infections after colorectal and noncolorectal general surgical operations. Am Surg, 76(7), 697-702 (2010).

105.Delgado-Rodriguez M, Gomez-Ortega A, Sillero-Arenas M, Llorca J. Epidemiology of surgical-site infections diagnosed after hospital discharge: a prospective cohort study. Infect Control Hosp Epidemiol, 22(1), 24-30 (2001).

106.Grinbaum RS, de Mendonca JS, Cardo DM. An outbreak of handscrubbingrelated surgical site infections in vascular surgical procedures. Infect Control Hosp Epidemiol, 16(4), 198-202 (1995).

107. Richet HM, Chidiac C, Prat A et al. Analysis of risk factors for surgical wound infections following vascular surgery. Am J Med, 91(3B), 170S-172S (1991).

108. Turrentine FE, Wang H, Simpson VB, Jones RS. Surgical risk factors, morbidity, and mortality in elderly patients. J Am Coll Surg, 203(6), 865877 (2006).

109. Landi F, Liperoti R, Fusco D et al. Prevalence and risk factors of sarcopenia among nursing home older residents. J Gerontol A Biol Sci Med Sci, 67(1), 48-55 (2012).

110.Yu R, Wong M, Leung J, Lee J, Auyeung TW, Woo J. Incidence, reversibility, risk factors and the protective effect of high body mass index against sarcopenia in community-dwelling older Chinese adults. Geriatr Gerontol Int, 14 Suppl 1, 15-28 (2014).

111.Yip C, Goh V, Davies A et al. Assessment of sarcopenia and changes in body composition after neoadjuvant chemotherapy and associations with 
clinical outcomes in oesophageal cancer. Eur Radiol, 24(5), 998-1005 (2014).

112.Ariyaratnam $P$, Bland $M$, Loubani M. Risk factors and mortality associated with deep sternal wound infections following coronary bypass surgery with or without concomitant procedures in a UK population: a basis for a new risk model? Interact Cardiovasc Thorac Surg, 11(5), 543-546 (2010).

113. Degrate L, Garancini M, Misani M et al. Right colon, left colon, and rectal surgeries are not similar for surgical site infection development. Analysis of 277 elective and urgent colorectal resections. Int J Colorectal Dis, 26(1), 61-69 (2011).

114. Watanabe M, Suzuki H, Nomura S et al. Risk Factors for Surgical Site Infection in Emergency Colorectal Surgery: A Retrospective Analysis. Surg Infect (Larchmt), 15(3), 256-261 (2014).

115.Pincock T, Bernstein P, Warthman S, Holst E. Bundling hand hygiene interventions and measurement to decrease health care-associated infections. Am J Infect Control, 40(4 Suppl 1), S18-27 (2012).

116. Clarke K, Tong D, Pan Y et al. Reduction in catheter-associated urinary tract infections by bundling interventions. Int J Qual Health Care, 25(1), 43-49 (2013).

117.Korbkitjaroen M, Vaithayapichet S, Kachintorn K, Jintanothaitavorn D, Wiruchkul N, Thamlikitkul V. Effectiveness of comprehensive implementation of individualized bundling infection control measures for prevention of health care-associated infections in general medical wards. Am J Infect Control, 39(6), 471-476 (2011).

118. Lipke VL, Hyott AS. Reducing surgical site infections by bundling multiple risk reduction strategies and active surveillance. AORN J, 92(3), 288-296 (2010).

119. Barbut F, Yezli S, Mimoun M, Pham J, Chaouat M, Otter JA. Reducing the spread of Acinetobacter baumannii and methicillin-resistant Staphylococcus aureus on a burns unit through the intervention of an infection control bundle. Burns, 39(3), 395-403 (2013).

120. Lavu H, Klinge MJ, Nowcid LJ et al. Perioperative surgical care bundle reduces pancreaticoduodenectomy wound infections. J Surg Res, 174(2), 215-221 (2012). 
121.Leverstein-van Hall MA, Hopmans TE, van der Sprenkel JW et al. A bundle approach to reduce the incidence of external ventricular and lumbar drain-related infections. J Neurosurg, 112(2), 345-353 (2010).

122. Lutfiyya W, Parsons D, Breen J. A colorectal "care bundle" to reduce surgical site infections in colorectal surgeries: a single-center experience. The Permanente journal, 16(3), 10-16 (2012).

123. Bull A, Wilson J, Worth LJ et al. A bundle of care to reduce colorectal surgical infections: an Australian experience. J Hosp Infect, 78(4), 297-301 (2011).

124.Liau KH, Aung KT, Chua N et al. Outcome of a strategy to reduce surgical site infection in a tertiary-care hospital. Surg Infect (Larchmt), 11(2), 151159 (2010).

125.Anthony T, Murray BW, Sum-Ping JT et al. Evaluating an evidence-based bundle for preventing surgical site infection: a randomized trial. Arch Surg, 146(3), 263-269 (2011).

126.Pastor C, Artinyan A, Varma MG, Kim E, Gibbs L, Garcia-Aguilar J. An increase in compliance with the Surgical Care Improvement Project measures does not prevent surgical site infection in colorectal surgery. Dis Colon Rectum, 53(1), 24-30 (2010).

127. Poulsen KB, Jepsen OB. Failure to detect a general reduction of surgical wound infections in Danish hospitals. Dan Med Bull, 42(5), 485-488 (1995).

128. Larochelle M, Hyman N, Gruppi L, Osler T. Diminishing surgical site infections after colorectal surgery with surgical care improvement project: is it time to move on? Dis Colon Rectum, 54(4), 394-400 (2011).

129.Stulberg JJ, Delaney CP, Neuhauser DV, Aron DC, Fu P, Koroukian SM. Adherence to surgical care improvement project measures and the association with postoperative infections. JAMA, 303(24), 2479-2485 (2010).

130.Edmiston CE, Spencer M, Lewis BD et al. Reducing the risk of surgical site infections: did we really think SCIP was going to lead us to the promised land? Surg Infect (Larchmt), 12(3), 169-177 (2011).

131.Crolla RM, van der Laan L, Veen EJ, Hendriks Y, van Schendel C, Kluytmans J. Reduction of surgical site infections after implementation of a bundle of care. PLoS One, 7(9), e44599 (2012). 
132. Hedrick TL, Heckman JA, Smith RL, Sawyer RG, Friel CM, Foley EF. Efficacy of protocol implementation on incidence of wound infection in colorectal operations. J Am Coll Surg, 205(3), 432-438 (2007).

133. Cataife G, Weinberg DA, Wong HH, Kahn KL. The effect of Surgical Care Improvement Project (SCIP) compliance on surgical site infections (SSI). Med Care, 52(2 Suppl 1), S66-73 (2014).

134.van der Slegt J, van der Laan L, Veen EJ, Hendriks Y, Romme J, Kluytmans J. Implementation of a bundle of care to reduce surgical site infections in patients undergoing vascular surgery. PLoS One, 8(8), e71566 (2013).

135. Mortenius H, Marklund B, Palm L, Bjorkelund C, Baigi A. Implementation of innovative attitudes and behaviour in primary health care by means of strategic communication: a 7-year follow-up. J Eval Clin Pract, 18(3), 659665 (2012).

136.Johnson B, Starks I, Bancroft G, Roberts PJ. The effect of care bundle development on surgical site infection after hemiarthroplasty: an 8-year review. The journal of trauma and acute care surgery, 72(5), 1375-1379 (2012).

137. Munez E, Ramos A, Espejo TA et al. Microbiology of surgical site infections in abdominal tract surgery patients. Cir Esp, (2011).

138.van Kasteren ME, Gyssens IC, Kullberg BJ, Bruining HA, Stobberingh EE, Goris RJ. [Optimizing antibiotics policy in the Netherlands. V. SWAB guidelines for perioperative antibiotic prophylaxis. Foundation Antibiotics Policy Team]. Ned Tijdschr Geneeskd, 144(43), 2049-2055 (2000).

139. Emori TG, Gaynes RP. An overview of nosocomial infections, including the role of the microbiology laboratory. Clin Microbiol Rev, 6(4), 428-442 (1993).

140.Jones RN. Resistance patterns among nosocomial pathogens: trends over the past few years. Chest, 119(2 Suppl), 397S-404S (2001).

141.Solomkin JS, Mazuski JE, Bradley JS et al. Diagnosis and management of complicated intra-abdominal infection in adults and children: guidelines by the Surgical Infection Society and the Infectious Diseases Society of America. Surg Infect (Larchmt), 11(1), 79-109 (2010).

142. Ramcharan AA, den Heijer CD, Smeets EE et al. Microbiology of surgical site infections after gastrointestinal surgery in the south region of The Netherlands. Future Microbiol, 9(3), 291-298 (2014). 
143.Spellberg B, Bartlett JG, Gilbert DN. The future of antibiotics and resistance. N Engl J Med, 368(4), 299-302 (2013).

144.Dohmen PM. Antibiotic resistance in common pathogens reinforces the need to minimise surgical site infections. J Hosp Infect, 70 Suppl 2, 15-20 (2008).

145.Jean SS, Hsueh PR. Antimicrobial drug resistance in Taiwan. J Formos Med Assoc, 110(1), 4-13 (2011).

146. Chulain MN, Murray AM, Corbett-Feeney G, Cormican M. Antimicrobial resistance in $E$. coli associated with urinary tract infection in the west of Ireland. Ir J Med Sci, 174(4), 6-9 (2005).

147. Kamat U, Ferreira A, Savio R, Motghare D. Antimicrobial resistance among nosocomial isolates in a teaching hospital in goa. Indian journal of community medicine : official publication of Indian Association of Preventive \& Social Medicine, 33(2), 89-92 (2008).

148. Arya M, Arya PK, Biswas D, Prasad R. Antimicrobial susceptibility pattern of bacterial isolates from post-operative wound infections. Indian J Pathol Microbiol, 48(2), 266-269 (2005).

149. Khorvash F, Mostafavizadeh K, Mobasherizadeh S et al. Antimicrobial susceptibility pattern of microorganisms involved in the pathogenesis of surgical site infection (SSI); A 1 year of surveillance. Pakistan journal of biological sciences: PJBS, 11(15), 1940-1944 (2008).

150. Hidron Al, Edwards JR, Patel J et al. NHSN annual update: antimicrobialresistant pathogens associated with health care-associated infections: annual summary of data reported to the National Health care Safety Network at the Centers for Disease Control and Prevention, 2006-2007. Infect Control Hosp Epidemiol, 29(11), 996-1011 (2008).

151. Misteli H, Widmer AF, Rosenthal R, Oertli D, Marti WR, Weber WP. Spectrum of pathogens in surgical site infections at a Swiss university hospital. Swiss Med Wkly, 140, w13146 (2011).

152. Rasnake MS, Dooley DP. Culture-negative surgical site infections. Surg Infect (Larchmt), 7(6), 555-565 (2006).

153. Birgand G, Azevedo C, Toupet G et al. Attitudes, risk of infection and behaviours in the operating room (the ARIBO Project): a prospective, cross-sectional study. BMJ open, 4(1), e004274 (2014). 
154.Beldi G, Bisch-Knaden S, Banz V, Muhlemann K, Candinas D. Impact of intraoperative behavior on surgical site infections. Am J Surg, 198(2), 157162 (2009).

155. Borer A, Gilad J, Meydan N et al. Impact of active monitoring of infection control practices on deep sternal infection after open-heart surgery. Ann Thorac Surg, 72(2), 515-520 (2001).

156. Leaper DJ, Tanner J, Kiernan M, Assadian O, Edmiston CE, Jr. Surgical site infection: poor compliance with guidelines and care bundles. Int Wound J, (2014).

157.Pittet D, Hugonnet S, Harbarth S et al. Effectiveness of a hospital-wide programme to improve compliance with hand hygiene. Infection Control Programme. Lancet, 356(9238), 1307-1312 (2000).

158. Alp E, Elmali F, Ersoy S, Kucuk C, Doganay M. Incidence and risk factors of surgical site infection in general surgery in a developing country. Surg Today, 44(4), 685-689 (2014). 


\section{Samenvatting}

De laatste jaren wordt in steeds meer zorginstellingen aandacht besteed aan infectiepreventie en patiëntveiligheid. Een van de redenen is de toenemende antibiotica resistentie van bacteriën waardoor infecties steeds moeilijker te behandelen zijn. Ziekenhuisinfecties ontstaan tijdens het verblijf van een patiënt in het ziekenhuis en worden ook wel nosocomiale infecties genoemd. Infecties die binnen 48 uur na opname ontstaan, worden niet gedefinieerd als ziekenhuisinfectie, omdat deze waarschijnlijk niet geassocieerd zijn aan de betreffende opname. Ziekenhuisinfecties komen in alle ziekenhuizen voor en worden meestal veroorzaakt door bacteriën die de patiënt zelf bij zich draagt of die door anderen worden overgedragen. Ze zijn doorgaans onvermijdbaar, maar de mate waarin ze voorkomen verschilt per ziekenhuis, per specialisme en per ingreep.

Voor patiënten die een operatie ondergaan zijn postoperatieve wondinfecties (POWI's) de meest voorkomende ziekenhuisinfecties en maken ongeveer $17 \%$ uit van alle ziekenhuisinfecties. POWI's zijn infecties die voorkomen binnen 30 dagen na een chirurgische ingreep of binnen één jaar na de operatie wanneer een implantaat is achtergelaten. Andere veel voorkomende infecties zijn urineweginfecties, bloedstroominfecties, pneumonie, gastro-intestinale infecties en infecties van het centrale zenuwstelsel. De literatuur beschrijft verschillende preventieve maatregelen om het aantal ziekenhuisinfecties terug te dringen.

In dit proefschrift wordt het voorkomen, de risicofactoren en het effect van infectiepreventie maatregelen op het voorkomen van POWI's na verschillende chirurgische ingrepen beschreven. Een POWI is in dit onderzoek gedefinieerd volgens de criteria van het landelijk PREZIES netwerk en de CDC.

Een algemene introductie over ziekenhuisinfecties, infectiepreventie en daaraan gerelateerde onderwerpen wordt beschreven in hoofdstuk 1. De surveillance van POWI's in een academisch ziekenhuis voor verschillende onderzoekspopulaties, namelijk een patiëntengroep na een gastro-intestinale ingreep (inclusief de colorectale sarcopene ouderen), wordt beschreven in de hoofdstukken 2, 3 en $\mathbf{5}$. In hoofdstuk 4 wordt het voorkomen van POWI's na een vasculaire ingreep weergegeven. Tenslotte worden de resultaten in hoofdstuk 6 bediscussieerd en worden de belangrijkste bevindingen samengevat en suggesties gegeven voor toekomstig onderzoek. 


\section{Veiligheids Management Systeem}

Surveillance is een belangrijk onderdeel van een infectiepreventie programma. Verschillende studies hebben aangetoond dat feedback van infectiepercentages aan behandelaars bijdraagt aan het verminderen van het aantal wondinfecties en zodoende bijdraagt aan de verbetering van de patiëntveiligheid. Nationale en internationale surveillance-systemen zijn opgezet om het voorkomen van het aantal POWI's te registreren en zo mogelijk te verminderen. In Nederland is het VeiligheidsManagementSysteem (VMS) geïntroduceerd voor Nederlandse ziekenhuizen, met het doel het aantal vermijdbare ziekenhuisinfecties met $50 \%$ te verlagen. Het veiligheidsprogramma bevat verschillende thema's waarvan één is gericht op het voorkomen van POWI's na een operatie, ook wel de POWI interventiebundel genoemd. De bundel bestaat uit vier maatregelen: het achterwege laten van preoperatief ontharen, adequate timing, dosering en keuze van antibiotica profylaxe, beperking van in- en uitloop op de operatie kamer en perioperatieve normothermie (handhaving van de juiste lichaamstemperatuur tijdens een operatie). Om inzicht te krijgen in de naleving van deze maatregelen werd het aantal POWI's vóór en na implementatie van de VMS bundel geregistreerd. Voor dit manuscript resulteerde implementatie van de VMS bundel niet tot een significante daling in percentage postoperatieve wondinfecties tijdens de studieperiode. Mogelijke redenen hiervoor zijn dat de naleving van de maatregelen van de bundel alleen eenmalig is gemeten, de evaluatie periode te kort was en dat de patiëntengroepen verschilden in onderliggend lijden. Bovendien is geen onderscheid gemaakt in de verschillende operatieve procedures en de verschillen in complexiteit ervan.

\section{Surveillance tijdens opname en na ontslag}

Door de afname van het aantal opnamedagen na een operatie manifesteren POWI's zich steeds vaker nadat de patiënt ontslagen is uit het ziekenhuis. Het is daarom van essentieel belang dat, ook nadat de patiënt ontslagen is uit het ziekenhuis, het optreden van een infectie, gerelateerd aan de ingreep, in kaart wordt gebracht. Dit om een onderschatting van het aantal ziekenhuisinfecties te voorkomen. Onze surveillance, tijdens en na opname, van POWI's werd vóór en na implementatie van de VMS bundel uitgevoerd en geëvalueerd. De trends in POWI percentages werden berekend, risicofactoren voor het ontwikkelen van POWI's in 
de verschillende patiënten populaties werden geanalyseerd en vervolgens in de hoofdstukken 2, 3, 4 en $\mathbf{5}$ beschreven. Gedurende een follow-up periode van 30 dagen na de ingreep werd $36 \%$ van alle POWI's na een gastro-intestinale ingreep na ontslag gedetecteerd (hoofdstuk 2). Na een vasculaire ingreep bedroeg dit percentage $50 \%$ (hoofdstuk 4). Uitvoering van surveillance na ontslag heeft dus tot een duidelijke toename van het aantal geregistreerde POWI's geleid. Deze cijfers onderstrepen het belang van surveillance na ontslag.

In de literatuur is er een grote variatie in percentage POWI beschreven, wat o.a. afhankelijk is van de soort chirurgische ingreep, van verschillen in risicofactoren voor POWI's, maar ook van de verschillen in surveillance methodiek. Surveillance kan zowel passief als actief worden uitgevoerd. In ons onderzoek is tijdens opname een actieve surveillance uitgevoerd, na ontslag een passieve surveillance. Tevens zijn infecties onderverdeeld in oppervlakkige, diepe en anatomische infecties en zijn de wonden geclassificeerd in verschillende wondklassen: schoon, schoongecontamineerd, gecontamineerd of vies. Deze onderverdeling is van belang vanwege het verschil in ernst van de infectie. Immers, diepe POWI's zijn veel ernstiger dan oppervlakkige, vereisen vaak intraveneuze antibiotica behandeling en leiden tot een langere opnameduur en wondbehandeling. Daarnaast is het risico op een infectie hoger in wonden met een hogere wondklasse (gecontamineerd of vies) vergeleken met schone wonden.

\section{Risicofactoren}

Een ander belangrijk aspect van surveillance is de analyse van risicofactoren, afhankelijk van de verschillen in patiënt case-mix. Denk bijvoorbeeld aan verschillen tussen ziekenhuizen en operatieve procedures. Sommige ingrepen zijn complexer of urgenter dan andere. Risicofactoren kunnen dan ook zowel wel of niet vermijdbaar zijn, sommige risico factoren zijn patiënt specifiek, terwijl andere operatie- of omgevings-gerelateerd zijn. In de hoofdstukken 2, 4 en 5 zijn risicofactoren voor POWI's in de verschillende patiëntenpopulaties beschreven. In hoofdstuk 2 zijn de risicofactoren voor POWI's in de gastro-intestinale patiëntengroep geanalyseerd; oudere patiënten en patiënten met gecontamineerde of vieze wonden hadden een hoger risico voor het ontwikkelen van een POWI vergeleken bij jongere patiënten met schone wonden. De risicofactoren voor de vasculaire patiëntengroep waren diabetes, leeftijd ouder dan 60 en hogere wondklasse (hoofdstuk 4). Hoewel patiënten ouder dan 65 jaar een 
hogere kans hadden op sarcopenie, werd geen associatie gevonden tussen sarcopenie en het ontwikkelen van POWI's (hoofdstuk 5).

De risicofactoren voor POWI's die tijdens deze studie zijn gevonden zijn deels vergelijkbaar met andere studies. De verschillen in resultaten worden verklaard door o.a. de grote verscheidenheid in operatieve procedures, de case-mix van patiënten met verschillende risicofactoren en het ontbreken van bepaalde patiënten data (ASA klasse, operatieduur) voor een adequate risicoanalyse.

\section{Microbiologie}

Tenslotte werd gedurende deze studie aandacht besteed aan de antibiotica gevoeligheid van de uit post-operatieve wonden geïsoleerde micro-organismen. Veel POWI's worden veroorzaakt door micro-organismen die reeds bij de patiënt aanwezig zijn, zoals Staphylococcus aureus en Escherichia coli. Het ontstaan van een POWI is afhankelijk van verschillende factoren, zoals de locatie van de wond en het aantal en de virulentie van de micro-organismen. In de hoofdstukken 3, 4 en $\mathbf{5}$ worden de microbiologische data beschreven in de verschillende onderzochte patiëntenpopulaties. De meest voorkomende micro-organismen in de verschillende patiënten populaties waren Escherichia coli, Pseudomonas aeruginosa en Staphylococcus aureus. Het antibiotica-resistentiepatroon van de microorganismen werd bepaald door de wondkweken, afgenomen binnen de eerste 48 uur na de operatie, te vergelijken met de wondkweken die daarna zijn afgenomen tot 30 dagen na de operatie. We zagen geen significante toename in antibiotica resistentie binnen deze follow-up periode van 30 dagen werd gevonden. Om het antibiotica-resitentiepatroon in een bepaald ziekenhuis te bepalen, is analyse van een voldoende hoog aantal kweken in het laboratorium, gekoppeld aan het antibiotica gebruik, vereist.

Variatie in microbiologische data in de literatuur kan o.a, (deels) verklaard worden door verschil in antibiotica gebruik van de patient, de virulentie van het microorganisme, maar ook de afweer van de patiënt zelf speelt een belangrijke rol bij het al dan niet optreden van een infectie.

\section{Conclusie}

Dit proefschrift toont aan dat infectieregistratie tijdens en na opname cruciaal is om een betrouwbaar inzicht te verkrijgen in het voorkomen van POWI's na een chirurgische ingreep. Registratie door eenzelfde ervaren, onafhankelijk persoon is 
hierbij essentieel. Het onderzoek laat geen verlaging zien in het infectiepercentage na implementatie van de VMS bundel.

Infectiepreventie wordt steeds belangrijker in de dagelijkse praktijk. Er is doorgaans meer vraag en aandacht voor scholing, samenwerking tussen verschillende disciplines (arts-microbiologen, chirurgen, verplegend personeel, ziekenhuishygiënisten) voor het uitvoeren van surveillance studies en, indien nodig, interventies te ontwikkelen. Het is daarom des te belangrijker dat informatie betreffende infectie prevalentie cijfers duidelijk en gemakkelijk toegankelijk zijn om zo adequate interventies op te zetten en de patiënten zorg te verbeteren.

Concluderend, voor een succesvolle implementatie van infectiepreventieve maatregelen is een multidisciplinaire benadering essentieel. Activiteiten gebaseerd op infectiepreventieve protocollen behoren geïntegreerd te zijn in de dagelijkse praktijk en dienen nageleefd te worden door alle zorgmedewerkers. Continue feedback is nodig voor een optimale bewustwording van de consequenties voor de patiënt wanneer richtlijnen niet accuraat worden opgevolgd. Tenslotte, ook hier geldt, voorkomen is beter dan genezen! 


\section{List of Abbreviations}

ASA

BIA

BMI

CAPHRI

CaRe

CDC

CEA

$\mathrm{Cl}$

CRP

CT

DXA

EUCAST

ESBL

FDR

HAI

$\mathrm{HB}$

HU

IBD

ICN

IRR

L3

LOS

$\mathrm{MQ}$

MUMC+.

MUST

MRI

NFU

NHSN

NNIS

NVZ

OR

OR
American Society of Anaesthesiologists

Bio-Impedance Analysis

Body Mass Index

School for Public Health and Primary Care

Netherlands School of Primary Care Research

Centers for Disease Control and Prevention

Carcino Embryonic Antigen

Confidence Intervals

C-Reactive Protein

Computed Tomography

Dual energy X-ray Absorptiometry

European Committee on Antimicrobial Susceptibility Testing

Extended-Spectrum Beta-Lactamase

False Discovery Rate

Health care-associated infection

Haemoglobin

Hounsefield Unit

Inflammatory Bowel Disease

Infection control nurse

The inter-rater reliability

Third Lumbar vertebral level

Length of Stay

Muscle Quality

Maastricht Universiteit Medisch Centrum

Malnutrition Universal Screening Tool

Magnetic Resonance Imaging

Dutch Federation of University Medical Centers (Dutch:

Nederlandse Federatie van Universitair Medische Centra

The National Health care Safety Network

National Nosocomial Infections Surveillance

Dutch Society of Hospitals (Dutch: Nederlandse Vereniging van Ziekenhuizen)

Operating Room

Odds Ratio 
PAD

PDS

PDSA

PREZIES

SENIC

SSI

SWAB

VMS

V\&VN

WHO

WIP
Peripheral Artery Disease

Postdischarge surveillance

Plan Do Study Act

Dutch: Preventie van Ziekenhuisinfecties door Surveillance

Study on the efficacy of nosocomial infection control

Surgical Site Infection

Dutch working party on Antibiotic policy (Dutch: Stichting Werkgroep AntibioticaBeleid

Dutch: VeiligheidsManagementSysteem

Dutch Association of Medical Specialists and Nurses \& Carers (Dutch: Verpleegkundigen \& Verzorgenden Nederland)

World Health Organization

Dutch Working Party on Infection Prevention (Dutch: Werkgroep InfectiePreventie 


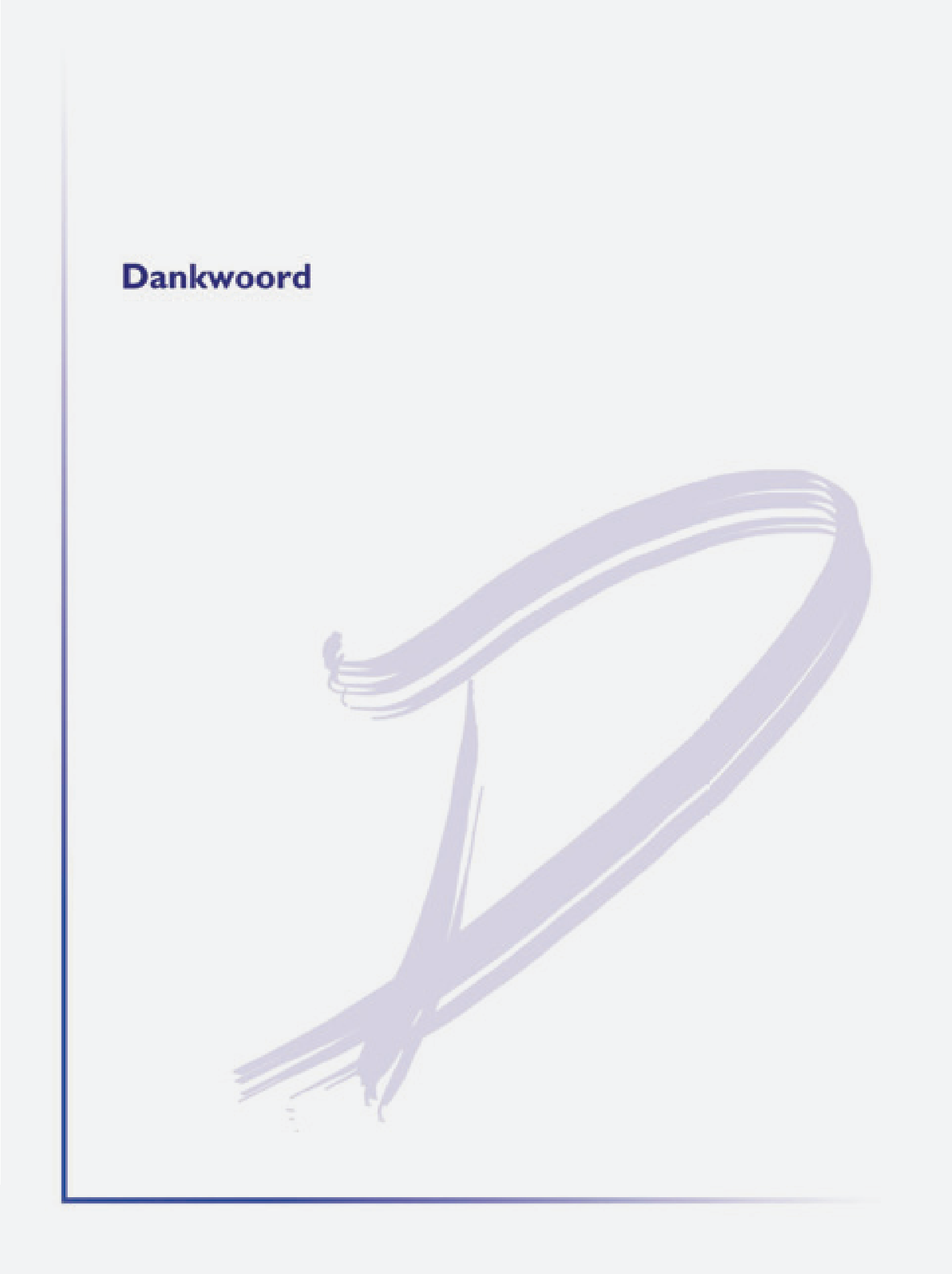




\section{Dankwoord}

1 April 2010, mijn eerste dag op de afdeling van de Medische Microbiologie. Vier jaar geleden begon ik aan dit avontuur. Ik wist totaal niet wat me te wachten zou staan. Die onzekerheid is gelukkig weg en ik kan met trots zeggen dat mijn promotieonderzoek nu is afgerond! Ik heb de afgelopen vier jaar ervaren als een periode van vallen en opstaan. Allerlei emoties hebben de revue gepasseerd. Nu realiseer ik me pas hoeveel ik heb geleerd en hoe snel de tijd voorbij is gevlogen. Ik prijs mezelf heel gelukkig met de mensen die ik heb leren kennen en ik wil daarom iedereen persoonlijk bedanken.

Allereerst mijn promotieteam.

Lieve Ellen, halverwege het onderzoek werd $u$ mijn co-promotor en heeft $u$ mij geleerd problemen aan te pakken en knopen door te hakken. Het begin van onze samenwerking vond ik best spannend, maar ik kreeg al heel gauw veel bewondering voor $\mathrm{u}$. Ondanks al uw werkzaamheden, en tevens uw begeleiding van andere promovendi, deed u niemand tekort en kon ik altijd op u rekenen. Het was erg jammer toen $u$ de afdeling verliet en bij het RIVM in Utrecht ging werken, maar toch stond $u$ voor mij klaar wanneer nodig. Met het openbaar vervoer konden we door heel Nederland afspreken. Daarnaast hebben we leuke tijden beleefd tijdens congressen. Eén ding hebben we in ieder geval gemeen: winkelen. Bedankt voor uw geloof in mij, uw kritische blik en uw steun gedurende dit traject. Ik heb veel van $u$ geleerd en dat zal ik zeker meenemen bij mijn volgende baan. Ik wens $u$ veel succes bij het RIVM, maar neem ook af en toe een beetje rust!

Mijn tweede co-promotor. Beste Frank, we begonnen aan een project met een heel andere insteek. Allerlei plannen waren gemaakt, maar uiteindelijk zijn we toch een andere weg in geslagen. Je bent tot de helft van het traject mijn directe begeleider geweest. Ook daarna, wanneer ik je om advies vroeg, nam je de tijd en kwam je met goede adviezen. Frank, ik kon altijd bij je aankloppen, je was vriendelijke en enthousiast, vooral tijdens de laatste loodjes heb ik jouw betrokkenheid erg gewaardeerd, en daarvoor wil ik je hartelijk bedanken.

Mijn promotor. Beste em. Prof. Dr. Bruggeman, Cathrien, bedankt voor de mogelijkheid te promoveren op de afdeling van de Medische Microbiologie en uw 
kritische blik op mijn proefschrift. Ik wens $u$ een mooie tijd toe met uw man, kinderen en kleinkinderen.

Dan de overige mensen die betrokken zijn geweest bij dit onderzoek.

Beste Margriet,

Nauwkeurig en volhardend zijn slechts een greep uit vele woorden die bij mij opkwamen tijdens het schrijven van dit stukje. Want zo ben je altijd te werk gegaan. Je weet ontzettend veel en ik heb ook veel van je geleerd. Een groot gedeelte van mijn data heb je met grote toewijding door de jaren heen verzameld. Bedankt hiervoor en ik wens je veel succes met de infectieregistratie!

Beste Dr. Jan Tordoir, em. Prof. Dr. Cor Baeten, Dr. Stephanie Breukink en Dr. Steven Olde-Damink. Ik heb tijdens dit promotietraject op verschillende momenten met jullie mogen samenwerken. Bedankt voor jullie hulp en deskundige bijdrage aan mijn promotieonderzoek! Em. Prof. Dr. Baeten, ik wens u een fijne tijd met uw vrouw, kinderen en kleinkinderen, waar u altijd vol lof over praat.

Beste Peter, we hebben wat moeite had met de database. Gelukkig is het toch goedgekomen en heb ik met de verkregen data mijn boekje kunnen schrijven. Bedankt voor de tijd die je nam en ik wil je succes wensen met alle ICTwerkzaamheden op de afdeling, samen met Chantal.

Beste Awin, Steven Jeuring en Kostan, we zijn eigenlijk per toeval in contact gekomen met elkaar. Onze communicatie verliep altijd goed en ik heb onze samenwerking dan ook als zeer fijn en productief ervaren. Bedankt voor jullie bijdrage aan mijn promotieonderzoek en succes met het verloop van jullie medische carrière!

Beste Prof. Dr. Savelkoul, beste Paul, als volgend afdelingshoofd heeft u niet veel met mijn onderzoek te maken gehad; we zaten slechts samen in de koffiekamercommissie. Ik wil u en Wil bedanken voor de onbeperkte toegang tot de afdeling en mijn bestanden na de beëindiging van mijn contract. Daarnaast wil ik u veel succes wensen met alle veelbelovende ideeën voor de afdeling. 
Mijn (ex-) collega's wil ik bedanken, want zonder hen was het werk niet zo leuk geweest.

Mijn (ex-) kamergenoten, Gie(eeee)I, Wendy, Gert, Erik, Anne, Christel, Tanja, Chris en Danyta, ik had geen andere kamergenoten kunnen wensen. We hebben veel gelachen, maar er werd ook hard gewerkt. En bij vragen kon ik altijd bij één van jullie terecht. Ik ga jullie missen en hoop met mijn volgende baan net zulke leuke collega's te krijgen.

Marijke, Judith, Sander, Michelle, Ellen Broex, Ruud, ondanks dat we geen kamergenoten zijn geweest hebben we veel gelachen. Het was erg jammer toen jullie de afdeling verlieten en wil jullie heel veel succes wensen met het vervolg van jullie carrières! En Marijke, ik vind het erg leuk dat wij elkaar nog regelmatig zien! Jij bent binnenkort ook aan de beurt.

Beste (ex-) mede-promovendi, Carla, Charlotte, Birke, ondanks we niet bij elkaar op de kamer hebben gezeten, hebben we toch leuke tijden beleefd, zoals borrels na werk en Sinterklaas surprise. Heel veel succes met het vervolg van jullie promotieonderzoek. Ik weet zeker dat dat, onder leiding van Frank, goed gaat komen! Fahad, I admire your persistence during your PhD-research. I hope I will defend my thesis as good as you! We have laughed a lot and I wish all the best in your future career.

Lieve Resi, ik, en met mij vele anderen, vonden het erg jammer toen je onze afdeling ging verlaten. Ik kon altijd bij je terecht met vragen en verhalen. Bedankt voor jouw luisterend oor en succes bij je baan als officemanager. Ze hebben maar geluk met jou!

Beste (ex-) ziekenhuishygiëne, beste Ed, Frank, Math, Ella, Corien, Josephine, Karen, Peter, Astrid en Sandra, tijdens de eerste maanden van mijn promotieonderzoek mocht ik met jullie meelopen. Daarna bleven jullie geïnteresseerd in mijn werk en kon ik bij jullie terecht met vragen. Bedankt hiervoor en ik wens jullie een succesvolle samenwerking met Bonaire! Astrid, bedankt voor je goede adviezen! Jij vormt daarnaast samen met Selwyn en Dirk een mooi team. 
Beste Casper en John,

Jullie zijn de statistiek-experts van de afdeling. Bedankt voor jullie hulp als ik weer kwam aankloppen met een statistische vraag. Jullie stonden altijd klaar en dat heeft me enorm geholpen tijdens het analyseren van mijn data. Casper, succes bij de GGD in Heerlen/Geleen en veel geluk met jullie tweede kindje!

Beste (ex-) AIOS, Remco, Guy, Vishal, Fleur, Robin, Elly, Michiel en Anne. Jullie vormen een te gekke groep! Bedankt voor jullie deskundigheid en hulp als ik die nodig had. Ondanks jullie drukke schema's kon ik bij jullie terecht. Bedankt hiervoor en ik wens jullie heel veel succes met het vervolg van jullie onderzoek en opleiding, en Remco in Zuid-Afrika!

Beste collega's van bacteriologie research, Jacqueline Peeters, Jacqueline Maes, Nicole, Christel, Marie-Louise en Mayk. Met jullie was het altijd gezellig, zowel tijdens de koffiepauzes als tijdens de lunch. Als ik vragen had over lab-gerelateerde dingen stonden jullie altijd klaar om het uit te leggen. En in het bijzonder Mayk, bedankt voor het ontwerp van mijn kaft en overige illustraties. Met jouw creatieve geest heb je er iets moois van gemaakt!

Beste collega's van de moleculaire diagnostiek, Judith (2x), Bart, Selma, Katrien, Raymond, Anita en Marco. Ik heb niet met jullie samengewerkt, maar als ik iets nodig had (verhuisdozen) stonden jullie klaar. Jullie zijn een ontzettend leuk team!

Beste MMM-ers (in opleiding), Petra, Marlies, Lieke, en Tanja. Jullie vormen een goede groep. Antoinette, je bent helaas niet meer werkzaam op onze afdeling, maar gelukkig helemaal op je plaats bij je nieuwe baan. Ik wens jullie heel veel succes als MMM-ers!

De arts-microbiologen: Sandra, Helke, Danielle, Inge en Guy, succes met alle werkzaamheden!

Beste secretariaat, José, Angèle, Fia en Natascha, jullie vorm(d)en een goed en gezellig secretariaat. José, jammer dat je onze afdeling hebt verlaten, maar volgens mij heb je het nu ook erg naar je zin in het Bonnefantenmuseum. Bedankt dat jullie altijd klaarstonden en bereid waren mij te helpen waar nodig. 
Beste Ans en John, bedankt dat jullie altijd het voorraadkamertje open deden als ik weer iets nodig had! Ans, onze gesprekken heb ik altijd zeer gewaardeerd. Ik wens je veel geluk met alles!

Ik wil alle overige collega's, collega's bij de GGD en stagiaires die ik niet bij naam heb genoemd ook bedanken voor hun collegialiteit. Ik heb me altijd zeer vertrouwd gevoeld op de afdeling en dat is mede dankzij jullie! Lieve Laura, ik ben blij dat ik je heb leren kennen en hoop je nog vaker te zien!

Lieve vrienden/vriendinnen, familie, en DAS;), tijdens alle feestjes, uitstapjes en etentjes kon ik volop genieten en mijn verstand op nul zetten. Bedankt voor jullie enthousiasme en interesse in mijn onderzoek.

Natuurlijk een persoonlijk woordje voor mijn paranimfen.

Lieve Tannie, Tanja,

Ik heb niet hoeven twijfelen om jou als paranimf te vragen. Eind vorig jaar mocht ik jou bijstaan en dat was een grote eer. Toen ik pas begon op de MMB nam je altijd even de tijd een praatje te maken. Door de jaren heen werden we steeds beter bevriend en kon ik altijd bij je terecht. We hebben heel wat met elkaar gedeeld en veel gelachen. Dat heeft me altijd erg goed gedaan. Ook de afgelopen maanden heb je me meer geholpen dan je waarschijnlijk weet. Je was mijn voorbeeld en gelukkig kon je me goede adviezen geven. Dank je daarvoor. Je bent meer dan een collega en ik hoop dan ook dat ons contact blijft. Ik ben daarom ook erg blij dat je op deze bijzondere dag achter mij staat!

Lieve An, Anne, Penotti;

Voor jou geldt hetzelfde; de keuze om jou te vragen als paranimf was snel gemaakt. Met jou is het altijd een feestje. Ik ben blij dat ik je heb leren kennen als een collega die ik iedereen kan aanraden. Je bent altijd geïnteresseerd en je hebt me op allerlei manieren geholpen. We hebben ook heel wat gelachen, zowel op het werk als daarbuiten wanneer we gezellig een terrasje gingen pakken of uiteten gingen. Ik vind het daarom des te erger dat ik de MMB heb verlaten en ik hoop dat ik ooit nog 
zo'n collega mag krijgen! Ik wens je heel veel succes met je opleiding tot artsmicrobioloog en jouw promotie en hoop je natuurlijk nog vaak te zien!

En als laatste natuurlijk mijn (schoon-) familie en lieve vriend.

Lieve Maria, Jan, Manon en Martijn, bedankt voor jullie steun en belangstelling in mij en voor het feit dat ik altijd bij jullie kan aankloppen. Jan en Maria, ik prijs me gelukkig dat ik in de familie Smits ben opgenomen. Jullie staan altijd klaar en zorgen dat we nooit tekort komen. Lieve Manon, je bent een topper, zowel privé, als zakelijk in je baan als huisarts. Ik ben blij met jou als 'schoonzus' en vooral als vriendin. Bedankt voor je luisterend oor en alle gezellige momentjes samen. Martijn, op jou kan ik ook altijd rekenen. Succes met je opleiding tot uroloog. Je gaat dat zeker goed doen! Als we samen zijn en tijdens onze vakanties hebben we de grootste lol en ik prijs mezelf daarom erg gelukkig met jullie als schoonfamilie, helemaal met een kleintje op komst. Jullie worden fantastische (groot-) ouders!

Lieve mam, pap, didi/zus (Wanita), Joost en Philippa, bedankt voor jullie steun en enthousiasme de afgelopen jaren. Mams en paps, jullie hebben me altijd in alles gesteund en goede adviezen gegeven, zowel tijdens mijn opleiding als tijdens dit promotietraject. Zonder jullie stond ik hier niet! Jullie zijn nu trotse nani en nana/oma en opa en ik vind het heerlijk jullie te zien met jullie kleindochter. Ik houd van jullie! Lieve di, ik kon je altijd bellen en ik ben blij met jou als zus. Ik bewonder je als moeder van Philippa en binnenkort als huisarts. Joost, je bent altijd super enthousiast en over een tijdje sta jij ook je proefschrift te verdedigen, met Philippa en Wanit naast je. Heel veel succes, het gaat je zeker lukken!

Lieve Philly, Philippa, jouw geboorte was één van de hoogtepunten tijdens deze periode. We wonen helaas wat ver uit elkaar (wellicht binnenkort niet meer), maar als ik jouw prachtige gezichtje via Skype of op foto's zie, is mijn hele dag weer goed!

Lieve Ivo, het laatste gedeelte van mijn dankwoord is natuurlijk voor jou. Tijdens mijn promotietraject heb ik de nodige frustraties gehad. Gelukkig had ik ook vele momenten van vreugde. Op al die momenten was jij er. Je woorden waren soms streng, maar bemoedigend. Daarnaast hebben we samen verschillende flessen geopend om goed nieuws te vieren. Je berichtjes met daarin dat je trots op me bent, betekenden enorm veel. Ik heb heel wat gepiekerd, maar mede dankzij jou 
kan ik deze periode nu met trots afronden. Je weet dat ik de verdediging enorm spannend vind, maar met jou tegenover me gaat het me zeker lukken. Schat, we gaan weer een nieuw avontuur tegemoet, nieuwe baan, nieuwe woning, nieuwe stad, maar jij bent de enige met wie ik dat wil gaan doen! 


$$
\bar{Q}
$$




\section{Curriculum Vitae}

Amita Ramcharan werd geboren op 11 juni 1986 in Noord-Brabant en zij groeide op in Eindhoven. Van 1998 tot 2004 heeft zij het middelbaar onderwijs gevolgd aan het Augustinianum te Eindhoven. In 2004 is ze gaan studeren in Maastricht en startte zij met de opleiding Rechten aan de Universiteit van Maastricht. Toen ze besefte dat dit niet haar passie was, besloot ze Gezondheidswetenschappen te gaan studeren in 2005. Tijdens deze opleiding heeft ze haar kennis en vaardigheden ontwikkeld door als vrijwilliger naar Nicaragua te gaan om daar een onderwijsproject op te zetten voor risico-leerlingen in het dorp Rama, ze heeft in het bestuur gezeten van een studentensportvereniging en ze heeft voor haar Master scriptie onderzoek verricht naar dementia bij ouderen in Seattle, VS.

$\mathrm{Na}$ haar opleiding heeft ze kort als onderzoeksassistent gewerkt aan een donorregistratie-project in de afrondende fase. Daarna heeft ze de overstap gemaakt naar ZonMw in Den Haag. Daar heeft ze gedurende een half jaar ervaring opgedaan als staf-assistent Algemeen Beleid. Vervolgens wekte een promotieonderzoek in het Maastricht Universitair Medisch Centrum, op de afdeling van de Medische Microbiologie, haar interesse. Gedurende 4 jaar heeft ze kwantitatief onderzoek verricht naar risico factoren voor en de preventie van postoperatieve wondinfecties, onder leiding van Ellen Stobberingh, Frank van Tiel en em. Prof. Dr. Cathrien Bruggeman. De resultaten van dit onderzoek zijn te lezen in dit proefschrift. Sinds 1 september van dit jaar is ze werkzaam als consultant Financial Services bij Capgemini. Momenteel is ze (nog) woonachtig in Maastricht samen met haar vriend Ivo Smits. 


\section{List of publications}

Ramcharan A, Penders J, Smeets E et al. A cross-sectional study on surveillance of surgical site infections after vascular surgery. Future Microbiol. 8(11), 1373-1380 (2013)

Ramcharan A, Smeets E, Rouflart M et al. What determines the (in-) efficacy of a surveillance system to reduce surgical site infections after gastrointestinal surgery? International Journal of Infection Control. 2014, v10:i.2

Ramcharan A, den Heijer C, Smeets E et al. Microbiology of surgical site infections after gastrointestinal surgery in the south region of The Netherlands. Future Microbiol, 9(3), 291-298 (2014)

Ramcharan A, Ahmad A, Reisinger K et al. Does sarcopenia result in a higher risk for developing surgical site infections after colorectal surgery? Diseases of the Colon \& Rectum (Submitted for acceptance) 


\title{
Valorisation of the manuscript
}

\author{
Relevance for society and economy
}

The prevention of health care associated infections (HAIs) has received lots of public attention during the last decade, since the consequences of these infections have a significant impact on health-related quality of life. The main focus of this manuscript is the onset of surgical site infections (SSIs), the most common HAls in surgical patients. SSIs, either superficial or deep, result in longer hospital stay, longer absence at work, reduced quality of life, greater likelihood of death due to inadequate or delayed treatment, increased burden on family of infected patients, and additional cost for hospitals due to increased overall health care expenditure. The American Centers for Disease Control and Prevention (CDC) estimates that approximately 500.000 SSIs occur annually in the United States. Studies in the Netherlands have shown that the costs per SSI vary between 1000 euros for superficial to more than 20.000 euros for deep SSIs. It is well known that the costs and outcomes related to SSIs vary by location of the surgical incision and type of surgical intervention, but also by type of hospital and country. This manuscript focusses on the prevalence of SSI among gastrointestinal and vascular patient populations in a University hospital in the Netherlands.

The risk for infections and the spread in- and outside the health care facility depend in part on the (adequate) attention for infection preventive policy in hospitals. The lessons learned underscore the importance to educate health care professionals about the increasing problem of antibiotic resistance and the relevance to control the increasing rate of resistance. It is important for health care institutions to continue to improve their policy regarding infection prevention and antibiotic use to minimise the risk on $\mathrm{HAl}$ as much as possible. The main reasons for this are the increased costs, morbidity, and mortality in patients with infections due to resistant versus susceptible organisms, which are higher in the first group.

The goals of this study were to 1 ) get insight into the infection prevention policy, 2) to determine the prevalence in SSI rates in different patient populations, 3) to determine the quality of care for surgical patients with regards to infection preventive measures, 4) to analyse risk factors to develop SSIs, 5) to investigate antibiotic patterns of the causative microorganisms of SSI in surgical patients, and 
6) to formulate infection preventive measures, based on the study results, for health care providers, future infection preventive researchers, and other involved parties.

\section{Target groups}

Nowadays, policy regarding infection prevention in health care facilities is becoming increasingly important for different target groups, i.e., for all involved health care professionals and for the patients and their family. It is therefore important for scientific researchers to perform studies on the topic. Adequate communication between different disciplines (infection prevention experts, surgeons and anesthesiologists, microbiologists, nursing staff) is an important tool to implement infection prevention policy. Hereby, infection control professionals carry the main task to stimulate communication about practical implications of infection control in a health care setting. And as antibiotic resistance is a major concern to the society as a whole, it is important to educate or train the professional, the patient and the society about infection control and proper antibiotic use, starting at the primary school.

\section{Activities}

There are many activities to think of in order to stimulate infection prevention. For instance, the implementation of infection preventive programs according to the Plan-Do-Study-Act (PDSA) cycle, the implementation of a care bundle (e.g., VMS bundle), infection registration during hospitalisation and after discharge, audit and feedback, and education on infection control and on antibiotic resistance.

Many studies have shown that hospital infections are preventable with simple measures, such as better hand hygiene and correct administration of antibiotic prophylaxis. Moreover, the on-going and long-term promotion of infection prevention measures is essential for a successful implementation and to measure the compliance with infection preventive policies. The implementation of infection preventive measures should therefore become a standard of quality patient care within health care institutions. Senior staff members (e.g., medical consultants, nurse managers, managers in the health professional groups, and other role models) should actively promote infection prevention policy. 
Another current phenomenon investigated for this manuscript, is that the postoperative hospital stay is shortened, and that more outpatient surgeries and same-day surgeries are carried out. This results in more SSIs diagnosed after discharge from the hospital. Consequently, more SSIs are missed with infection control surveillance programs when performed only during hospitalisation. Thus, for reliable data concerning the prevalence of $\mathrm{HAI}$ in general, SSI in particular, surveillance activities need to be performed during and after hospitalisation.

Regarding infection preventive measures, monitoring the compliance with these measures should be continuously carried out in order to control the risk and safety framework of health care institutions. And again, this can be performed through audits with feedback of results.

The patient's health care environment can also be a source of contamination. Each contact with hospital furniture, doors, and many medical devices can be a major risk to patients. Sterilisation is needed for surgical instruments and other devices, but it is not necessary for all items and surfaces.

As infection prevention policy is an essential component of care, all health care workers who work in the surgical environment must be educated in infection preventive theory and techniques prior to their work related actions. This can be achieved through an infection control component within the introduction program for which attendance must be mandatory. Furthermore, undergraduate medical, nursing, infection prevention practice, and other surgical health care course curricula should include education and examination theory and techniques. There are a variety of options to educate when it comes to reliable resources, for instance: local and online information, study days, conferences, courses, practice and e-learning resources, the health care industry or commercial companies, and professional organisations (e.g., the Centers for Disease Control and prevention (CDC), the Dutch PREZIES network, the Infection Prevention Society (IPS), and the Healthcare Infection Society (HIS)).

With regards to the antibiotic resistance, it is important to analyse the antibiotic resistance patterns and to know common errors physicians are dealing with when prescribing antibiotics. For the physicians, by prescribing antibiotics without properly diagnosing an illness or without properly weighting the consequences of the antibiotics, they are promoting antibiotic resistance in their patients and society as well.

Efforts to describe the global impact of antimicrobial resistance are hampered by the lack of data on the impact of resistance outside the hospital settings. There has 
been little, if any, effort to assess the larger societal and macroeconomic costs of resistance, especially in the developing world, related to lost wages, the costs of caring for patients with SSI, and the impact of increased mortality, or the costs for surveillance and other infection preventive interventions. Treatment failure is another contributor to increased health care costs and can lead to additional investigations, additional or alternative treatments, often much more expensive than drugs used to treat infections caused by sensitive organisms. Thus, more research should be performed to deal with these issues.

Innovation based on existing knowledge and offer

Risk factors for SSI can be differentiated into those which are modifiable and those which are not. During the study period of this manuscript, the Dutch VMS safety care bundle was implemented. The general goals of care bundles are to enable staff to quickly see what actions should be taken, when and by whom. Furthermore, care bundles allow clinical practice to be standardised and reduce variation in the treatment plans for patients.

The VMS bundle consisted of a small set of evidence-based interventions for surgical patients and care setting that, when implemented together, aimed to result in significantly better outcomes than when implemented individually. The bundle allowed us to focus our efforts on four measurable strategies: no skin shaving before surgery, administration of antibiotic prophylaxis (adequate choice, dose and timing), normothermia, and restriction of entry in the operating theatre. The number of door movements of the operating theatre contributes to an increased number of microorganisms in the air and to an increased risk on an infection.

Implementing a bundle of care with high reliability requires redesign of work processes, communication strategies, and infrastructure, along with compliance measurement. This requires high quality of care to ensure that the surgeons' judgement is supported by best available practice evidence at the point of care, and that barriers of implementation of evidence based results are reduced.

Finally, postdischarge surveillance, as mentioned above, results in more identified SSIs among surgical patients. It has been demonstrated that hospitals with comprehensive postdischarge surveillance after surgical procedures are likely to record higher SSI rates than those that do not perform such surveillance. 


\section{Planning and realisation}

As previously mentioned, many activities can be carried out to prevent infections (e.g., implementation of infection preventive programs according to the PDSA cycle, implementation of a care bundle, infection registration during hospitalisation and after discharge, audit and feedback, and education on infection control and antibiotic resistance). However, the timeframe is situation-dependent.

Recommendations towards infection prevention are known; routine observation and feedback, education to health care staff and patients, reminders at the workplace, administrative sanctions, and rewards. Furthermore, it is important to obtain active participation at individual and institutional level in order to ensure a safety climate, to enhance self-efficacy, and to avoid understaffing and workload. With regards to the use of antibiotics, measuring the impact of drug resistance is an important step in understanding the scope of the problem, and to develop policies to limit the emergence and spread of resistant microorganisms. Although there is little doubt that antimicrobial resistance is increasing the global burden of disease, we are a long way from being able to quantify this burden.

To conclude, this manuscript adds more insight into infection prevention policy for surgical patients and health care workers. Since SSIs are unintended and in some cases preventable, it is recommended to establish multidisciplinary teams and to provide feedback to the involved parties. It is up to practitioners in each health care setting to review the evidence and work together to implement SSI preventive interventions. There are two main activities related to infection prevention. The first is to encourage infection prevention, for which the measures are to develop infection preventive guidelines for health care facilities, and to implement these guidelines. In this regard, the target group is the personnel of the facility. The second main activity is the surveillance of SSIs by systematically gather, analyse, and report infection rates. In this regard, the target groups are all health care personnel and the (surgical) patients. The executors involve the WIP, SWAB, microbiologists, and infection control professionals.

The benefits of preventing SSIs are the decreasing patient mortality and the decreasing burden that SSIs pose on the national health care system. Therefore, it is up to all health care workers to continue supporting SSI prevention initiatives! 
"Live as if you were to die tomorrow. Learn as if you were to live forever"

Mahatma Gandhi 


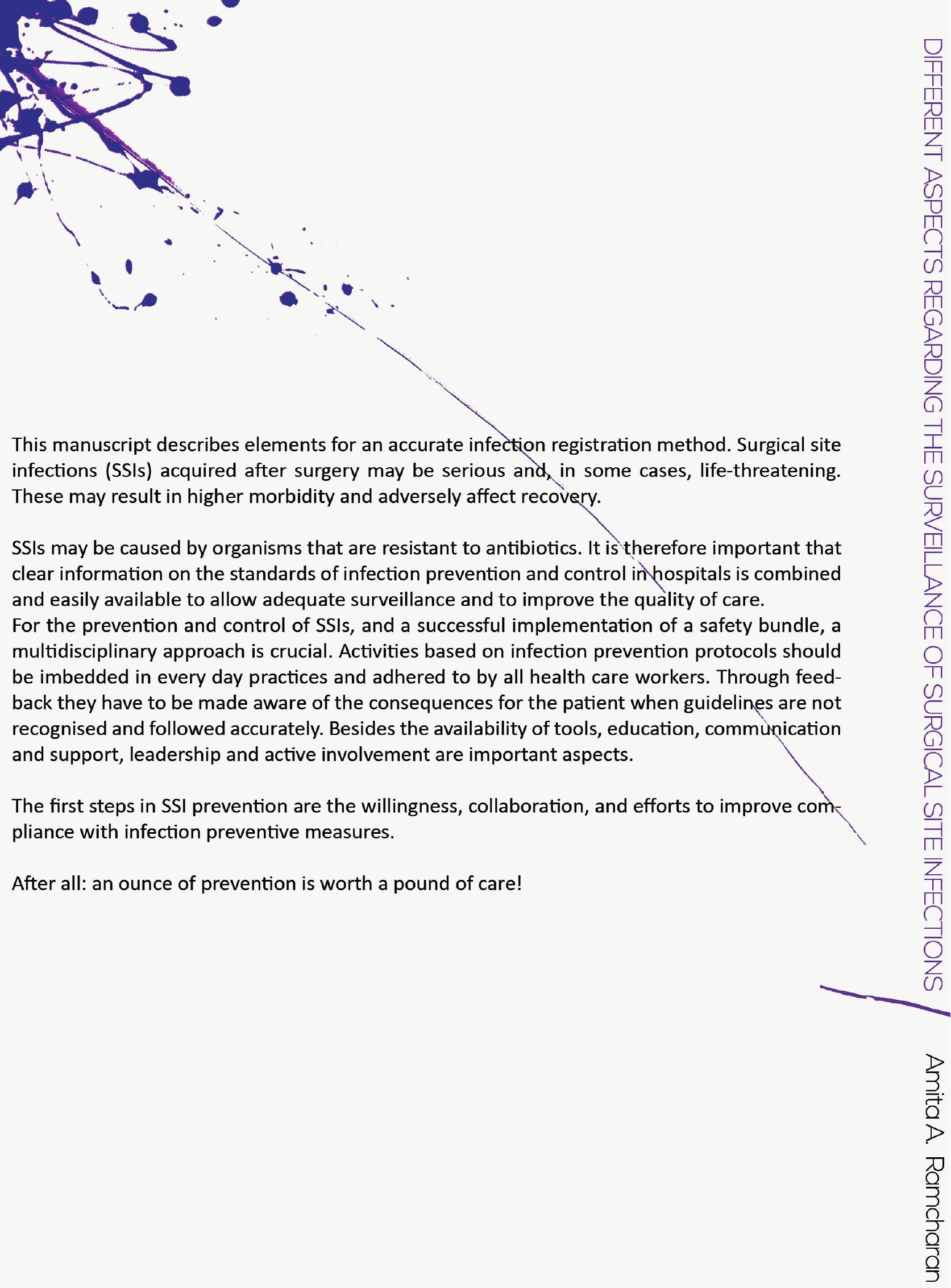

This manuscript describes elements for an accurate infection registration method. Surgical site infections (SSIs) acquired after surgery may be serious and in some cases, life-threatening. These may result in higher morbidity and adversely affect recovery.

SSIs may be caused by organisms that are resistant to antibiotics. It is therefore important that clear information on the standards of infection prevention and control in hospitals is combined and easily available to allow adequate surveillance and to improve the quality of care. multidisciplinary approach is crucial. Activities based on infection prevention protocols should be imbedded in every day practices and adhered to by all health care workers. Through feedback they have to be made aware of the consequences for the patient when guidelines are not recognised and followed accurately. Besides the availability of tools, education, communication and support, leadership and active involvement are important aspects.

The first steps in SSI prevention are the willingness, collaboration, and efforts to improve com pliance with infection preventive measures.

After all: an ounce of prevention is worth a pound of care! 